\title{
A STUDY OF THE NASAL BRIDGE IN THE ANTHROPOID APES AND ITS RELATIONSHIP TO THE NASAL BRIDGE IN MAN.
}

By KATHLEEN V. RYLEY, Crewdson-Benington Student in Craniometry AND JULIA BELL, M.A., assisted by KARL PEARSON, F.R.S.

\section{CONTENTS.}

(1) Introductory: Nature of Material and Measurements made . . . . . . . 391

(2) Reliability of Measurements: Effect of Personal Equation in Sexing, of Secular Change in Personal Equation of Measurer and of Differences in small Samples . . 393

(3) On the Observed and Calculated Values of the Subtense Mesodacryal Index. The Catenary

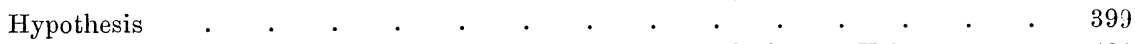

(4) On the Simotic and Mesodacryal Indices. Their Relative Evolutionary Value . . 401

(5) On the Absolute Nasal Measurements . . . . . . . . . . . . . . 405

(6) On the Absolute Mesodacryal Measurements . . . . . . . . . . . 407

(7) On the relative Racial Variability of the Nasal Bridge Characters. Sexual Differences in Variability . . . . . . . . . . . . . . . . . . 409

(8) Racial Relationship as based on Nasal Bridge Mcasurements. Ancestral Tree . . 417

(9) On the Correlations of the Nasal Bridge Characters _ . . . . . . . . $\quad$. 418

(10) The Maxillary and Simotic Nasal Angles, $\phi$ and $\phi^{\prime}$. The Inter-relationships of Anatomical 420

(11) General Classification of Nasal Bridges by aid of Angles $\phi$ and $\phi^{\prime}$. Homoclinic and Heteroclinic Nasal Bridges. Measurements of Simosis and Gephyrosis. Contours

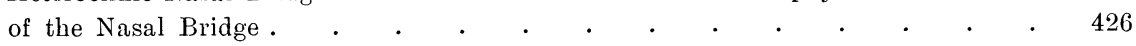

(12) Discussion of Projections of Nasal and Maxillary Portions of Nose on Base of Nasal Bridge 430

(13) Concluding Remarks . . . . . . . . . . . . . . . . . . . 435

(1) Introductory.

The measurements on which the following paper is based were taken by Kathleen V. Ryley, in part at the Museum of the Royal College of Surgeons by the kindness of Professor Arthur Keith; in part at the British Museum (Natural History), where we have especially to thank $\mathrm{Mr}$ W. P. Pycraft; in part at the Cambridge Anatomical Museum and in the private collection of Dr Duck worth, whom we have heartily to thank for his courteous and ready aid; in part at the Oxford Museum by the kindness of Professor Bourne. Lastly we owe the possibility of measuring a few specimens to Professors Thane and Hill of University College, London, who readily placed their material at our disposal. We have further to express our indebtedness to Professor Thane and to Dr Derry for aid in a variety of other ways. Only by the great help received from all these authorities would 


\section{A Study of the Nasal Bridge in the Anthropoid Apes}

it have been possible to bring together even the slender numbers now dealt with, and a very full sense of our obligations to these gentlemen must here be expressed.

In a recent paper entitled "A Study of the Negro Skull" (Biometrika, Vol. viII. pp. 315-320) a special study was made of the nasal bridge in the Congo and Gaboon crania and the results compared with measurements on Egyptian and English series. There resulted values so suggestive that a wider study was promised, and that promise is to some extent fulfilled in the present paper.

In the former paper it will be remembered that the chord from dacryon to dacryon $(D C)$ was measured - the mesodacryal chord-and the minimum arc from dacryon to dacryon $(D A)$ - the mesodacryal arc. The ratio 100 (arc-chord)/chord was termed the mesodacryal index $\beta$. If on the other hand we measure the subtense of the minimum arc $\left(D S^{r}\right)$ and take the index 100 subtense/chord, we obtain a second mesodacryal index, which we will term here the mesodacryal index $\alpha_{0}$ As a cannot be found without a special instrument, or a special construction, an attempt was made to determine the second mesodacryal index $a$ from the first $\beta$ by the hypothesis that in man the bridge of the nose may be sufficiently closely represented by a catenary, which seemed a fairly justifiable assumption in this case. The index thus indirectly found will be termed in this paper the mesodacryal index $\alpha^{\prime}$. 'Tables to determine $\alpha^{\prime}$ from $\beta$ calculated by one of us (Julia Bell) were published in the same number of Biometrika, pp. 338--9, as the paper on the negro skull. An extension of these Tables due to H. E. Soper, rendered necessary when we deal with apes, will be found in the footnote on p. 401 of the present paper. Meanwhile our attention was drawn by Professor G. D. Thane to Mérejkowsky's pioneer work of 1882 on the nasal bones. He measured the shortest horizontal chord from nasal suture to nasal suture $(S C)$ and the minimum subtense $(S S)$ and took the index $100 S S / S C$, which we have ventured to term the Simotic Index, $S$. There is little doubt that this index is of a more simple anatomic character, as being only concerned with the nasal bones, than the mesodacryal indices. But it is by no means so marked a physiognomic feature in the living as the mesodacryal index. It has further to be obtained by aid of a special instrument-in our case a modified Mérejkowsky instrument, which may be termed the simometer. This simometer may also be used to test the relationship between observed $\alpha$ and calculated $\alpha^{\prime}$.

In the present investigation $\alpha, \beta, S$ have been measured and $\alpha^{\prime}$ calculated for Gorilla, Chimpanzee, Gibbon and Orang. But in the case of the latter ape it was found possible to measure the simotic index in only a few cases,- - the index taking frequently the form of the ratio of two almost vanishing quantities*. In

* There were three cases in which the simotic chord was recorded among the Orang-utans. In two males it was 5.7 and $5.8 \mathrm{~mm}$. In both these cases the subtense was zero, for the bones were practically flat; thus the simotic index was zero. In the third case, a female, the simotic chord was $7 \cdot 0 \mathrm{~mm}$. and the subtense $1 \cdot 2 \mathrm{~mm}$. and therefore the simotic index was $17 \cdot 1$. There were a few further cases in which the chord only was measurable. Thus on the basis of such isolated cases we should have to place the Orang-utan below the Chimpanzee, and both of course below the Negroes. 
Kathleen V. Ryley and Julia Bell

the Orang the nasal bones are fused into a narrow flat strip from 5 to $6 \mathrm{~mm}$. wide, sometimes there is only a thread at the nasal bridge or the nasals are entirely absent. In some cases the maxillary bones stand out forming a ledge which overhangs the region of the dacryon and extends beyond it, thus making it very difficult to measure with Mérejkowsky's instrument. Initially we excluded entirely from our measurements the Gibbon, but notwithstanding the difficulties of including this ape, it afterwards appeared to us that it might be worth while to indicate the results in rough numbers. The difficulties partly arise from the fact that a large proportion of the Gibbon crania available are without any statement as to sex and we did not feel that an attempt at sexing would be really profitable, as the total numbers were not large enough to give double series. Further we are compelled to distinguish between Hylobates and Symphalangus, and even of the former with the sparse data as to locus usually provided, it is impossible to assert that we are dealing with anything like a homogeneous race. Thus we found ourselves ultimately with only 25 cases- $\delta+q+8-$ Hylobates-indeed only 16 for the simotic characters, and 9 cases- $-\delta+q+8-S y m p h a l a n g u s$ - with merely six for the simotic characters. Our results in this case can therefore only be rough indications of the racial characters of the nose of these apes. Our Museums have yet to learn that for comparative study we want at least 50 to 100 crania of each sex drawn from definite districts. To compare with those of the apes the corresponding indices were measured in a number of human races selected in order to contrast the values, if possible, with those of the anthropoid apes of the same continent. A few other human races are taken to indicate general relationships. The Hindoo, Egyptian and English crania used are at University College either in the Biometric Laboratory or in the Department of Anatomy; the Asiatic skulls and the Congo skulls are at the Royal College of Surgeons; the Gaboon skulls at the British Museum of Natural History. The nasal features of the latter as well as of the English and Egyptian crania had already been discussed in Dr Crewdson-Benington's paper referred to above.

(2) Reliability of Measurements.

The first point to be considered is the degree of reliability in the measurements made, and here we must again emphasise the difficulty of accuracy. Not only do the quantities measured differ by their extreme smallness from the customary cranial measurements, but the points for measurement and the instrument for measurement are by no means all that could be desired. When a small quantity has to be measured, an error of reading which would have no importance in the case of either head breadth or head length, the cephalic index being in question, becomes of very great significance in the case of the simotic or even the mesodacryal indices. Further in the handling of Mérejkowsky's instrument, there is much play for personal equation, and only after long practise will the recorder settle down into a process, which repeats within reasonable limits the values of the indices previously determined. In the next place for our present purposes only small series of crania were as a rule available, e.g. 20 to 40 of either 


\section{A Study of the Nasal Bridge in the Anthropoid Apes}

sex of each ape, 10 to 40 of the various Asiatic races. Considering the smallness of these numbers, it did not appear needful, in view of the labour involved, to measure more than 50 of each sex of the English (Whitechapel) and Egyptian (XXVI-XXX dynasties) crania of which far larger numbers were at hand.

Further in such small series the question of sexing becomes of considerable influence. With a large series of crania of one type, we sex on our knowledge of that series itself. But in short series one is apt to sex by a priori impressions of sex in other races, because we have not before us wide enough material to appreciate sex differences within the race itself.

We propose to illustrate first the order of the differences which may arise from these sources, and we will deal first with sexing. Owing to the courtesy of Dr Derry we were able to test this point on 35 Nubian crania in his possession. They were independently sexed by Professor G. D. Thane and by Dr Derry himself*. The nasal measurements were taken and the mean values of the indices calculated. The following values were obtained, where we have added for comparative purposes those of other negro series:

TABLE I.

\begin{tabular}{|c|c|c|c|c|c|c|c|c|c|}
\hline & & \multicolumn{2}{|c|}{$m_{a}$} & \multicolumn{2}{|c|}{$m_{\boldsymbol{a}^{\prime}}$} & \multicolumn{2}{|c|}{$m_{\beta}$} & \multicolumn{2}{|c|}{$m_{S}$} \\
\hline & & $\widehat{\sigma}$ & $q$ & ô & $q$ & 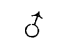 & $q$ & oै & q \\
\hline Nubians: Professor Thane & $\ldots$ & $48 \cdot 0$ & $40 \cdot 9$ & $49 \cdot 7$ & $43 \cdot 6$ & $49 \cdot 6$ & $40 \cdot 0$ & $34 \cdot 5$ & $23 \cdot 4$ \\
\hline , $\quad$ Dr Jerry $\quad \ldots$ & $\ldots$ & $48 \cdot 9$ & $39 \cdot 7$ & $51 \cdot 0$ & $42 \cdot 1$ & $51 \cdot 6$ & $37 \cdot 7$ & $33 \cdot 7$ & $23 \cdot 5$ \\
\hline Gaboon : $1864 \ldots$ & $\ldots$ & $42 \cdot 9$ & $44 \cdot 0$ & $43 \cdot 6$ & $44 \cdot 9$ & $40 \cdot 0$ & $42 \cdot 0$ & $30 \cdot 9$ & $27 \cdot 7$ \\
\hline $1880 \ldots$ & ... & $42 \cdot 9$ & $44 \cdot 1$ & $44 \cdot 8$ & $45 \cdot 1$ & $41 \cdot 9$ & $42 \cdot 3$ & $29 \cdot 0$ & $22 \cdot 9$ \\
\hline$\cdots \quad \cdots$ & $\cdots$ & $39 \cdot 1$ & $37 \cdot 2$ & $40 \cdot 5$ & $38 \cdot 6$ & $35 \cdot 5$ & $32 \cdot 6$ & $25 \cdot 6$ & $25 \cdot 7$ \\
\hline "Nègres" : Mérejkowsky & $\cdots$ & - & - & - & - & 一 & - & & \\
\hline
\end{tabular}

It will be seen that for short series the personal equation of sexing makes 1 to 2 points difference in the indices, but that in two series of the same raceGaboon, 1864 and 1880,--differences of this order may occur at least in the simotic index. If we compare Mérejkowsky's value for the simotic index with ours, we see that there would be excellent agreement if his somewhat vague "Nègres" were from the Congo district. But we lay no stress on this agreement because we believe that Mérejkowsky tends almost invariably to get a higher simotic index than we do. This is illustrated in Table II.

Of course there are but few races common to both series and in Mérejkowsky's series as in ours the numbers dealt with are miserably small, but still cases where

* Before discussion there were four crania in a total of 35 on which there was difference of opinion, say 11 per cent., and we have used the original determinations, putting as usual ? $\delta$ and ? with the $\sigma$ 's and $q$ 's respectively. 
Kathleen V. Ryley and Julia Bell

we can compare and the general appearance of the Table are both against the view that the differences are wholly racial. We believe them to be largely due to personal equation in taking a delicate measurement with a not very reliable instrument, and consider that without determination of personal equations by direct comparison of measurements on the same individual crania, it is not possible at present to compare simotic indices found by different craniologists.

TABLE II.

Values of the Simotic Index.

\begin{tabular}{|c|c|c|c|c|c|c|c|c|}
\hline \multirow{2}{*}{ Race } & & \multicolumn{2}{|c|}{ Mérejkowsky } & \multirow{2}{*}{\multicolumn{3}{|c|}{ Race }} & \multicolumn{2}{|c|}{ Ryley } \\
\hline & & $\delta$ & q & & & & o & $q$ \\
\hline Negroes & $\ldots$ & $25 \cdot 6$ & - & Congo & $\cdots$ & $\ldots$ & $25 \cdot 6$ & $25 \cdot 7$ \\
\hline Malays & $\ldots$ & $31: 3$ & - & Moluccas & & $\ldots$ & $26 \cdot 5$ & - \\
\hline New Caledonians & $\ldots$ & $38 \cdot 5$ & $30 \cdot 6$ & Gaboon, 18 & & $\ldots$ & $29 \cdot 0$ & $22 \cdot 9$ \\
\hline Mongols $\quad \ldots$ & $\ldots$ & $40 \cdot 5$ & - & Sumatra & $\ldots$ & $\ldots$ & $29 \cdot 2$ & - \\
\hline Melanesians... & $\ldots$ & $41 \cdot 9$ & $35 \cdot 2$ & Celebes & $\ldots$ & $\ldots$ & $29 \cdot 7$ & - \\
\hline Marquesas Island & $\ldots$ & $43 \cdot 9$ & $34 \cdot 0$ & Borneo & $\ldots$ & $\ldots$ & $30 \cdot 2$ & $34 \cdot 7$ \\
\hline Maoris $\quad \ldots$ & $\ldots$ & $47 \cdot 9$ & $43 \cdot 3$ & Philippines & & $\ldots$ & $30 \cdot 4$ & $29 \cdot 0$ \\
\hline American Indians & $\ldots$ & $48 \cdot 0$ & $46 \cdot 2$ & Gaboon, 18 & & $\ldots$ & $30 \cdot 9$ & $27 \cdot 7$ \\
\hline New Hebrides & $\ldots$ & $49 \cdot 1$ & $44 \cdot 5$ & Malay & $\ldots$ & $\ldots$ & $33 \cdot 7$ & - \\
\hline Hindoos & $\ldots$ & $51 \cdot 1$ & $42 \cdot 5$ & Java and M & adura & $\ldots$ & $33 \cdot 9$ & $32 \cdot 7$ \\
\hline Auvergnats ... & $\ldots$ & $51 \cdot 8$ & $45^{\circ} 0$ & Nubians & $\ldots$ & $\ldots$ & $34 \cdot 1$ & $2: 3 \cdot 4$ \\
\hline Gypsies $\quad \ldots$ & $\ldots$ & $53 \cdot 8$ & - & Ainos & $\ldots$ & & $43 \cdot 4$ & - \\
\hline Tahitians & $\ldots$ & $54 \cdot 3$ & - & Veddahs & $\ldots$ & $\ldots$ & $43 \cdot 6$ & $36 \cdot 9$ \\
\hline French & $\ldots$ & $54 \cdot 8$ & $47 \cdot 1$ & Egyptians & $\ldots$ & $\ldots$ & $44 \cdot 4$ & $36 \cdot 9$ \\
\hline Dutch & $\ldots$ & $58 \cdot 6$ & $55 \cdot 2$ & Hindloos & $\ldots$ & $\ldots$ & $44 \cdot 7$ & $39 \cdot 1$ \\
\hline French Cymry & $\ldots$ & $59 \cdot 6$ & $50 \cdot 3$ & English & $\ldots$ & $\ldots$ & $50 \cdot 8$ & $46 \cdot 6$ \\
\hline
\end{tabular}

In two points, however, we agree fairly well with Mérejkowsky, i.e. in the general order of races and in the fact that the simotic index is a marked sexual character. In all cases-22 in number-except the Congo and Borneo crania, the female has a lower simotic index than the male and this is true for the apes, where we can determine it:

\begin{tabular}{lcc} 
& \multirow{2}{*}{} & $q$ \\
Chimpanzee & $21 \cdot 4$ & $18 \cdot 5$ \\
Gorilla & $56 \cdot 8$ & $55 \cdot 1$
\end{tabular}

The two exceptions are the Congo crania, where the two sexes are practically alike, and the crania from Borneo, where the female has the higher simotic index, but the probable errors being introduced, i.e. Borneo : $\delta$ "s $30 \cdot 2 \pm 1 \cdot 2$, $q$ 's $34 \cdot 7 \pm 2 \cdot 1$, show us that even here the difference is quite possibly non-significant. Thus we conclude that in the female the nasal bones are flatter than in the male, and this secondary sexual character may be used-as far as it is ocularly appreciable-as a help in sexing. It may be remarked-in order to avoid circular reasoning-that 


\section{A Study of the Nasal Bridge in the Anthropoid Apes}

with the possible exception of Dr Derry's classifications, the judgment in sexing has not been influenced by nasal characters*.

While it appears to us that the difference of sexing will not be greater than that of two small samples of the same race and less probably than the difference of measurement of two different craniologists, we have still to answer the important question of how far the same craniologist will repeat results in the case of these delicate nasal measurements. We are able to make some interesting comparisons from this standpoint. K. V. Ryley made her first measurements of the nose on the Whitechapel, Egyptian, Congo and Gaboon series in the summer of 1911 for use in the paper on the negro skull (Biometrika, Vol. vill. p. 316). She was then new to these particular measurements, and before the second series were made she had nearly a year's practice on a great variety of races. In the English Whitechapel series 13 crania measured in one series (1911) are not in the other series (1912), that is to say one quarter of the crania are not the same in the two series. These 13 crania of the first series were originally Museum specimens, i.e. skulls having some abnormality (other than nasal), or remarkable feature, and placed in the Anatomical Museum for exhibition. It was thought better to exclude these individuals in the second series and replace them by more normal examples. Thus the divergencies between the $A(1911)$ and $B$ (1912) English series are not solely due to personal equation. The Congo and Gaboon 1864 series are practically the same crania for $A$ and $B$ as nearly every skull which was measurable was measured on each occasion.

The two Egyptian series are not the same crania, for they consisted of the 100 crania of the series of 1800 skulls, which were being otherwise measured at the time when these nasal measurements were taken. Thus we may conclude that the Congo and Gaboon 1864 series represent changes due to the same measurer repeating operations at the beginning and end of a period during which experience was growing and methods being standardised; the Egyptian series represent this variation in the measurer together with the difference between random samples; and the English series represent not only the variation due to the measurer, but further the effect of modifying by $25 \%$ the actual sample

* Dr Derry does give weight to nasal features in sexing, but if we examine the results in Table I from this standpoint, we have

\begin{tabular}{lccrc}
\multicolumn{5}{r}{ Difference of male and female, i.e. $\delta-\uparrow}$. \\
& $m_{\alpha}$ & $m_{a^{\prime}}$ & $m_{\beta}$ & $m_{S}$ \\
Professor Thane & $7 \cdot 1$ & $6 \cdot 1$ & $9 \cdot 6$ & $11 \cdot 1$ \\
Dr Derry $\quad \ldots$ & $9 \cdot 2$ & $8 \cdot 9$ & $13 \cdot 9$ & $10 \cdot 2$
\end{tabular}

It will be clear from these results that Dr Derry used the mesodacryal indices, i.e. the entire bridge of the nose, rather than the nasal bones in his sexual appreciation; for he has a less sexual difference in the simotic index than Professor Thane, while he has greater values in the mesodacryal indices. As a matter of fact the sexual differences in the Nubians seem to us of such an exaggerated character, that we venture to suggest that the females may have been captives and thus may be more definitely negresses, with whom their indices accord, than the males were negroes; the males being possibly a conquering race. 


\section{Kathleen V. Ryley and Julia Bell}

measured. Finally to test the extent to which K. V. Ryley's methods were finally standardised, a third measurement of the male Whitechapel crania was made four months later than $B$, namely $C$ in December, 1912. In the case of $C$ the same 50 crania exactly were remeasured*. There now resulted a very close accordance between all the measurements absolute and indicial. It will be noticed on examination of the Table that:

(i) The error in the value of the simotic index due to variation of personal equation never exceeds a point.

\section{TABLE III.}

Comparison of Measurements on the Nasal Bridge made at intervals and on different samples.

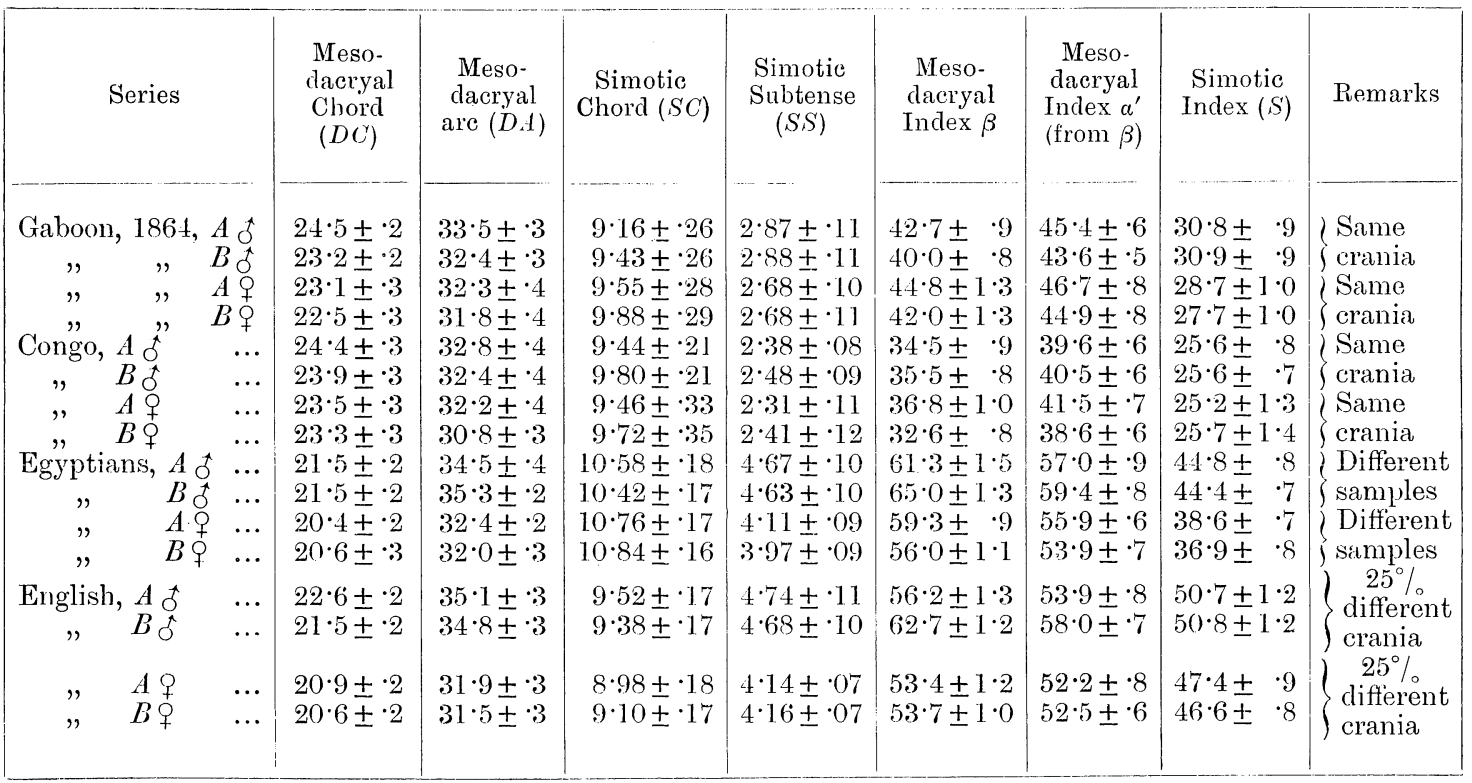

TABLE III bis.

English Crania, 50 Males.

\begin{tabular}{|c|c|c|c|c|c|c|c|c|c|}
\hline Series & $\begin{array}{l}\text { Meso- } \\
\text { dacryal } \\
\text { Chord } \\
(D C)\end{array}$ & $\begin{array}{c}\text { Meso- } \\
\text { dacryal } \\
\text { arc }(D A)\end{array}$ & $\begin{array}{c}\text { Meso- } \\
\text { dacryal } \\
\text { Subtense } \\
(D S)\end{array}$ & $\begin{array}{c}\text { Simotic } \\
\text { Chord } \\
(S C)\end{array}$ & $\begin{array}{c}\text { Simotic } \\
\text { Subtense } \\
\quad(S S)\end{array}$ & $\begin{array}{c}\text { Meso- } \\
\text { dacryal } \\
\text { Index } \beta\end{array}$ & $\begin{array}{l}\text { Meso- } \\
\text { dacryal } \\
\text { Index } \alpha^{\prime}\end{array}$ & $\begin{array}{l}\text { Meso- } \\
\text { dacryal } \\
\text { Index } a\end{array}$ & $\begin{array}{l}\text { Simotic } \\
\text { Index } S\end{array}$ \\
\hline$B$ & $21 \cdot 5 \pm \cdot 2$ & $34 \cdot 8 \pm \cdot 3$ & $12 \cdot 1 \pm \cdot 1$ & $9 \cdot 38 \pm \cdot 17$ & $4 \cdot 68 \pm \cdot 10$ & $62 \cdot 7 \pm 1 \cdot 2$ & $58 \cdot 0 \pm \cdot 7$ & $56 \cdot 8 \pm \cdot 7$ & $50 \cdot 8 \pm 1 \cdot 2$ \\
\hline$\cdots$ & $21 \cdot 4 \pm \cdot 2$ & $34 \cdot 6 \pm \cdot 3$ & $12 \cdot 1 \pm \cdot 1$ & $9 \cdot 43 \pm \cdot 17$ & $4 \cdot 72 \pm \cdot 10$ & $62 \cdot 7 \pm 1 \cdot 2$ & $58 \cdot 1 \pm \cdot 7$ & $57 \cdot 4 \pm \cdot 7$ & $51 \cdot 2 \pm 1 \cdot 2$ \\
\hline
\end{tabular}

$A$ are measurements taken at start of investigation, $B$ at conclusion of investigation after practise and standardisation, $B$ only used in this memoir. In the Table III bis both series, $B$ and $C$, were taken on the same crania at the end of the investigation with an interval of four months.

* K. V. Ryley, it is needless to say, had not her eariier values before her when making her remeasurements.

Biometrika Ix 


\section{A Study of the Nasal Bridge in the Anthropoid Apes}

That is, it is of the order of the probable error. It may amount to $1 \cdot 7$, which is only about twice the probable error when we combine the effect of random sampling with personal error.

(ii) The differences in the mesodacryal index $\beta$ can amount for personal variation to $4 \cdot 2$ (Congo $q$ 's), which is as large a value as we obtain on the Egyptian series for combined personal error and random sampling, and even to 6.6 points in the Whitechapel with change of sample and personal variation, which is five times the probable error. Corresponding differences will of course exist in $\alpha^{\prime}$ deduced from $\beta$. We believe that this difference in the early and late values of $\beta$ is due to greater standardisation of method in determining the dacryon with a rather blunt pointed instrument and to greater mastery of the difficulties arising from damaged crania and in the case of the apes from partially obliterated sutures.

(iii) In the absolute measurements mesodacyral chord $(D C)$, mesodacryal subtense $(D S)$, mesodacyral arc $(D A)$, simotic chord $(S C)$, simotic subtense $(S S)$ there is a maximum error in the means of about $4.5 \%$, but this is rare, and reduces to insignificance with practise in the measurements*.

(iv) A comparison of $B$ and $C$ shows that in all cases after continuous practise and standardisation of method, the variations in absolute measurements or in indices are less than the probable errors of random sampling.

Of course the whole of the above remarks apply to a comparison of mean values and not to measurements on an individual cranium. We should conclude as follows:

(a) The measuremonts on the nasal bridge need great care, and the same measurer may on repetition differ considerably from a previous determination on the same skull.

(b) But with long practise and careful standardisation of method the racial values obtained will repeat themselves, if the series be measured afresh, and values obtained by the same recorder are quite intercomparable.

(c) We are doubtful--especially having regard to Mérejkowsky's resultswhether racial values obtained by different craniologists, who are fresh to this side of cranial measurement, or who have not tested their personal equation on the same series, will be directly comparable.

(d) Notwithstanding these difficulties, which are really only an intensification of difficulties which occur in all branches of craniometry, we believe these measurements on the nasal bridge to be really valuable and think that they ought to occupy more attention. They are of course only a phase of what may reach greater importance in the future: namely of what we may term micrometric as distinguished from the usual or macrometric measurements of the skull.

* The earlier series of measurements tended rather to exaggerate the mesodacryal chord and arc. 


\section{Kathleen V. Ryley and Julia Bell}

There are bones other than those of the nasal bridge which might give racially significant micrornetric measurements, although specially designed apparatus, or an adaption of existing physical instruments as yet unused in craniometry, would have to be employed in their determination.

(3) On the observed $(\alpha)$ and calculated $\left(\alpha^{\prime}\right)$ values of the subtense mesodacryal index.

In the discussion on the negro skull (loc. cit. pp. 297, 316) it was pointed out that our original measurements of the mesodacryal chord and arc leading to the index $\beta$ did not enable us to determine the subtense directly, or indirectly, until some assumption was made as to the shape of the bridge of the nose. We were not at the time these measurements were suggested to Dr Crewdson-Benington a ware of Mérejkowsky's instrument, which is as available for finding the mesodacryal subtense as for its designed purpose the determination of the simotic subtense. Accordingly after some consideration the catenary was selected as a fairly suitable curve for the nasal bridge and by means of it the value of the subtense mesodacryal index $\left(\alpha^{\prime}\right)$ was deduced from $\beta$. In the present investigation $\alpha$ has been found directly and it is of much interest to test the legitimacy of the catenary hypothesis.

TABLE IV. Differences $\alpha^{\prime}-\alpha$ of Calculated $\left(\alpha^{\prime}\right)$ and Observed ( $\left.\alpha\right)$ Values of Mesodacryal Subtense Index.

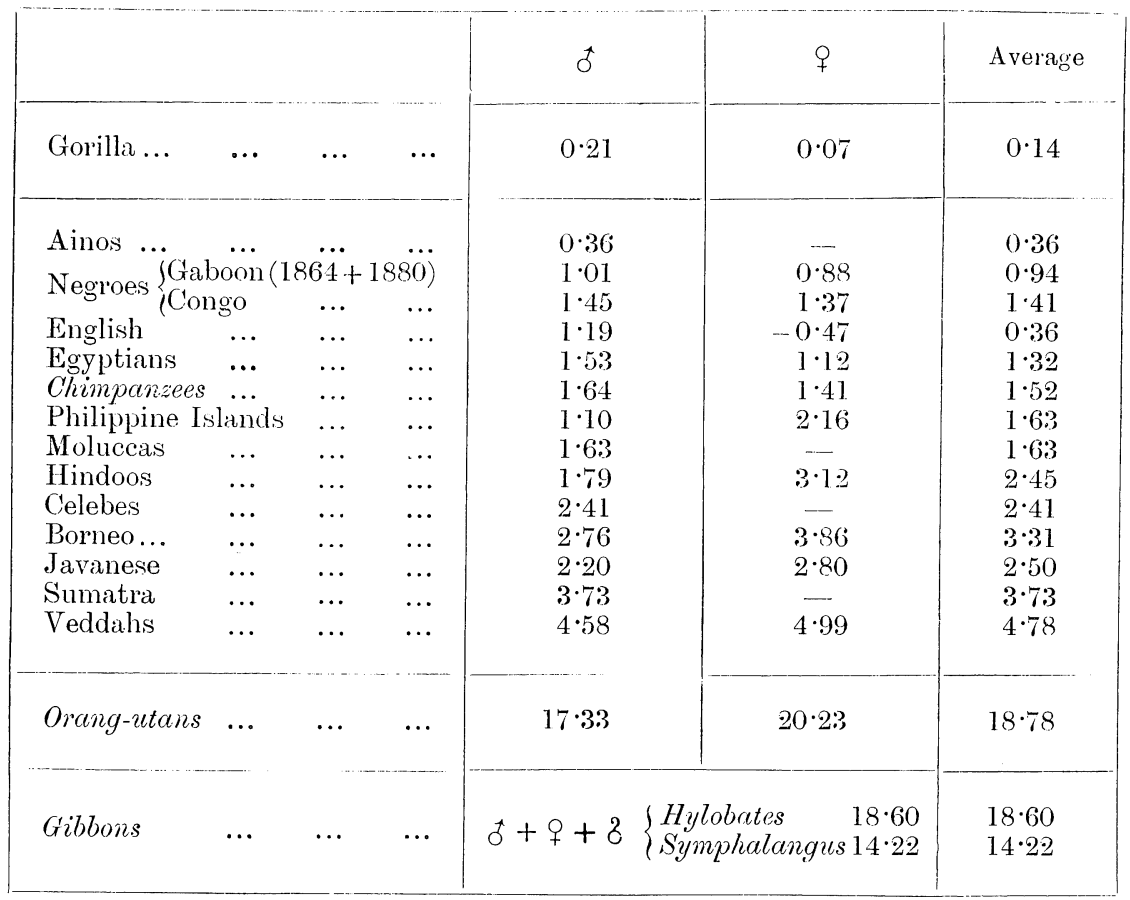

We see, to judge by this Table, that the hypothesis of the catenary suits the Gorilla and the Aino nose very closely; it is fairly good for Negro, English and 


\section{A Study of the Nasal Bridge in the Anthropoid Apes}

Egyptian, roughly we must subtract one point from the calculated to get the actual value of the index; for the Chimpanzee, the Hindoos and the inhabitants of the Philippine and Molucca Islands two points must be subtracted; for those of the Celebes, Borneo, Java and Sumatra three points, for the Veddahs five points, and for the Orang-utan and Gibbon 14 to 20! Thus as we pass from Africa and the region of the Gorilla through Europe to Asia and to the East Indian Islands and the region of the Orang-utan we get roughly a continuous divergence from the catenary hypothesis, which fits the Gorilla, to a markedly non-catenary relation as in the case of the Orang*. While the Aino and Veddah have equal flatness of the nasal bones as measured by the simotic index, they stand at opposite ends of the scale with regard to a catenary hypothesis of the whole bridge of the nose. No attempt, however, is made to deduce any racial order from Table IV although it is not without suggestiveness.

Another method of approaching the degree of relationship of $\alpha^{\prime}$ to $\alpha$ is to consider the correlation coefficient between them, $r_{a a^{\prime}}$. A glance at Table XX shows that it is very high. We have, averaging results:

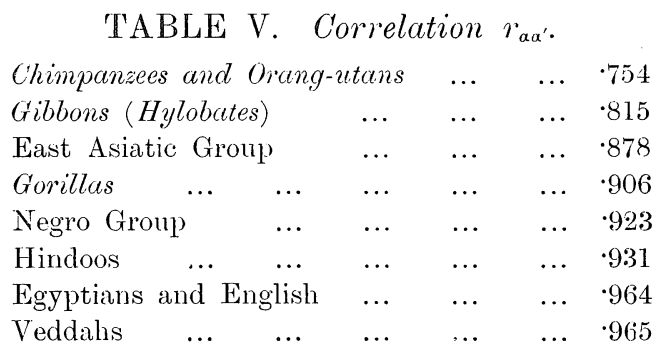

Finally in order to calculate the value of $\alpha$ from $\alpha^{\prime}$ for a given individual of one of the races dealt with, we append the regression lines, which provide the most probable value of $\alpha$ for a given $\alpha^{\prime}$.

\section{TABLE VI.}

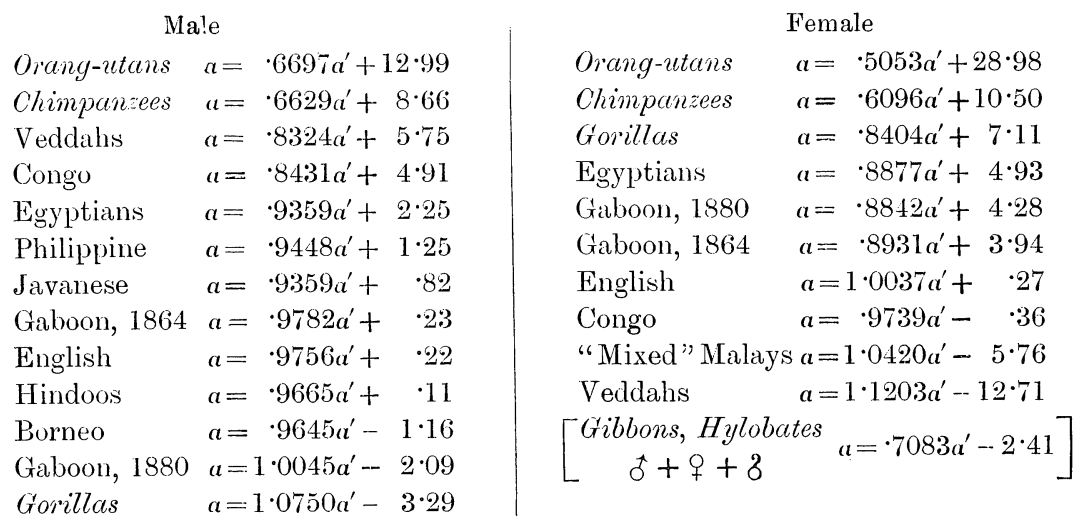

* The reader will observe (see contours, pp. 428-9) that it is not proper to speak of a catenary form of the nose. The English and Gorilla noses are not at all catenary in contour, but the chord and subtense relation is on the average clearly that of the catenary chord and subtense. 


\section{Kathleen V. Ryley and Julia Belli}

It will be seen that the catenary assumption as to the bridge of the nose, notwithstanding the relatively high correlations of $\alpha$ and $\alpha^{\prime}$, is not very satisfactory *. If it were, the best fitting or regression line would be simply $\alpha=\alpha^{\prime}$. Thus the regression coefficient should be unity and the constant term zero. This is roughly true for English females, less true for English and Hindoo males, and approximately the case in Congo females and Gaboon (1864) males. For the anthropoids the deviations are very considerable, and this is also true for the Veddahs. The catenary form of the nose appears to be an impression largely based on familiarity with the higher racial types. Thus the mesodacryal subtense index $\alpha$ can only be deduced from the mesodacryal arcual index $\beta$ for individuals of the higher races. At the same time Table IV shows that the racial value $\alpha^{\prime}$ of $\alpha$ as deduced from $\beta$ is very little in excess of the true value for a number of races, and we conclude that the hypothesis has greater value for interracial than for intraracial comparisonst.

(4) On the Simotic and Mesodacryal Indices.

If we are going to use these indices as a racial scale, it becomes of some importance to determine which provides the better classification. Unfortunately the simotic index cannot be determined for the Orang-utan. But an examination of Table IX shows that the Chimpanzee is placed at one end, the Gorilla at

\footnotetext{
* It serves excellently, however, as a control of individual measurements, and when $a^{\prime}$ is not approximately $a$ it is always worth reconsidering the measurements involved.

+ In order to obtain the values of $\alpha^{\prime}$ from those of $\beta$ for the catenary hypothesis in the case of the Chimpanzee and Orang-utan, the table published in Biometrika, Vol. vir. pp. 338--9, had to be somewhat extended. The values in Table VII below were obtained.
}

\section{TABLE VII.}

Supplementary Tables for Subtense Mesodacryal Index a as calculated from the arcual value $\beta$ on the Catenary Hypothesis.

(A) Values of $\alpha$.

\begin{tabular}{|c|c|c|c|c|c|c|c|c|c|c|}
\hline$\beta$ & $\cdot 0$ & $\cdot 1$ & $\mathscr{\mathscr { Q }}$ & $\mathscr{9}$ & $\cdot 4$ & .5 & $\cdot 6$ & $\%$ & $\cdot 8$ & $\cdot 9$ \\
\hline 6 & $15 \cdot 3$ & $15 \cdot 4$ & $15 \cdot 6$ & $15 \cdot 7$ & $15 \cdot 8$ & $16 \cdot 0$ & $16 \cdot 1$ & $16 \cdot 2$ & $16 \cdot 3$ & 16.5 \\
\hline$y$ & $16 \cdot 6$ & $16 \cdot 7$ & $16 \cdot 8$ & $17 \cdot 0$ & $17 \cdot 1$ & $17 \cdot 2$ & $17 \cdot 3$ & $17 \cdot 4$ & $17 \cdot 6$ & $17 \cdot 7$ \\
\hline 8 & $17 \cdot 8$ & $17 \cdot 9$ & $18 \cdot 0$ & $18 \cdot 1$ & $18 \cdot 3$ & $18 \cdot 4$ & $18 \%$ & $18 \cdot 6$ & $18 \cdot 7$ & $18 \cdot 8$ \\
\hline 9 & $18 \cdot 9$ & $19 \cdot 1$ & $19 \cdot 2$ & $19 \cdot 3$ & $19 \cdot 4$ & $19 \cdot 5$ & $19 \cdot 6$ & $19 \cdot 7$ & $19 \cdot 8$ & $19 \cdot 9$ \\
\hline 10 & $20 \cdot 0$ & $20 \cdot 1$ & $20 \cdot 2$ & $20 \cdot 3$ & $20 \cdot 4$ & $20 \cdot 6$ & $20 \cdot 7$ & $20 \cdot 8$ & $20 \cdot 9$ & $21^{\circ} 0$ \\
\hline 11 & $21 \cdot 1$ & $21 \cdot 2$ & $21 \cdot 3$ & $2 l \cdot 4$ & $21 \cdot 5$ & $21 \cdot 6$ & $21 \cdot 7$ & $21 \cdot 8$ & $21 \cdot 9$ & $22 \cdot 0$ \\
\hline 12 & $22 \cdot 1$ & $22 \cdot 2$ & $22 \cdot 3$ & $22 \cdot 4$ & $22 \cdot 5$ & $22 \cdot 6$ & $22 \cdot 7$ & $22 \cdot 8$ & $22 \cdot 9$ & $23 \cdot 0$ \\
\hline
\end{tabular}




\section{A Study of the Nasal Bridge in the Anthropoid Apes}

the other end of the simotic scale*, while in the case of the mesodacryal indices the Chimpanzee and Gorilla although widely separated from each other are both placed at the low end of the scale next the Negroes, while the Orang-utan appears next the Veddahs at the top of the scale. This appears an arrangement at least more in keeping with geographical relations, although we make no assertion that similarity in nasal form between Veddah and Orang and again between Negro and Gorilla or Chimpanzee is due either to closer descent relationship, or to a common environment compelling species dwelling under it to follow similar nasal developmentst. As far as the mesodacryal indices are concerned, English, Egyptian and Hindoo are closer to the Veddah than they are to the Negro, and may in nasal form be considered closer to the Orang than to

TABLE VII. (continued).

(B)

\begin{tabular}{|c|c|c|c|c|c|c|c|c|c|c|c|}
\hline$\beta$ & $a$ & $\beta$ & $a$ & $\beta$ & $a$ & $\beta$ & $a$ & $\beta$ & $a$ & $\beta$ & $a$ \\
\hline 101 & $80 \cdot 2$ & 120 & $94 \cdot 0$ & 151 & $107 \cdot \tilde{0}$ & $1 \% 6$ & $120 \cdot 8$ & 201 & 133.9 & 226 & $147 \cdot 0$ \\
\hline $10 \%$ & $80 \cdot 8$ & $19 \%$ & $94 \cdot 5$ & 152 & $108^{\circ} 0$ & $1 \%$ & $121 \cdot 3$ & $\mathscr{Q} 0$ & 134.5 & 92 & $147 \cdot 5$ \\
\hline 109 & $81: 3$ & 128 & $95 \cdot 1$ & $15 \%$ & $108 \cdot 5$ & $1 \% 8$ & $121 \cdot 8$ & Q08 & $135 \cdot 0$ & $98 S^{\prime}$ & $148 \cdot 0$ \\
\hline 104 & $81 \cdot 9$ & 199 & $95 \cdot 6$ & 154 & $109 \cdot 1$ & 179 & $122 \cdot 4$ & 904 & $135 \cdot 5$ & 929 & $148 \cdot 6$ \\
\hline $10 \tilde{5}$ & $82 \cdot 4$ & 130 & $96 \cdot 2$ & 155 & $109 \cdot 6$ & 180 & $122 \cdot 9$ & 205 & $136 \cdot 0$ & 280 & $149 \cdot 1$ \\
\hline $100^{\circ}$ & $83 \cdot 0$ & 191 & $96 \cdot 7$ & 150 & $110 \cdot 2$ & 181 & $123 \cdot 4$ & $20 G$ & $136 \cdot 6$ & 981 & $149 \cdot 6$ \\
\hline $10^{\prime 2}$ & $83 \cdot 5$ & 132 & $97 \cdot 2$ & $15 \%$ & $110 \cdot 7$ & 180 & $124^{\circ} 0$ & $90^{\prime y}$ & $137 \cdot 1$ & 939 & $150 \cdot 1$ \\
\hline 108 & $84 \cdot 1$ & 130 & $97 \cdot 8$ & 158 & $111 \cdot 2$ & 183 & $124 \cdot 5$ & $\mathscr{Q} 08$ & $137 \cdot 6$ & Q98 & $150 \cdot 6$ \\
\hline 109 & $84 \cdot 6$ & 194 & $98 \cdot 3$ & 159 & $111 \cdot 8$ & 184 & $125^{\circ} 0$ & $\mathscr{2} 09$ & $138 \cdot 1$ & 234 & $151 \cdot 2$ \\
\hline 110 & $85 \cdot 2$ & 135 & $98 \cdot 9$ & 160 & $112 \cdot 3$ & 185 & $125 \cdot 5$ & 210 & $138 \cdot 7$ & 935 & $151 \cdot 7$ \\
\hline 111 & $85 \cdot 8$ & 136 & $99 \cdot 4$ & 161 & $112 \cdot 8$ & 186 & $126 \cdot 1$ & 911 & $139 \cdot 2$ & 236 & $152 \cdot 2$ \\
\hline 112 & $86 \cdot 3$ & $13 \%$ & $99 \cdot 9$ & 162 & $113 \cdot 4$ & $18 \%$ & $126 \cdot 6$ & 219 & $139 \cdot 7$ & 984 & $152 \cdot 7$ \\
\hline 113 & $86 \cdot 9$ & 138 & $100 \cdot 5$ & 163 & $113 \cdot 9$ & 188 & $127 \cdot 1$ & Q13 & $140 \cdot 2$ & 988 & $153 \cdot 2$ \\
\hline 114 & $87 \cdot 4$ & 139 & $101 \cdot 0$ & 164 & $114 \cdot 4$ & 189 & $127 \cdot 7$ & \$1.4 & $140 \cdot 8$ & 939 & 153.8 \\
\hline 115 & $88 \cdot 0$ & 140 & $101 \cdot 6$ & 165 & $114 \cdot 9$ & 190 & $128 \cdot 2$ & 215 & $141 \cdot 3$ & 240 & $154 \cdot 3$ \\
\hline 116 & $88 \cdot 5$ & 141 & $102 \cdot 1$ & 166 & $115 \cdot 5$ & 191 & $128 \cdot 7$ & $\$ 16$ & $141 \cdot 8$ & 941 & 154.8 \\
\hline $11 \%$ & $89 \cdot 1$ & 149 & $102 \cdot 7$ & $16 \%$ & $116 \cdot 0$ & $19 ?$ & $129 \cdot 2$ & $91 \%$ & $142 \cdot 3$ & 949 & $155 \cdot 3$ \\
\hline 118 & $89 \cdot 6$ & 143 & $103 \cdot 2$ & 168 & $116 \cdot 5$ & 193 & $129 \cdot 8$ & 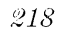 & $142 \cdot 8$ & 943 & $155 \cdot 8$ \\
\hline 119 & $90 \cdot 1$ & 14.4 & $103 \cdot 7$ & 169 & $117 \cdot 1$ & 194 & $130 \cdot 3$ & 919 & $143 \cdot 4$ & Q 44 & $156 \cdot 3$ \\
\hline 190 & $90 \cdot 7$ & 145 & $104 \cdot 3$ & $1 \% 0$ & $117 \cdot 6$ & 195 & $130 \cdot 8$ & 䍐( & 143.9 & 245 & 156.9 \\
\hline 191 & $91 \cdot 2$ & 146 & $104 \cdot 8$ & $1 \% 1$ & $118 \cdot 1$ & 196 & $131 \cdot 3$ & Q91 & $144^{\circ} 4$ & ${ }^{2} 40^{\circ}$ & $157 \cdot 4$ \\
\hline 192 & $91 \cdot 8$ & $1 y_{4} \mathrm{r}$ & $105 \cdot 3$ & $1 \% 9$ & $118 \cdot 7$ & $19^{\prime}$ & $131 \cdot 8$ & Q⿻心 & $144 \cdot 9$ & D.4 & 157.9 \\
\hline 123 & $92 \cdot 3$ & 148 & $105 \cdot 9$ & 173 & $119 \cdot 2$ & 198 & $132 \cdot 4$ & 299 & $145 \cdot 4$ & 948 & $158 \cdot 4$ \\
\hline 124 & $92 \cdot 9$ & 149 & $106 \cdot 4$ & 174 & $119 \cdot 7$ & 199 & $132 \cdot 9$ & 294 & $146^{\circ} 0$ & 949 & $159 \cdot 0$ \\
\hline 125 & $93 \cdot 4$ & 150 & $106 \cdot 9$ & 175 & $120 \cdot 2$ & $\mathscr{2} 00$ & $133 \cdot 4$ & 925 & $146 \cdot 5$ & 250 & $159 \cdot 5$ \\
\hline
\end{tabular}

* There is slender evidence also to place the Orang-utan out of position below the Chimpanzee and Negroes in the matter of this index.

† Dr Hans Friedenthal (Beiträge zur Naturgeschichte des Menschen, Th. v. "Sonderform der menschlichen Leibsbildung," Jena, 1910, S. 61) considers the nasal form determined by environmental conditions: "Die anthropoiden Affen als Baumbewohner bedurften keiner Vervolkommung der Atemröhre während der Reduktion des Riechorgans, wie die bodenbewohnenden Menschen und Paviane. Die Gorilla, mehr dem Bodenleben angepasst als die übrigen Anthropoiden, ja, mehr als viele Ostaffen und Westaffen, zeigt eine ausgebildetere äussere Nase als Schimpanse, Orang und Hylobates." 
TABLE VIII. Man and the Anthropoid Apes. Means of Nasal Bridge Measurements.

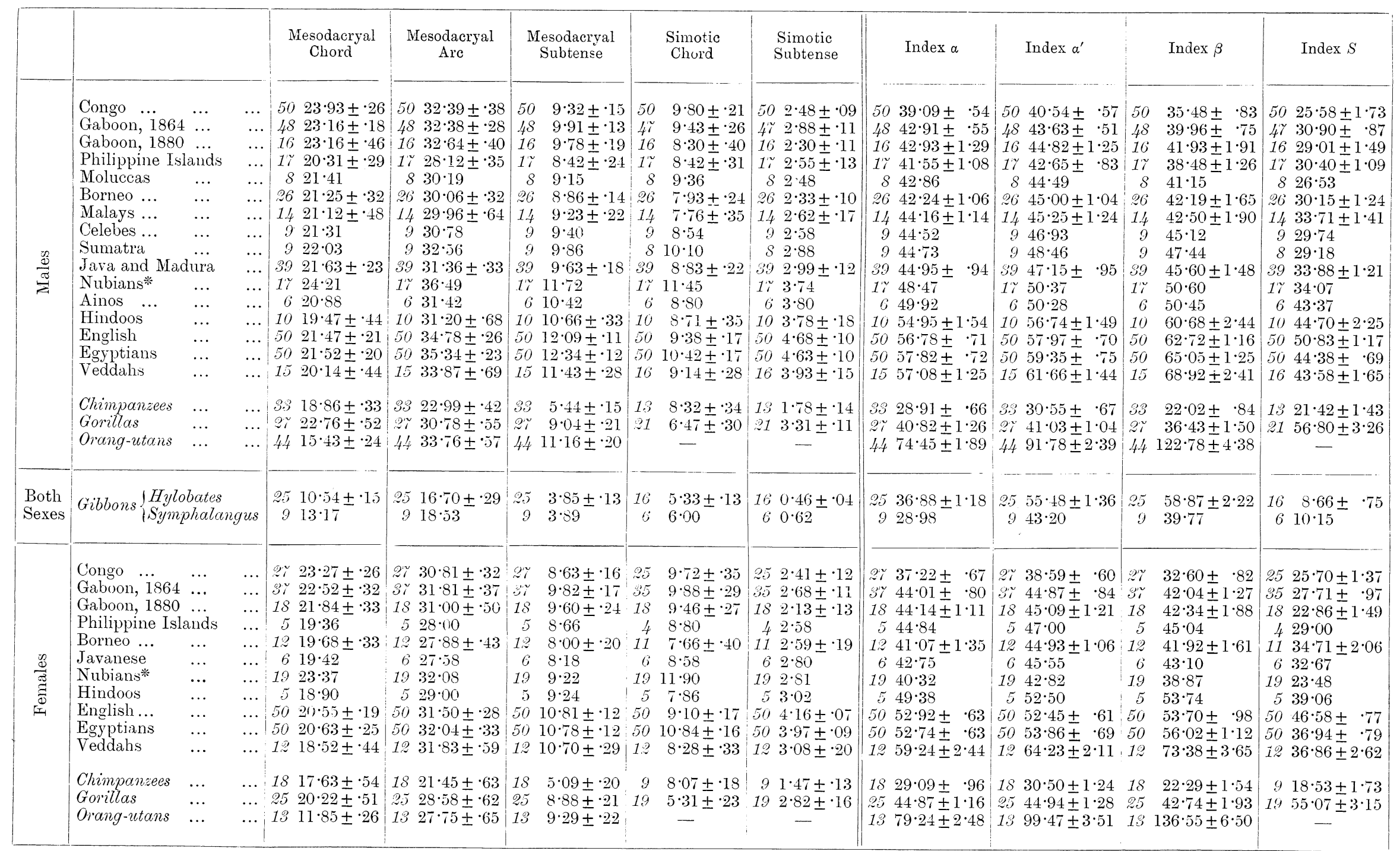

* Mean of results obtained by two sexings. 


\section{A Study of the Nasal Bridge in the Anthropoid Apes}

the Chimpanzee, although all the races dealt with are nearer to the Gorilla than either of the two apes. The following table gives the racial order for the simotic and two mesodacryal indices:

TABLE IX.

Simotic and Mesodacryal Indices. Mean Vahues*.

\begin{tabular}{|c|c|c|c|c|c|c|c|c|c|c|c|}
\hline \multicolumn{4}{|c|}{ Simotic Index $(S)$} & \multicolumn{4}{|c|}{ Mesodacryal (Subtense) Index $(a)$} & \multicolumn{4}{|c|}{ Mesodacryal (Arcual) Index $(\beta)$} \\
\hline & \multicolumn{2}{|l|}{$q$} & \multicolumn{2}{|l|}{$\hat{\sigma}$} & \multicolumn{2}{|l|}{$q$} & \multicolumn{2}{|l|}{$\hat{o}$} & \multicolumn{2}{|l|}{ q } \\
\hline [Orang-utans & 0 ?] & {$[0 r a n g \cdot u t a n s$} & 17 ?] & - & & $\ldots$ & & - & & - & \\
\hline Chimpanzees & 21 & Chimipanzees & 19 & Chimpanzees 2 & 29 & Chimpanzees & 29 & Chimpanzess & 22 & Chimpanzees & 22 \\
\hline Congo & 26 & Nubianst & 23 & Congo 3 & 39 & Congo & 37 & Congo. & 35 & Congo & 33 \\
\hline Moluccas & 27 & - & & Gorillas & 41 & Nubianst & 40 & Gorillas & 36 & - & \\
\hline Gaboon, 1880 & 29 & Gaboon, 1880 & 23 & Philippines & 42 & Borneo & 41 & Philippines & 38 & - & \\
\hline Sumatra & 29 & Congo & 26 & Borneo & 42 & Javanese & 43 & Gaboon, 1864 & 40 & Nubianst & 39 \\
\hline Celebes & 30 & - & & Moluccas & 43 & Gaboon, 1880 & 44 & Moluccas & 41 & Gaboon, 1864 & 42 \\
\hline Borneo & 30 & -- & & Gaboon, 1864 & 43 & Gaboon, 1864 & 44 & Gaboon, 1880 & 42 & Gaboon, 1880 & 42 \\
\hline Philippines & 30 & Gaboon, 1864 & 28 & Gaboon, 1880 & 43 & Gorillas & 45 & Borneo & 42 & Borneo & 42 \\
\hline Gaboon, 1864 & 31 & Philippines & 29 & Malays & 44 & Philipyines & 45 & Malays & 43 & Gorillas & 43 \\
\hline Malays & 32 & - & & Celebes & 45 & - & & Celebes & 45 & Javanese & 43 \\
\hline Javanese & 34 & Javanese & 33 & Sumatra & 45 & - & & Javanese & 46 & Philippines & 45 \\
\hline Nubianst & 34 & Borneo & 35 & Javanese & 45 & - & & Sumatra & 47 & 11 & \\
\hline Ainos & 43 & - & & Nubianst & 48 & - & & Ainos & 50 & - & \\
\hline Veddahs & 44 & Veddahs & 37 & Ainos & 50 & - & & Nubianst & 51 & - & \\
\hline Egyptians & 44 & Egyptians & 37 & Hindoos & 55 & Hindoos & 49 & Hindoos & 61 & Hindoos & 54 \\
\hline Hindoos & 45 & Hindoos & 39 & English & 57 & English & 53 & English & 63 & English & 54 \\
\hline English & 51 & English & 47 & Veddahs & 57 & Egyptians & 53 & Egyptians & 65 & Egyptians & 56 \\
\hline Gorillas & 57 & Gorillas & 55 & Egyptians & 58 & Veddahs & 59 & Veddahs & 69 & Veddahs & 73 \\
\hline - & & - & & Orang-utans & 74 & Orang-utans & 79 & Orong-utans 1 & 123 & Orang-utans & 137 \\
\hline
\end{tabular}

Now if we compare the results given in this table we see that with one exception, that of the Borneo crania, the simotic index is greater in the males than in the females; but there is a greater agreement between the sexes-the Hindoos, English and Egyptians excepted-in the mesodacryal indices. For the mesodacryal index, $\alpha$, there are 7 cases (judging from Table VIII, p. 403) in which the female is greater, as against 7 in which the male is greater; for the mesodacryal index $\beta$, there are also 7 cases for the male and 7 for the female with greater value, and

* The following are the values for the Gibbons :

\begin{tabular}{|c|c|c|c|}
\hline & $\begin{array}{l}\text { Simotic } \\
\text { Index }\end{array}$ & $\begin{array}{c}\text { Mesodacryal } \\
\text { (Subtense) Index }\end{array}$ & $\begin{array}{c}\text { Mesodacryal } \\
\text { (Arcual) Index }\end{array}$ \\
\hline $\int$ Hylobates $\quad \hat{\sigma}+q+\delta$ & 9 & 37 & 55 \\
\hline Symphalangus of $+q+8$ & 10 & 29 & 43 \\
\hline
\end{tabular}

$\dagger$ The position of the "Nubians" confirms the view that the men were more Egyptian and the women almost negroes. 


\section{Kathleen V. Ryley and Julia Bell}

the individual cases are the same for $\alpha$ and $\beta$. On the whole it is the lower races for which the female has the greater value, and the higher races-in the scale of civilisation-for which the male has the greater value. Thus the mesodacryal index appears more of a racial and less of a sexual character than the simotic index. Roughly also the two sexes give nearly the same racial order, especially if we regard the large probable errors (see Table VIII, p. 403) of some of our results. Looked at in broad outline we have the nose of the Gorilla closely associated with that of the Negro, and the Negro lies between the Chimpanzee and the Asiatic races. At the bottom of the scale we have the Orang-utans closest of all to the Veddahs, who lie between the Orang-utans and the higher races, so far as such are provided by these measurements*. On the whole the racial scale of the mesodacryal indices seems far more suggestive than that of the simotic index, where the Gorilla is widely separated from the Negro, and is divided from the Veddahs by English, Hindoos and Egyptianst. We believe that a measure of the mesodacryal index is likely to be of as much value as the determination of the simotic index, possibly of greater value.

\section{(5) On the Absolute Nasal Measurements.}

We are doubtful as to what if any stiress can be laid on the absolute measurements. Mércjkowsky, however, cites the absolute values of the simotic subtenses and it is of interest to compare our results with his. This is done in Table X. It will be seen that for Negroes, Malays and "White races" our results are in fair agreement with Mérejkowsky's; with his Melanesian, Polynesian and American groups, we have nothing to compare. There is relatively little difference in the order between the two sexes, but the actual height of the nasal bones, with the one exception of the Borneo crania, is considerably less for the females. This smaller value of the simotic subtense in the female is not true for the chord, which in Nubians, Egyptians, Gaboon (1864), Gaboon (1850), and Philippine Islanders is greater in the female as will be seen in Table XI. There is very little we think to be learnt concerning racial differences in either Table $\mathrm{X}$ or Table XI.

The races are mixed in a rather meaningless way-at least we have failed to find any clue to their order, although in this respect the simotic chord appears worse than the simotic subtense. On the whole we believe little of real value is to be learnt from the absolute size of the nasal bones.

* The Gibbons agree with the Orang for the simotic index, but are nearer to the Chimpanzee than to the Orang for the mesodacryal index $a$, while for the arcual index $\beta$ their position, like that of the Gorilla, is within the human range.

+ Judged by the mesodacryal indices the Gorilla has a flatter nose than any human race, the Negroes approaching most closely; judged by the simotic index the Gorilla has a sharper nose than any human race, the English approaching most closely. At any rate from the standpoint of physiognomy, there can be no doubt that the mesodacryal indices express better the general visual state of affairs: see, however, the contours, pp. 428-9.

Biometrika Ix 


\section{A Study of the Nasal Bridge in the Anthropoid Apes}

TABLE X. Simotic Subtense*.

\begin{tabular}{|c|c|c|c|c|c|}
\hline \multicolumn{2}{|l|}{ Males } & \multicolumn{2}{|l|}{ Females } & \multicolumn{2}{|c|}{ Sex $\nmid \uparrow$ Mérejkowsky } \\
\hline Chimpansees & $1 \cdot 78$ & Chimpanzees & $1 \cdot 47$ & - & \\
\hline Gaboon, 1880 & $2 \cdot 30$ & Gaboon, 1880 & $2 \cdot 13$ & - & \\
\hline Borneo & $2 \cdot 33$ & Congo & $2 \cdot 41$ & - & \\
\hline Congo & $2 \cdot 45$ & Philippines & $2 \cdot 58$ & Negroes & $2 \cdot 60$ \\
\hline Moluccas & $2 \cdot 48$ & $11-$ & & - & \\
\hline Philippines & 2.55 & Borneo & $2 \cdot 59$ & Mongols & $3 \cdot 00$ \\
\hline Celebes & $2 \cdot 58$ & -- & & - & \\
\hline Malays & $2 \cdot 62$ & - & & Malays & $2 \cdot 90$ \\
\hline Gaboon, 1864 & $2 \cdot 88$ & Gaboon, 1864 & $2 \cdot 68$ & - & \\
\hline Sumatra & $2 \cdot 88$ & - & & Polynesians & $3 \cdot 13$ \\
\hline Javanese & $2 \cdot 99$ & Javanese & $2 \cdot 80$ & - & \\
\hline Govillas & $3 \cdot 31$ & Nubiaus & $2 \cdot 81$ & - & \\
\hline Nubians & $3 \cdot 74$ & Gorillas & $2 \cdot 82$ & - & \\
\hline Hindoos & $3 \cdot 78$ & Hindoos & $3 \cdot 02$ & - & \\
\hline Ainos & $3 \cdot 80$ & - & & American Indians & $3 \cdot 80$ \\
\hline Veddahs & $3 \cdot 93$ & Veddahs & $3 \cdot 08$ & Melanesians & $3 \cdot 85$ \\
\hline Egyptians & $4 \cdot 63$ & Egyptians & $3 \cdot 97$ & - & \\
\hline English & $4 \cdot 68$ & English & $4 \cdot 16$ & White races & $4 \cdot 74$ \\
\hline
\end{tabular}

TABLE XI. Simotic Chord +

\begin{tabular}{|c|c|c|c|}
\hline \multicolumn{2}{|l|}{ Males } & \multicolumn{2}{|l|}{ Females } \\
\hline Gorillas & $6 \cdot 47$ & Gorillas & $5 \cdot 31$ \\
\hline Mallays & $7 \cdot 76$ & - & \\
\hline Borneo & $7 \cdot 93$ & Borneo & $7 \cdot 66$ \\
\hline Gaboon, 1880 & $8 \cdot 30$ & Hindoos & $7 \cdot 86$ \\
\hline Chimpansees & $8 \cdot 32$ & Glimpuniees & $8 \cdot(17$ \\
\hline Philiplpines & 8.42 & Veddiuhs & $8 \cdot 28$ \\
\hline Colchess & $8 \cdot 54$ & - & \\
\hline Hindoos & 8.71 & Javanese & 8.58 \\
\hline Ainos & $8 \cdot 80$ & - & \\
\hline Javauese & 8.83 & Philippines' & $8 \cdot 80$ \\
\hline Veddahs & $9 \cdot 14$ & - & \\
\hline Moluccits & $9 \cdot 36$ & English & $9 \cdot 10$ \\
\hline English & $9 \cdot 38$ & - & \\
\hline Gaboon, $186 t$ & $9 \cdot 13$ & Gaboon, 1880 & $9 \cdot 46$ \\
\hline Congo & $9 \cdot 80$ & C'ongo & $9 \cdot 72$ \\
\hline Sumatra & $10 \cdot 10$ & Gaboon, 1864 & $9 \cdot 88$ \\
\hline Egyptians & $10 \cdot 42$ & Egyptians & $10 \cdot 84$ \\
\hline Nubians & $11 \cdot 45$ & Nubians & 11.90 \\
\hline
\end{tabular}

* The Gibbons lie at the very top of this scale close to the Orang-utan with its practically zero value of the subtense. Thus for the simotic subtense we have:

$$
\text { Gibbons, } \hat{o}+q+8 \begin{cases}\text { Hylobates } & 046 \\ \text { Symphalangus } & 0 \cdot 62\end{cases}
$$

+ Apparently Mérejkowsliy mixes both sexes together, which is hardly permissible considering the large sexual differences.

$+$

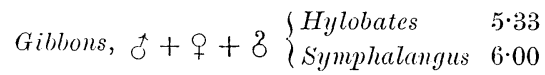


TABLE XII.

Racial Order of Mesodacryal Measurements.

\begin{tabular}{|c|c|c|c|c|c|c|c|c|c|c|c|}
\hline \multicolumn{4}{|c|}{ Subtense } & \multicolumn{4}{|c|}{ CHORD } & \multicolumn{4}{|c|}{ ARC } \\
\hline$\hat{0}$ & & q & & $\hat{s}$ & & $q$ & & s & & $q$ & \\
\hline $\begin{array}{l}\text { Chimpanzees } \\
\text { Philippines } \\
\text { Borneo } \\
\text { Gorillas } \\
\text { Moluccas } \\
\text { Malays } \\
\text { Congo } \\
\text { Celebes } \\
\text { Javanese } \\
\text { Gaboon (1880) } \\
\text { Sumatra } \\
\text { Gaboon (1864) } \\
\text { Ainos } \\
\text { Hindoos } \\
\text { Orcangs } \\
\text { Veddahis } \\
\text { Nubians } \\
\text { English } \\
\text { Egyptians }\end{array}$ & $\begin{array}{r}5 \cdot 44 \\
8 \cdot 42 \\
8 \cdot 86 \\
9 \cdot 04 \\
9 \cdot 15 \\
9 \cdot 2 \cdot 3 \\
9 \cdot 32 \\
9 \cdot 40 \\
9 \cdot 63 \\
9 \cdot 78 \\
9 \cdot 86 \\
9 \cdot 91 \\
10 \cdot 42 \\
10 \cdot 66 \\
11 \cdot 16 \\
11 \cdot 43 \\
11 \cdot 72 \\
12 \cdot 09 \\
12 \cdot 34\end{array}$ & \begin{tabular}{l} 
Chimpcciaces \\
Borneo \\
Javanese \\
Congo \\
\multicolumn{1}{c}{-} \\
Philippines \\
Gorillas \\
Nubians \\
Hindoos -- \\
Orangs - \\
Gaboon (1880) \\
Gaboon (1864) \\
Veddahs \\
Egyptians \\
English
\end{tabular} & $\begin{array}{r}8 \cdot 66 \\
\\
8 \cdot 88 \\
9 \cdot 22 \\
9 \cdot 24 \\
9 \cdot 29 \\
9 \cdot 60 \\
9 \cdot 82 \\
10 \cdot 70 \\
10 \cdot 78 \\
10 \cdot 81\end{array}$ & $\begin{array}{l}\text { Oircings } \\
\text { Chimpanzees } \\
\text { Hindoos } \\
\text { Veddahs } \\
\text { Philippines } \\
\text { Ainos } \\
\text { Ifalays } \\
\text { Borneo } \\
\text { Celebes } \\
\text { IIoluccas } \\
\text { English } \\
\text { Egyptians } \\
\text { Javanese } \\
\text { Sumatra } \\
\text { Goritlcts } \\
\text { Gaboon (1864) } \\
\text { Gaboon (1880) } \\
\text { Comgo } \\
\text { Nubians }\end{array}$ & \begin{tabular}{l|}
$15 \cdot 4$ \\
$18 \cdot 9$ \\
$19 \cdot 5$ \\
$20 \cdot 1$ \\
$20 \cdot 3$ \\
$20 \cdot 9$ \\
$21 \cdot 1$ \\
$21 \cdot 2$ \\
$21 \cdot 3$ \\
$21 \cdot 4$ \\
$21 \cdot 5$ \\
$21 \cdot 5$ \\
$21 \cdot 6$ \\
$22 \cdot 0$ \\
$22 \cdot 8$ \\
$23 \cdot 2$ \\
$23 \cdot 2$ \\
$23 \cdot 9$ \\
$24 \cdot 2$
\end{tabular} & $\begin{array}{l}\text { Orangs } \\
\text { Chimpanzees } \\
\text { Veddahs } \\
\text { Hindoos } \\
\text { Philippines } \\
\text { Javinese - } \\
\qquad- \\
\text { Borneo - } \\
\text { Gorillas } \\
\text { English } \\
\text { Egyptians } \\
\text { Gaboon (1880) } \\
\text { Gaboon (1864) } \\
\text { Congo } \\
\text { Nubians }\end{array}$ & $\begin{array}{l}19 \cdot 7 \\
20 \cdot 2 \\
20 \cdot 6 \\
20 \cdot 6 \\
21 \cdot 8 \\
22 \cdot 5 \\
23 \cdot 3 \\
23 \cdot 4\end{array}$ & $\begin{array}{l}\text { Chimpanzees } \\
\text { Philippines } \\
\text { Malays } \\
\text { Borneo } \\
\text { IIoluccas } \\
\text { Celebes } \\
\text { Goirllas } \\
\text { Hindoos } \\
\text { Ainos } \\
\text { Javanese } \\
\text { Gaboon (1864) } \\
\text { Congo } \\
\text { Sumatra } \\
\text { Gaboon (1880) } \\
\text { Oichis } \\
\text { Veddahs } \\
\text { English } \\
\text { Egyptians } \\
\text { Nubians }\end{array}$ & \begin{tabular}{l|}
$23 \cdot 0$ \\
$28 \cdot 1$ \\
$30 \cdot 0$ \\
$30 \cdot 1$ \\
$30 \cdot 2$ \\
$30 \cdot 8$ \\
$30 \cdot 8$ \\
$31 \cdot 2$ \\
$31 \cdot 4$ \\
$31 \cdot 4$ \\
$32 \cdot 4$ \\
$32 \cdot 4$ \\
$32 \cdot 6$ \\
$32 \cdot 6$ \\
$33 \cdot 8$ \\
$33 \cdot 9$ \\
$31 \cdot 8$ \\
$35 \cdot 3$ \\
$36 \cdot 5$
\end{tabular} & \begin{tabular}{l} 
Chimpanzes \\
Javanese \\
Oiangs -- \\
Borneo - \\
Philippines \\
Gorillas - \\
Hindoos - \\
Congo \\
Gaboon (1880) \\
\multicolumn{1}{c}{-} \\
English \\
Veddahs \\
Gaboon (1864) \\
Egyptians \\
Nubians
\end{tabular} & $\begin{array}{l}21 \cdot 4 \\
27 \cdot 6 \\
27 \cdot 8 \\
27 \cdot 9 \\
\\
28 \cdot 0 \\
28 \cdot 6 \\
29 \cdot 0 \\
30 \cdot 8 \\
31 \cdot 0\end{array}$ \\
\hline Gibbons, of & ? & $\left\{\begin{array}{l}\text { Hylobates } \\
\text { Symphalangu }\end{array}\right.$ & $\begin{array}{l}3 \cdot 85 \\
3 \cdot 89\end{array}$ & Gibbons, of + & -8 & $\left\{\begin{array}{l}\text { Hylobates } \\
\text { S.ymphedengus } 1\end{array}\right.$ & $\begin{array}{l}10 \cdot 54 \\
13 \cdot 12\end{array}$ & Gibboins, $\hat{o}+q$ & ++8 & $\left\{\begin{array}{l}\text { Hylobates } \\
\text { Symphalangus }\end{array}\right.$ & $\begin{array}{l}16 \cdot 70 \\
18 \cdot 53\end{array}$ \\
\hline
\end{tabular}




\section{A Study of the Nasal Bridge in the Anthropoid Apes}

Now we have already seen that the sexual differences in the mesodacryal indices are not very large, but we notice at once that these sexual differences are very considerable in the absolute measurements. It becomes rather meaningless to assert that the Hindoo's eyes are closer together than the Englishman's, when the difference in mesodacryal chord is less than that between male and female Javanese. They are less for the same reason, namely, because the cranium as a whole is smaller. Practically the female is less-and often very considerably lessin every mesodacryal absolute measurement, and we caunot usefully compare males and females-except as to absolute size, a sexual difference we are already familiar with-unless we get rid of this problem of size by using as we have already done the indices. But surely if this be true for sex, it is also true for race. Our scales become scales of absolute size and of very small racial significance. In all probability absolute lengths or breadths of the head would tell just as much as is to be learnt from these tables of relative racial sizes of the bridge of the nose. In our opinion there is little that has bearing on racial relationships. In, for example, the chord scales, it is possible that Veddah and Orang-utans are close together because of an ancestral link, but the Hindoo appears in this part of the scale because of his small size. The association of the Negrnes with the Gorillas may again be partly ancestral, but the association of English and Javanese in the same part of the scale as the Gorillas is probably fortuitous. We are inclined to say that very little indeed cau be deduced from absolute scales of this kind for nasal characters.

It is often asserted that a characteristic feature of the negro lies in the fact that he has his eyes farther apart than other races of man. The average value of the mesodacryal chord for the Congo and Gaboon male negroes is 23.5 and for English and Egyptians 21.5; for the females, Congo and Gaboon, it is $22 \cdot 6$, and for English and Egyptians 20.6. There is thus $2 \mathrm{~mm}$. difference on the average. Is it possible for the human eye to appreciate this difference? We are inclined to doubt it and believe that it is the marked simotic platygephyrosis (see p. 430 below) of the negro nose which produces largely the impression of greater ocular

Value of Ratio $100 \times$ Mesodacryal Chord/Minimum

Frorehead Breadth.

\begin{tabular}{|ll|c|c|}
\hline \multicolumn{1}{|c|}{ Race } & & o & \\
\hline Congo $\ldots$ & $\ldots$ & $24 \cdot 6$ & $25 \cdot 1$ \\
Gaboon, 1864 & $\ldots$ & $24 \cdot 0$ & $24 \cdot 3$ \\
Gaboon, 1880 & $\ldots$ & $23 \cdot 5$ & $23 \cdot 5$ \\
Egyptians & $\ldots$ & $22 \cdot 6$ & $22 \cdot 4$ \\
Veddahs ... & $\ldots$ & $22 \cdot 0$ & $21 \cdot 2$ \\
English ... & $\ldots$ & $21 \cdot 9$ & $22 \cdot 1$ \\
Hindoos ... & $\ldots$ & $21 \cdot 3$ & $21 \cdot 0$ \\
\hline
\end{tabular}


Kathleen V. Ryley and Julita Behla

breadth*. As the total size of the skull varies much from race to race it seems desirable to compare the mesodacryal chord with another horizontal measure and we have taken the minimum forehead brealth: see Table, p. 408.

It will be seen that the Negroes stand at one end of the list and the IndoEuropeans at the other, but again the change of index is relatively small, and it may be legitimately doubted whether it would be visually significant.

\section{(7) On the relative Racial Variability of the Nasal Bridge Characters.}

Tables XIII and XIV give respectively the Standard Deviations and the Coefficients of Variation of the characters determined in such series as supplied sufficient data for even an attempt at these constants. There is no loubt in our minds that the coefficient of variation is the better measure for racial purposes in the case of absolute measurements. We will consider first what points arise from a discussion of the variability of the mesodacryal subtense, chord and arc from this standpoint. The relative orders of variability are given in Table XV.

Again beyond the broad fact that the apes on the whole are far more variable than the races of men, perhaps little can be learnt from this table. In the apes the female is more variable than the male in 5 out of 9 cases; the same ratio of 5 to 4 is maintained in the case of the negro races; in the lower races from Borneo and the Veddahs, the males are more variable than the females in the ratio of 5 cases to 1, while in the higher races-Egyptian and English-the ratio is 5 cases of the female to 1 case of the male more variable. Altogether therefore the female is more variable in 16 and the male in 14 cases. Generally there is no evidence for greater male variation in these coefficients of variation of the mesodacryal absolute lengths. Even if we based our comparison on the absolute variations of the mesodacryal characters, we find among the apes the male is more variable in 5 the female in 3, with one case-the Chimpanzee mesodacryal subtense-of equality; in the lower races (Veddahs and Borneo) the male is more variable in all 6 cases; in the negro races in 5 out of 9 , but in the higher races (English and Egyptian) in only 1 out of 6 cases. Thus in absolute measurement the male is mure variable in 17 , the female in 12 cases.

\footnotetext{
* The reader must not judge from Figs. $6--9$ of the contours, pp. 428-9. These all have the mesodacryal chord in considerable excess of the negro mean, and were selected to give approximately mean angles, not mean absolute lengths.
} 
TABLE XIII. Man and Anthropoid. Apes. Nasal Bridge Characters. Standurd Deviations.

\begin{tabular}{|c|c|c|c|c|c|c|c|c|c|c|}
\hline & & $\begin{array}{l}\text { Mesodacryal } \\
\text { Chord }\end{array}$ & $\begin{array}{l}\text { Mesodacryal } \\
\text { Are }\end{array}$ & $\begin{array}{c}\text { Mesodacryal } \\
\text { Subtense }\end{array}$ & $\begin{array}{l}\text { Simotic } \\
\text { Chord }\end{array}$ & $\begin{array}{l}\text { Simotic } \\
\text { Subtense }\end{array}$ & Index a & Index $a^{\prime}$ & Index $\beta$ & Index $S$ \\
\hline 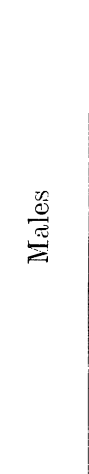 & $\begin{array}{lrr}\text { Congo } & \ldots & \ldots \\
\text { Gaboon, } & 1864 & \ldots \\
\text { Gaboon, } & \ldots 80 & \ldots \\
\text { Philippine Islands } \\
\text { Borneo } & \ldots & \ldots \\
\text { Malays } & \ldots & \ldots \\
\text { Java and } & \text { Madura } \\
\text { Hindoos } & \ldots & \ldots \\
\text { English } & \ldots & \ldots \\
\text { Egyptians } & \ldots \\
\text { Veddahs } & \ldots \\
& \ldots \\
\text { Chimpanzees } & \ldots \\
\text { Gorillas ... } & \ldots \\
\text { Orang-utans } & \ldots\end{array}$ & $\begin{array}{ll}50 & 2 \cdot 70 \pm \cdot 18 \\
48 & 1 \cdot 89 \pm \cdot 13 \\
16 & 2 \cdot 70 \pm \cdot 32 \\
17 & 1 \cdot 76 \pm \cdot 20 \\
26 & 2 \cdot 39 \pm \cdot 22 \\
1.4 & 2 \cdot 67 \pm \cdot 34 \\
99 & 2 \cdot 10 \pm \cdot 16 \\
10 & 2 \cdot 04 \pm \cdot 31 \\
50 & 2 \cdot 16 \pm \cdot 15 \\
50 & 2 \cdot 05 \pm \cdot 14 \\
15 & 2 \cdot 51 \pm \cdot 31 \\
& \\
93 & 2 \cdot 81 \pm \cdot 23 \\
27 & 3 \cdot 97 \pm \cdot 36 \\
44 & 2 \cdot 35 \pm \cdot 17\end{array}$ & $\begin{array}{ll}50 & 4 \cdot 02 \pm \cdot 27 \\
48 & 2 \cdot 86 \pm \cdot 20 \\
16 & 2 \cdot 37 \pm \cdot 28 \\
17 & 2 \cdot 15 \pm \cdot 25 \\
26 & 2 \cdot 43 \pm \cdot 23 \\
14 & 3 \cdot 53 \pm \cdot 45 \\
39 & 3 \cdot 05 \pm \cdot 23 \\
10 & 3 \cdot 20 \pm \cdot 48 \\
50 & 2 \cdot 71 \pm \cdot 18 \\
50 & 2 \cdot 45 \pm \cdot 17 \\
15 & 3 \cdot 95 \pm \cdot 49 \\
39 & 3 \cdot 61 \pm \cdot 30 \\
27 & 4 \cdot 23 \pm \cdot 39 \\
44 & 5 \cdot 56 \pm \cdot 40\end{array}$ & $\begin{array}{ll}50 & 1 \cdot 53 \pm \cdot 10 \\
48 & 1 \cdot 37 \pm \cdot 09 \\
16 & 1 \cdot 11 \pm \cdot 13 \\
17 & 1 \cdot 47 \pm \cdot 17 \\
26 & 1 \cdot 08 \pm \cdot 10 \\
14 & 1 \cdot 24 \pm \cdot 16 \\
39 & 1 \cdot 68 \pm \cdot 13 \\
10 & 1 \cdot 54 \pm \cdot 23 \\
50 & 1 \cdot 20 \pm \cdot 08 \\
50 & 1 \cdot 21 \pm \cdot 08 \\
15 & 1 \cdot 61 \pm \cdot 20 \\
& \\
99 & 1 \cdot 27 \pm \cdot 11 \\
96 & 1 \cdot 66 \pm \cdot 15 \\
44 & 1 \cdot 93 \pm \cdot 14\end{array}$ & \begin{tabular}{cc}
50 & $2 \cdot 24 \pm \cdot 15$ \\
41 & $2 \cdot 66 \pm \cdot 18$ \\
16 & $2 \cdot 38 \pm \cdot 28$ \\
17 & $1 \cdot 91 \pm \cdot 22$ \\
26 & $1 \cdot 81 \pm \cdot 17$ \\
14 & $1 \cdot 93 \pm \cdot 25$ \\
89 & $2 \cdot 04 \pm \cdot 16$ \\
10 & $1 \cdot 62 \pm \cdot 24$ \\
50 & $1 \cdot 77 \pm \cdot 12$ \\
50 & $1 \cdot 75 \pm \cdot 12$ \\
16 & $1 \cdot 68 \pm \cdot 20$ \\
18 & $1 \cdot 82 \pm \cdot 24$ \\
21 & $2 \cdot 01 \pm \cdot 21$ \\
\multicolumn{2}{c}{-}
\end{tabular} & $\begin{array}{rr}50 & \cdot 91 \pm \cdot 06 \\
47 & 1 \cdot 08 \pm \cdot 07 \\
16 & \cdot 67 \pm \cdot 08 \\
17 & \cdot 80 \pm \cdot 09 \\
26 & \cdot 77 \pm \cdot 07 \\
14 & \cdot 95 \pm \cdot 12 \\
39 & 1 \cdot 15 \pm \cdot 09 \\
10 & \cdot 83 \pm \cdot 13 \\
50 & 1 \cdot 04 \pm \cdot 07 \\
50 & 1 \cdot 07 \pm \cdot 07 \\
16 & \cdot 90 \pm \cdot 11 \\
13 & \cdot 73 \pm \cdot 10 \\
21 & -73 \pm \cdot 08\end{array}$ & 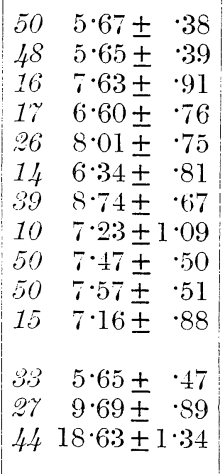 & 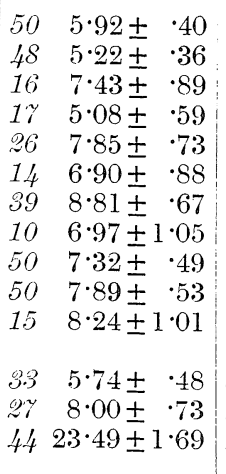 & 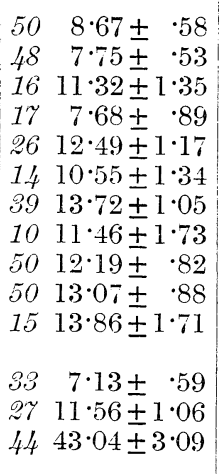 & 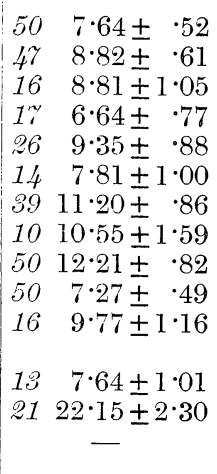 \\
\hline $\begin{array}{l}\text { Both } \\
\text { Sexes }\end{array}$ & Gibbons, Hylobates & $251 \cdot 13 \pm \cdot 11$ & $252 \cdot 12 \pm 20$ & . $550.55 \pm .08$ & $\begin{array}{ll}16 & 0 \cdot 77 \pm \cdot 09\end{array}$ & $16 \quad 0 \cdot 26 \pm \cdot 03$ & $25 \quad 8 \cdot 74 \pm 83$ & $25 \quad 10 \cdot 06 \pm \cdot 96$ & $25 \quad 16 \cdot 43 \pm 1 \cdot 57$ & $\begin{array}{ll}16 & 4 \cdot 48 \pm \cdot 53\end{array}$ \\
\hline 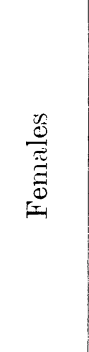 & $\begin{array}{lll}\text { Congo } & \ldots & \ldots \\
\text { Gaboon, } 1864 & \ldots \\
\text { Gaboon, } 1880 & \ldots \\
\text { Borneo } \ldots & \ldots \\
\text { English } \ldots & \ldots \\
\text { Egyptians } & \ldots \\
\text { Veddahs ... } & \ldots \\
& & \\
\text { Chimpanzees } & \ldots \\
\text { Gorillas ... } & \ldots \\
\text { Orang-utans } & \ldots\end{array}$ & $\mid \begin{array}{ll}\text { 27y } & 2 \cdot 00 \pm \cdot 18 \\
37 & 2 \cdot 86 \pm \cdot 22 \\
18 & 2 \cdot 10 \pm \cdot 24 \\
12 & 1 \cdot 69 \pm \cdot 23 \\
50 & 2 \cdot 04 \pm \cdot 14 \\
50 & 2 \cdot 59 \pm \cdot 17 \\
12 & 2 \cdot 27 \pm \cdot 31 \\
& \\
18 & 3 \cdot 38 \pm \cdot 38 \\
\text { 25 } & 3 \cdot 75 \pm \cdot 36 \\
13 & 1 \cdot 37 \pm \cdot 18\end{array}$ & $\begin{array}{ll}27 & 2 \cdot 43 \pm \cdot 22 \\
37 & 3 \cdot 35 \pm \cdot 26 \\
18 & 3 \cdot 15 \pm \cdot 35 \\
19 & 2 \cdot 23 \pm \cdot 31 \\
50 & 2 \cdot 90 \pm \cdot 20 \\
50 & 3 \cdot 47 \pm \cdot 23 \\
12 & 3 \cdot 04 \pm \cdot 42 \\
& \\
18 & 3 \cdot 93 \pm \cdot 44 \\
25 & 4 \cdot 57 \pm \cdot 44 \\
19 & 3 \cdot 49 \pm \cdot 46\end{array}$ & $\begin{array}{ll}27 & 1 \cdot 20 \pm \cdot 11 \\
97 & 1 \cdot 51 \pm \cdot 12 \\
18 & 1 \cdot 52 \pm \cdot 17 \\
12 & 1 \cdot 01 \pm \cdot 14 \\
50 & 1 \cdot 27 \pm \cdot 09 \\
50 & 1 \cdot 22 \pm \cdot 08 \\
19 & 1 \cdot 49 \pm \cdot 21 \\
18 & 1 \cdot 27 \pm \cdot 14 \\
95 & 1 \cdot 59 \pm \cdot 15 \\
19 & 1 \cdot 20 \pm \cdot 16\end{array}$ & $\left|\begin{array}{rr}95 & 2 \cdot 58 \pm \cdot 25 \\
35 & 2 \cdot 57 \pm \cdot 21 \\
18 & 1 \cdot 69 \pm \cdot 19 \\
11 & 1 \cdot 94 \pm \cdot 28 \\
50 & 1 \cdot 81 \pm \cdot 12 \\
50 & 1 \cdot 66 \pm \cdot 11 \\
1.2 & 1 \cdot 72 \pm \cdot 24 \\
9 & \cdot 82 \pm \cdot 13 \\
19 & 1 \cdot 51 \pm \cdot 17\end{array}\right|$ & \begin{tabular}{cc|}
95 & $\cdot 90 \pm \cdot 09$ \\
35 & $\cdot 92 \pm \cdot 07$ \\
18 & $\cdot 83 \pm \cdot 09$ \\
11 & $-95 \pm \cdot 14$ \\
50 & $-.8 \pm \pm \cdot 05$ \\
50 & $\cdot 90 \pm \cdot 06$ \\
10 & $1 \cdot 03 \pm \cdot 14$ \\
& $\cdot 58 \pm \cdot 09$ \\
9 & $\cdot 58 \pm$ \\
19 & $1 \cdot 04 \pm \cdot 11$ \\
& -
\end{tabular} & \begin{tabular}{rr|}
27 & $5 \cdot 15 \pm \cdot 47$ \\
37 & $7 \cdot 19 \pm \cdot 56$ \\
18 & $7 \cdot 00 \pm 78$ \\
19 & $6 \cdot 94 \pm .96$ \\
50 & $6 \cdot 64 \pm \cdot 45$ \\
50 & $6 \cdot 62 \pm \cdot 45$ \\
12 & $12 \cdot 52 \pm 1 \cdot 72$ \\
18 & $6 \cdot 05 \pm \cdot 68$ \\
25 & $8 \cdot 61 \pm .82$ \\
13 & $13 \cdot 27 \pm 1 \cdot 76$
\end{tabular} & 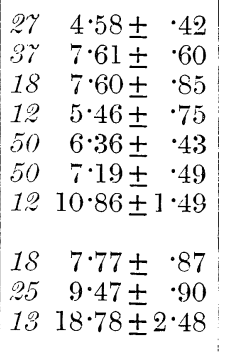 & 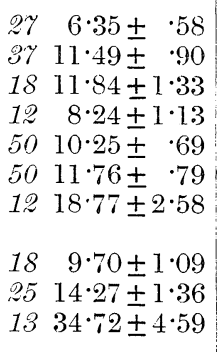 & 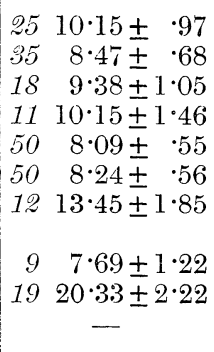 \\
\hline
\end{tabular}


TABLE XIV. Man and Anthropoid Apes. Nasal Bridge Characters. Coefficients of Variation.

\begin{tabular}{|c|c|c|c|c|c|c|c|c|c|c|}
\hline & & $\begin{array}{l}\text { Mesodacryal } \\
\text { Chord }\end{array}$ & $\begin{array}{l}\text { Mesodacryal } \\
\text { Arc }\end{array}$ & $\begin{array}{l}\text { Mesodacryal } \\
\text { Subtense }\end{array}$ & $\begin{array}{l}\text { Simotic } \\
\text { Chord }\end{array}$ & $\begin{array}{c}\text { Simotic } \\
\text { Subtense }\end{array}$ & Index $a$ & Index $a^{\prime}$ & Index $\beta$ & Index $S$ \\
\hline$\frac{\sqrt[n]{0}}{\frac{\pi}{2}}$ & $\begin{array}{lrr}\text { Congo } & \ldots & \ldots \\
\text { Gaboon, } & \ldots 64 & \ldots \\
\text { Gaboon, } & \ldots 80 & \ldots \\
\text { Philippine } & \text { Island } \\
\text { Borneo } & \ldots & \ldots \\
\text { Malays } & \ldots & \ldots \\
\text { Java and } & \text { Madura } \\
\text { Hindoos } & \ldots & \ldots \\
\text { English } & \ldots & \ldots \\
\text { Egyptians } & \ldots \\
\text { Veddahs ... } & \ldots \\
& \ldots \\
\text { Chimpanzes } & \ldots \\
\text { Gorillas } & \ldots & \ldots \\
\text { Orang-utans } & \ldots\end{array}$ & 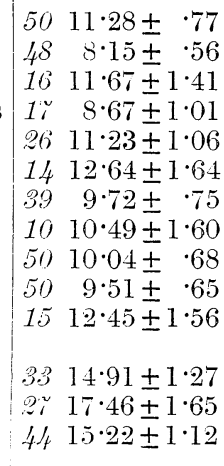 & 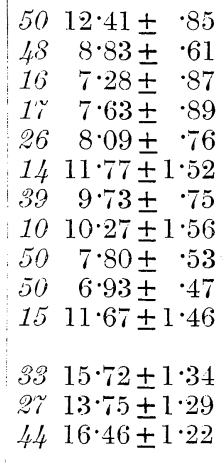 & 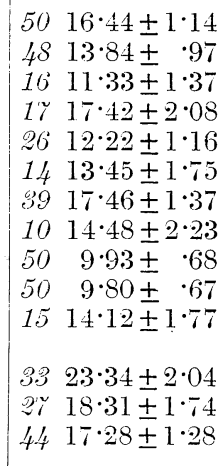 & \begin{tabular}{ll}
50 & $22 \cdot 89 \pm 1 \cdot 62$ \\
4. & $28 \cdot 15 \pm 2 \cdot 11$ \\
16 & $28 \cdot 66 \pm 3 \cdot 69$ \\
17 & $22 \cdot 68 \pm 2 \cdot 76$ \\
26 & $22 \cdot 78 \pm 2 \cdot 24$ \\
14 & $24 \cdot 81 \pm 3 \cdot 35$ \\
39 & $23 \cdot 06 \pm 1 \cdot 85$ \\
10 & $18 \cdot 60 \pm 2 \cdot 90$ \\
50 & $18 \cdot 85 \pm 1 \cdot 32$ \\
50 & $16 \cdot 84 \pm 1 \cdot 17$ \\
16 & $18 \cdot 35 \pm 2 \cdot 26$ \\
13 & $21 \cdot 88 \pm 3 \cdot 03$ \\
21 & $31 \cdot 12 \pm 3 \cdot 54$ \\
\multicolumn{3}{c}{-}
\end{tabular} & $\begin{array}{ll}50 & 36 \cdot 85 \pm 2 \cdot 80 \\
4 & 37 \cdot 35 \pm 2 \cdot 94 \\
16 & 29 \cdot 29 \pm 3 \cdot 78 \\
17 & 31 \cdot 27 \pm 3 \cdot 95 \\
26 & 32 \cdot 86 \pm 3 \cdot 39 \\
14 & 36 \cdot 32 \pm 5 \cdot 20 \\
39 & 38 \cdot 38 \pm 3 \cdot 34 \\
10 & 21 \cdot 94 \pm 3 \cdot 46 \\
50 & 22 \cdot 13 \pm 1 \cdot 56 \\
50 & 23 \cdot 10 \pm 1 \cdot 64 \\
16 & 23 \cdot 04 \pm 2 \cdot 89 \\
13 & 41 \cdot 07 \pm 6 \cdot 28 \\
21 & 21 \cdot 96 \pm 2 \cdot 39\end{array}$ & 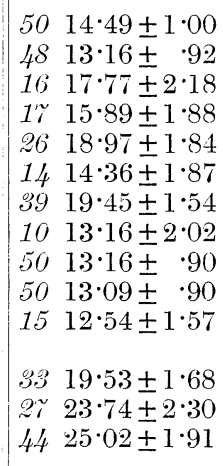 & 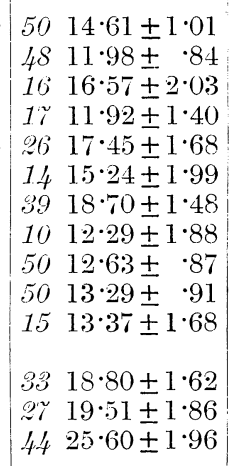 & $\begin{array}{ll}50 & 24 \cdot 43 \pm 1 \cdot 74 \\
48 & 19 \cdot 39 \pm 1 \cdot 38 \\
16 & 26 \cdot 99 \pm 3 \cdot 44 \\
17 & 19 \cdot 97 \pm 2 \cdot 40 \\
26 & 29 \cdot 61 \pm 3 \cdot 00 \\
14 & 24 \cdot 82 \pm 3 \cdot 35 \\
39 & 30 \cdot 10 \pm 2 \cdot 50 \\
10 & 18 \cdot 88 \pm 2 \cdot 95 \\
50 & 19 \cdot 43 \pm 1 \cdot 36 \\
50 & 20 \cdot 09 \pm 1 \cdot 41 \\
15 & 20 \cdot 11 \pm 2 \cdot 57 \\
39 & \\
38 & 32 \cdot 39 \pm 2 \cdot 96 \\
27 & 31 \cdot 74 \pm 3 \cdot 19 \\
44 & 35 \cdot 06 \pm 2 \cdot 81\end{array}$ & \begin{tabular}{cc}
50 & $29 \cdot 87 \pm 2 \cdot 19$ \\
47 & $28 \cdot 54 \pm 2 \cdot 14$ \\
16 & $30 \cdot 37 \pm 3 \cdot 94$ \\
17 & $21 \cdot 84 \pm 2 \cdot 64$ \\
26 & $31 \cdot 03 \pm 3 \cdot 17$ \\
14 & $23 \cdot 16 \pm 3 \cdot 11$ \\
39 & $33 \cdot 06 \pm 2 \cdot 79$ \\
10 & $23 \cdot 60 \pm 3 \cdot 75$ \\
50 & $24 \cdot 03 \pm 1 \cdot 71$ \\
50 & $16 \cdot 38 \pm 1 \cdot 13$ \\
16 & $22 \cdot 42 \pm 2 \cdot 80$ \\
10 & $35 \cdot 69 \pm 5 \cdot 29$ \\
21 & $38 \cdot 99 \pm 4 \cdot 63$ \\
\multicolumn{2}{c}{ - }
\end{tabular} \\
\hline $\begin{array}{r}\text { Both } \\
\text { Sexes }\end{array}$ & Gibbons, Hylobates & $95 \quad 10 \cdot 67 \pm 1 \cdot 03$ & $25 \quad 12 \cdot 69 \pm 1 \cdot 23$ & $2522 \cdot 05 \pm 2 \cdot 20$ & $16 \quad 14 \cdot 49 \pm 1 \cdot 76$ & $16 \quad 57 \cdot 15 \pm 8 \cdot 76$ & $25 \quad 23 \cdot 70 \pm 2 \cdot 38$ & $25 \quad 18 \cdot 13 \pm 1 \cdot 79$ & $95 \quad 27 \cdot 90 \pm 2 \cdot 86$ & $1651 \cdot 72 \pm 7 \cdot 64$ \\
\hline 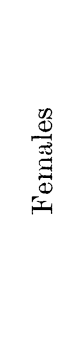 & $\begin{array}{lll}\text { Congo } & \ldots & \ldots \\
\text { Gaboon, } & 1864 & \ldots \\
\text { Gaboon, } & \ldots 80 & \ldots \\
\text { Borneo } & \ldots & \ldots \\
\text { English } \ldots & \ldots \\
\text { Egyptians } & \ldots \\
\text { Veddahs ... } & \ldots \\
& \ldots \\
\text { Chimpanzees } & \ldots \\
\text { Gorillas ... } & \ldots \\
\text { Orang-utans } & \ldots\end{array}$ & $\begin{array}{rr}97 & 8 \cdot 61 \pm \cdot 80 \\
97 & 12 \cdot 68 \pm 1 \cdot 01 \\
18 & 9 \cdot 60 \pm 1 \cdot 09 \\
12 & 8 \cdot 60 \pm 1 \cdot 19 \\
50 & 9 \cdot 93 \pm \cdot 68 \\
50 & 12 \cdot 5 \pm \pm .86 \\
19 & 12 \cdot 28 \pm 1 \cdot 72 \\
& \\
18 & 19 \cdot 19 \pm 2 \cdot 24 \\
95 & 18 \cdot 56 \pm 1 \cdot 83 \\
19 & 11 \cdot 54 \pm 1 \cdot 55\end{array}$ & $\begin{array}{rr}97 & 7 \cdot 89 \pm 73 \\
37 & 10 \cdot 54 \pm .84 \\
18 & 10 \cdot 17 \pm 1 \cdot 16 \\
12 & 7 \cdot 99 \pm 1 \cdot 11 \\
50 & 9 \cdot 21 \pm \cdot 63 \\
50 & 10 \cdot 83 \pm .74 \\
12 & 9 \cdot 56 \pm 1 \cdot 33 \\
& \\
18 & 18 \cdot 33 \pm 2 \cdot 13 \\
25 & 16 \cdot 00 \pm 1 \cdot 57 \\
19 & 12 \cdot 58 \pm 1 \cdot 69\end{array}$ & $\begin{array}{ll}27 & 13 \cdot 86 \pm 1 \cdot 30 \\
37 & 15 \cdot 34 \pm 1 \cdot 23 \\
18 & 15 \cdot 78 \pm 1 \cdot 82 \\
102 & 12 \cdot 56 \pm 1 \cdot 76 \\
50 & 11 \cdot 74 \pm \\
50 & 11 \cdot 32 \pm \\
50 & \cdot 77 \\
12 & 13 \cdot 95 \pm 1 \cdot 96 \\
18 & 24 \cdot 95 \pm 2 \cdot 97 \\
18 & 24 \\
25 & 17 \cdot 91 \pm 1 \cdot 76 \\
13 & 12 \cdot 88 \pm 1 \cdot 73\end{array}$ & $\mid$\begin{tabular}{rr|r}
25 & $26 \cdot 58 \pm 2 \cdot 71$ \\
35 & $25 \cdot 97 \pm 2 \cdot 23$ \\
18 & $17 \cdot 88 \pm 2 \cdot 07$ \\
11 & $25 \cdot 35 \pm 3 \cdot 87$ \\
50 & $19 \cdot 85 \pm 1 \cdot 39$ \\
50 & $15 \cdot 28 \pm 1 \cdot 05$ \\
12 & $20 \cdot 71 \pm 2 \cdot 97$ \\
& \\
9 & $10 \cdot 11 \pm 1 \cdot 62$ \\
19 & $28 \cdot 40 \pm 3 \cdot 35$ \\
\multicolumn{2}{c}{} &
\end{tabular} & \begin{tabular}{rc}
95 & $37 \cdot 33 \pm 4 \cdot 03$ \\
35 & $34 \cdot 50 \pm 3 \cdot 09$ \\
18 & $39 \cdot 15 \pm 5 \cdot 03$ \\
11 & $36 \cdot 59 \pm 5 \cdot 93$ \\
50 & $18 \cdot 83 \pm 1 \cdot 31$ \\
50 & $22 \cdot 78 \pm 1 \cdot 61$ \\
19 & $33 \cdot 44 \pm 5 \cdot 09$ \\
& \\
9 & $39 \cdot 22 \pm 7 \cdot 13$ \\
19 & $36 \cdot 95 \pm 4 \cdot 57$ \\
\multicolumn{2}{c}{-}
\end{tabular} & 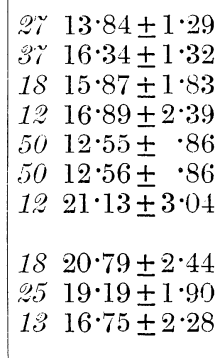 & $\begin{array}{ll}27 & 11 \cdot 88 \pm 1 \cdot 11 \\
37 & 16 \cdot 95 \pm 1 \cdot 37 \\
18 & 16 \cdot 85 \pm 1 \cdot 95 \\
12 & 12 \cdot 15 \pm 1 \cdot 70 \\
50 & 12 \cdot 14 \pm .83 \\
50 & 13 \cdot 35 \pm .92 \\
12 & 16 \cdot 90 \pm 2 \cdot 39 \\
18 & 25 \cdot 48 \pm 3 \cdot 05 \\
25 & 21 \cdot 07 \pm 2 \cdot 10 \\
19 & 18 \cdot 88 \pm 2 \cdot 59\end{array}$ & $\begin{array}{ll}27 & 19 \cdot 48 \pm 1 \cdot 85 \\
37 & 27 \cdot 34 \pm 2 \cdot 30 \\
18 & 27 \cdot 97 \pm 3 \cdot 38 \\
10 & 19 \cdot 66 \pm 2 \cdot 81 \\
50 & 19 \cdot 09 \pm 1 \cdot 33 \\
50 & 21 \cdot 00 \pm 1 \cdot 48 \\
12 & 25 \cdot 57 \pm 3 \cdot 74 \\
& \\
18 & 43 \cdot 51 \pm 5 \cdot 74 \\
25 & 33 \cdot 40 \pm 3 \cdot 52 \\
13 & 25 \cdot 43 \pm 3 \cdot 57\end{array}$ & $\begin{array}{rc}25 & 39 \cdot 47 \pm 4 \cdot 31 \\
35 & 30 \cdot 58 \pm 2 \cdot 69 \\
18 & 41 \cdot 04 \pm 5 \cdot 33 \\
11 & 29 \cdot 24 \pm 4 \cdot 55 \\
50 & 17 \cdot 36 \pm 1 \cdot 21 \\
50 & 22 \cdot 32 \pm 1 \cdot 58 \\
19 & 36 \cdot 48 \pm 5 \cdot 65 \\
& \\
9 & 41 \cdot 48 \pm 7 \cdot 65 \\
19 & 36 \cdot 91 \pm 4 \cdot 56 \\
c & -\end{array}$ \\
\hline
\end{tabular}


TABLE XV.

Variability Scales for Mesodacryal Characters*.

\begin{tabular}{|c|c|c|c|c|c|c|c|c|c|c|c|}
\hline \multicolumn{4}{|c|}{ Subtense } & \multicolumn{4}{|c|}{ Chord } & \multicolumn{4}{|c|}{ Arc } \\
\hline t & & 우 & & o & & $q$ & & $\delta$ & & $q$ & \\
\hline Egyptians & $9 \cdot 8$ & Egyptians & $11 \cdot 3$ & Gaboon (1864) & $8 \cdot 2$ & Borneo & $8 \cdot 6$ & Egyptians & $6 \cdot 9$ & Congo & $7 \cdot 9$ \\
\hline English & $9 \cdot 9$ & English & $11 \cdot 7$ & Philippines & $8 \cdot 7$ & - & & Gaboon (1880) & $7 \cdot 3$ & Borneo & $8 \cdot 0$ \\
\hline Gaboon (1880) & $11 \cdot 3$ & Borneo & $12 \cdot 6$ & Egyptians & $9 \cdot 5$ & Congo & $8 \cdot 6$ & Philippines & $7 \cdot 6$ & - & \\
\hline Borneo & $12 \cdot 2$ & Orangs & $12 \cdot 9$ & Jaranese & $9 \cdot \bar{T}$ & - & & English & $7 \cdot 8$ & English & $9 \cdot 2$ \\
\hline Malays & $13 \cdot 5$ & - & & English & $10 \cdot 0$ & Gaboon (1880) & $9 \cdot 6$ & Borneo & $8 \cdot 1$ & Veddahs & $9 \cdot 6$ \\
\hline Gaboon (1864) & $13 \cdot 8$ & Congo & $13 \cdot 9$ & Hindoos & $10 \cdot 5$ & - & & Gaboon (1864) & $8 \cdot 8$ & Gaboon (1880) & $10 \cdot 2$ \\
\hline Veddahs & $14 \cdot 1$ & Veddahs & $14 \cdot 0$ & Borneo & $11 \cdot 2$ & English & $9 \cdot 9$ & Javanese & $9 \cdot 7$ & - & \\
\hline Hindoos & $14 \cdot 5$ & - & & Congo & $11 \cdot 3$ & Orangs & $11 \div$ & Hindoos & $10 \cdot 3$ & - & \\
\hline Congo & $16 \cdot 4$ & Gaboon (1864) & $15 \cdot 3$ & Gaboon (1880) & $11 \cdot 7$ & Veddahs & $12 \cdot 3$ & Veddahs & $11 \cdot 7$ & Gaboon (1864) & $10 \cdot 5$ \\
\hline Philippines & $17 \cdot 4$ & - & & Veddahs & $12 \cdot 5$ & Egyptians & $12 \cdot 6$ & Malays & $11 \cdot 8$ & - & \\
\hline Orangs & $17 \cdot 3$ & - & & Malays & $12 \cdot 6$ & Gaboon (1864) & $12 \cdot 7$ & Congo & $12 \cdot 4$ & Egyptians & $10 \cdot 8$ \\
\hline Javanese & $17 \cdot 5$ & Gaboon (1880) & $15 \cdot 8$ & Chimpanzees & $14 \cdot 9$ & - & & Gorillas & $13 \cdot 8$ & Orangs & $12 \cdot 6$ \\
\hline Gorillas & $18 \cdot 3$ & Gorillas & $17 \cdot 9$ & Orangs & $15 \cdot 2$ & Gorillas & $18 \cdot 6$ & Chimpanzees & $15 \cdot 7$ & Gorillas & $16 \cdot 0$ \\
\hline Chimpanzees & $23 \cdot 3$ & Chimpanzees & $25 \cdot 0$ & Gorillas & $17 \cdot 5$ & Chimpanzees & $19 \cdot 2$ & Orangs & $16 \cdot 5$ & Chimpanzees & $18 \cdot 3$ \\
\hline
\end{tabular}

* The values for Hylobates are for both sexes together: Subtense $22 \cdot 1$ | Chord $10 \cdot 7$ | Arc $12 \cdot 7$ 
Kathleen V. Ryley and Julia Bell

For the simotic chord and subtense we have:

TABLE XVI.

Order of Racial Variability for Simotic Characters*.

\begin{tabular}{|c|c|c|c|c|c|c|c|}
\hline \multicolumn{4}{|c|}{ Simotic Subtense } & \multicolumn{4}{|c|}{ Simotic Chord } \\
\hline$\hat{\sigma}$ & & $q$ & & $\hat{\sigma}$ & & $q$ & \\
\hline Hindoos & $21 \cdot 9$ & - & & Egyptians & $16 \cdot 8$ & Chimpanzees & $10 \cdot 10$ \\
\hline Gorillas & $22 \cdot 0$ & English & $18 \cdot 8$ & Veddahs & $18 \cdot 4$ & Egyptians & $15 \cdot 3$ \\
\hline English & $22 \cdot 1$ & Egyptians & $22 \cdot 8$ & Hindoos & $18 \cdot 6$ & - - & \\
\hline Veddahs & $23 \cdot 0$ & Veddahs & $33 \cdot 4$ & English & $18 \cdot 9$ & Gaboon (1880) & $17 \cdot 9$ \\
\hline Egyptians & $23 \cdot 1$ & Gaboon (1864) & $34 \cdot 5$ & Chimpanzees & $21 \cdot 9$ & English & $19 \cdot 9$ \\
\hline Gaboon (1880) & $29 \cdot 3$ & Borneo & $36 \cdot 6$ & Philippines & $22 \cdot 7$ & - & \\
\hline Philippines & $31 \cdot 3$ & - & & Borneo & $22 \cdot 8$ & Veddahs & $20 \cdot 7$ \\
\hline Borneo & $32 \cdot 9$ & Goirllas & $37 \cdot 0$ & Congo & $22 \cdot 9$ & Borneo & $25 \cdot 4$ \\
\hline Malays & $36 \cdot 3$ & - & & Javanese & $23 \cdot 1$ & - & \\
\hline Congo & $36 \cdot 9$ & Congo & $37 \cdot 3$ & Malays & $24 \cdot 8$ & $\ldots$ & \\
\hline Gaboon (1864) & $37 \cdot 4$ & Gaboon (1880) & $39 \cdot 2$ & Gaboon (1864) & $28 \cdot 2$ & Gaboon (1864) & $26 \cdot 0$ \\
\hline Javanese & 38.4 & - & & Gaboon (1880) & $28 \cdot 7$ & Congo & $26 \cdot 6$ \\
\hline Chimpanzees & $41 \cdot 1$ & Chimpanzees & $39 \cdot 2$ & Gorillas & $31 \cdot 1$ & Gorillas & $28 \cdot 4$ \\
\hline
\end{tabular}

Again there is practically little to be learnt, the Gorillas are very variable in nasal chord and much less variable (in scale position) on the subtense, while the reverse holds for the Chimpanzees, the subtense being far more variable than the chord. The Negroes are as a rule low down on the scale, being considerably more variable than the English, Egyptians or Hindoos. In 9 cases the female and in 9 the male is more variable in simotic characters.

Lastly we pass to the indices, omitting the calculated mesodacryal subtense index $\alpha^{\prime}$. We find for Standard Deviations the order given in Table XVII.

Again there seems little to be learnt with regard to racial variability from these results, beyond the confirmation of what we have learnt from the earlier tables that the Orangs, and the Gorillas as a rule, have large variability; here, however,-as distinguished from the coefficients of variation of the absolute lengths-the Chimpanzee is seen to have very small variability. If, however, we take the coefficients of variation of the indices we find the Chimpanzee is associated with the other two anthropoids of our scales in high variability. Turning to the sexual differences, we find in the apes as many cases (4) of female as of male greater variability; among the human races there are 10 cases in which the female is more variable and 11 cases in which the male is more variable, or again there is little if any distinction of sex in variability.

An examination of Tables XIII and XIV will show the reader that much of the non-significance of the variation scale for racial purposes is quite possibly due

* The values for Hylobates, both sexes together, are: simotic chord 14.5 and simotic arc $57 \cdot 2$.

Biometrika Ix 
TABLE XVII.

Order of Standard Deviations of Nasal Bridge Indices*.

\begin{tabular}{|c|c|c|c|c|c|c|c|c|c|c|c|}
\hline \multicolumn{4}{|c|}{ Mesodacryal Subtense Index } & \multicolumn{4}{|c|}{ Mesodacryal Arcual Index } & \multicolumn{4}{|c|}{ Simotic Index } \\
\hline o & & q & & t & & $q$ & & ct & & $q$ & \\
\hline Chimpanzees & $5 \cdot 65$ & Congo & $5 \cdot 15$ & Chimpanzees & $7 \cdot 13$ & Congo & $6: 35$ & Philippines & $6 \cdot 64$ & - & \\
\hline Gaboon (1864) & $5 \cdot 65$ & Chimponiees & $6 \cdot 0 \tilde{3}$ & Philippines & $7 \cdot 68$ & - & & Egyptians & $7 \cdot 27$ & Chimpanzees & $7 \cdot 69$ \\
\hline Congo & $5 \cdot 67$ & Egyptians & $6 \cdot 62$ & Gaboon (1864) & $7 \cdot 75$ & Borneo & $8 \cdot 24$ & Congo & $7 \cdot 64$ & English & $8 \cdot 09$ \\
\hline Malays & $6 \cdot 34$ & - & & Congo & $8 \cdot 67$ & Chimpanzees & $9 \cdot 70$ & Chimpanzees & $7 \cdot 64$ & Egyptians & $8 \cdot 24$ \\
\hline Philippines & $6 \cdot 60$ & - & & Malays & $10 \cdot 55$ & - & & Malays & $7 \cdot 81$ & - & \\
\hline Veddahs & $7 \cdot 16$ & English & $6 \cdot 64$ & Gaboon (1880) & $11 \cdot 32$ & English & $10 \cdot 25$ & Gaboon (1880) & $8 \cdot 81$ & Gaboon (1864) & $8 \cdot 47$ \\
\hline Hindoos & $7 \cdot 23$ & - & & Hindoos & $11 \cdot 46$ & - & & Gaboon (1864) & $8 \cdot 82$ & Gaboon (1880) & $9 \cdot 38$ \\
\hline English & $7 \cdot 47$ & Borneo & 6.94 & Gorillas & 11.56 & Gaboon (1864) & $11 \cdot 49$ & Borneo & $9 \cdot 35$ & Congo & $10 \cdot 15$ \\
\hline Egyptians & $7 \cdot 57$ & Gaboon (1880) & $7 \cdot 00$ & English & $12 \cdot 19$ & Egyptians & $11 \cdot 76$ & Veddahs & $9 \cdot 77$ & Borneo & $10 \cdot 15$ \\
\hline Gaboon (1880) & $7 \cdot 63$ & Gaboon (1864) & $7 \cdot 19$ & Borneo & $12 \cdot 49$ & Gaboon (1880) & $11 \cdot 84$ & Hindoos & $10 \cdot 55$ & - & \\
\hline Borneo & $8 \cdot 01$ & Gorillas & $8 \cdot 61$ & Egyptians & $13 \cdot 07$ & Gorillas & $14 \cdot 27$ & Javanese & $11 \cdot 20$ & - & \\
\hline Javanese & $8 \cdot 74$ & - & & Javanese & $13 \cdot 72$ & - & & English & $12 \cdot 21$ & Veddahs & $13 \cdot 45$ \\
\hline Gorillas & $9 \cdot 69$ & Veddahs & $12 \cdot 52$ & Veddahs & $13 \cdot 86$ & Veddahs & $18 \cdot 77$ & Gorillas & $22 \cdot 15$ & Goritlas & $20 \cdot 33$ \\
\hline Orangs & $18 \cdot 63$ & Oiangs & $13 \cdot 27$ & Orangs & $43 \cdot 04$ & Orangs & $34 \cdot 72$ & - & & - & \\
\hline
\end{tabular}

* The values for Hylobates, both sexes together, are: Mesodacryal (Subtense) Index 8·7, Mesodacryal (Arcual) Index 10·1, Simotic Index 51·7. 


\section{Kathleeen V. Ryley and Julia Bell}

to the smallness of our samples. Except in the case of Egyptians and English, the size of these samples was not under our control; we set out to compare the African and Asiatic anthropoids with the human races of the same environment, and we measured all the crania available, and calculated the variabilities for all series of 10 and over*. Further the homogeneity of some of the series, as the Malay and Javanese, is possibly open to doubt. We have accordingly clubbed together our variation results for the coefficients of variation of the absolute measurements, with the results given in Table XVIII.

\section{TABLE XVIII.}

Average Values of Variability of Absolute Measurements on the Nasal Bridge.

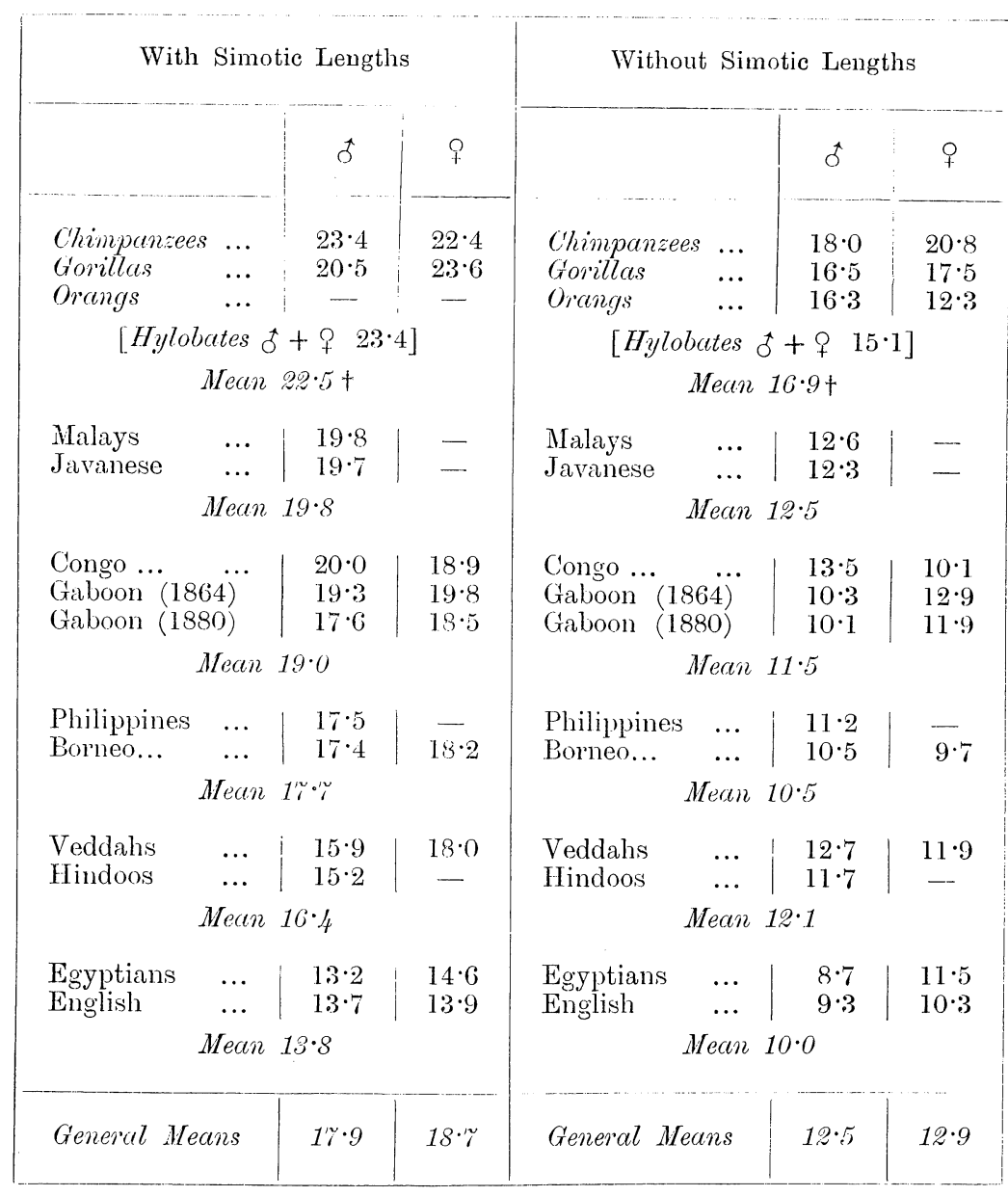

* Nubians excepted : these were included at a later date.

$\uparrow$ Hylobates not included. 


\section{A Study of the Nasal Bridge in the Anthropoid Apes}

Whether we take the number of cases in which the female is more variable than the male-i.e. 7 out of 9 in the first series and 6 out of 10 in the secondor the mean variabilities of the whole series, we see that the female is certainly not less variable than the male.

Massed as above the table seems to show more racial relationship to variability. The races group better together, and generally speaking--Veddahs, perhaps, excepted-there is decreasing variability as we reach higher degrees of civilisation, i.e. as we pass from the Apes through East Asiatics and Negroes to Hindoo, Ancient Egyptian and English. It is as well to see if these results correspond with those for the two mesodacryal and the simotic indices.

It will be seen in the first place that these results (Table XIX) confirm those of the previous table (XVIII) for the variation of the absolute lengths, in that

TABLE XIX.

Average Values of Variability of Indices of Nasal Bridge ( $\alpha, \beta$ and $S$ )

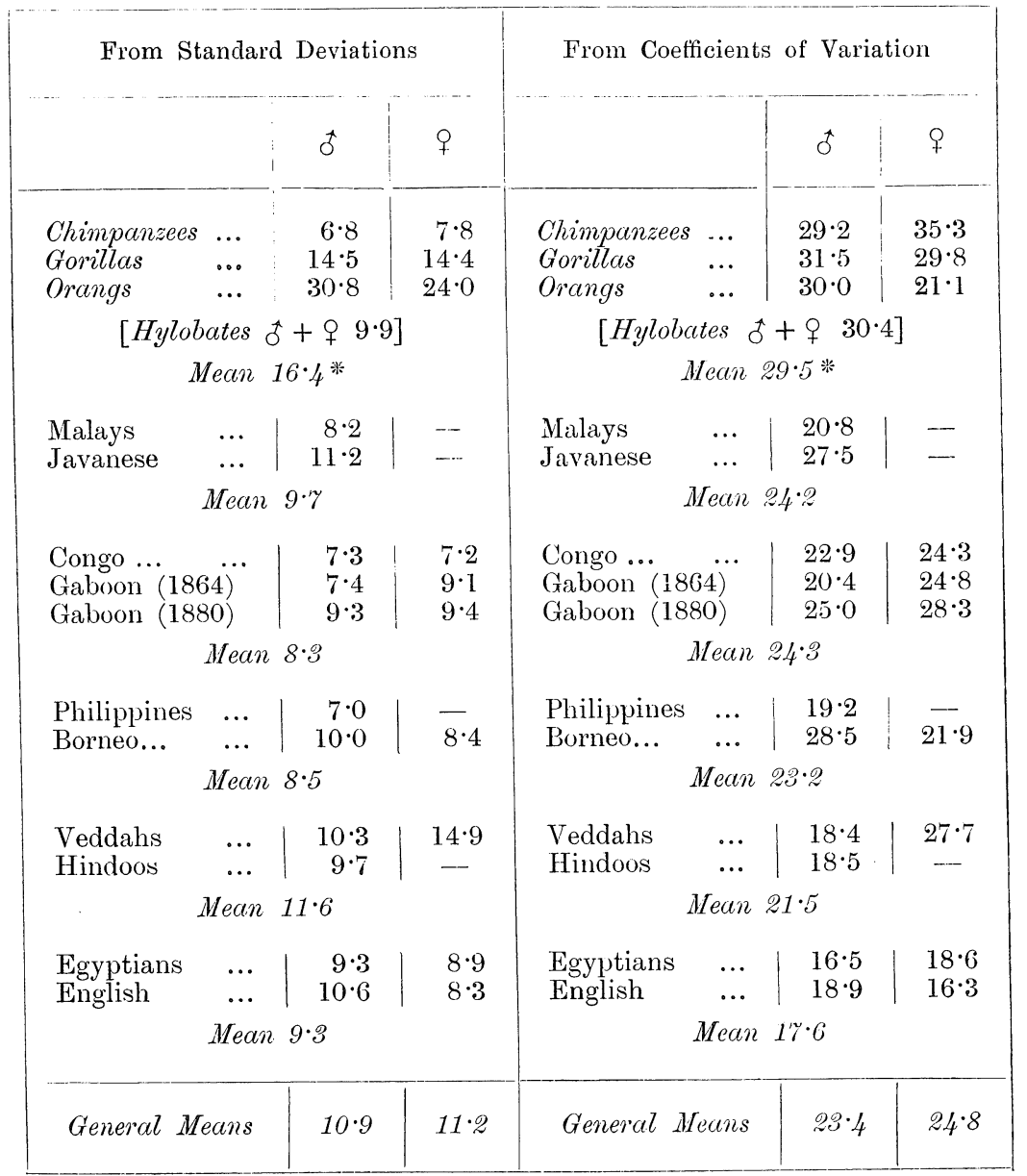

* Hylobates not included. 
Kathleen V. Ryley and Julia Bell

they make the female slightly more variable on the average than the male. For the standard deviations the male is more variable in 6 out of 10 cases; for the coefficients of variation the female is more variable in 6 out of 10 cases. In either method of measurement the apes are more variable than men, with the one exception of the Chimpanzees in the case of the standard deviations, where the small variation is associated with small variation in the Negro group.

\section{(8) Racial Relationship as based on Nasal Bridge Measurements.}

Having general regard to Tables XV-XIX for variability, and comparing the orders therein with those for the racial order of absolute lengths, it seems impossible to suggest any linear scale of arrangement which will mark racial relationship; it is impossible to assert that the Negroes or the East Asiatic group stand regularly higher or lower in a linear scale. Still there does appear to be some order in the scales both for absolute mesodacryal values and for variabilities. Thus the Veddah nasal bridge is more closely related to that of the Orang than the latter's to the Negro group, which on the whole is closer to that of the African apes. Our numbers are too small, our probable errors too large, for insistance on any individual point, but the measurements lead to constants both for index and variability suggesting a scheme of the fullowing type:

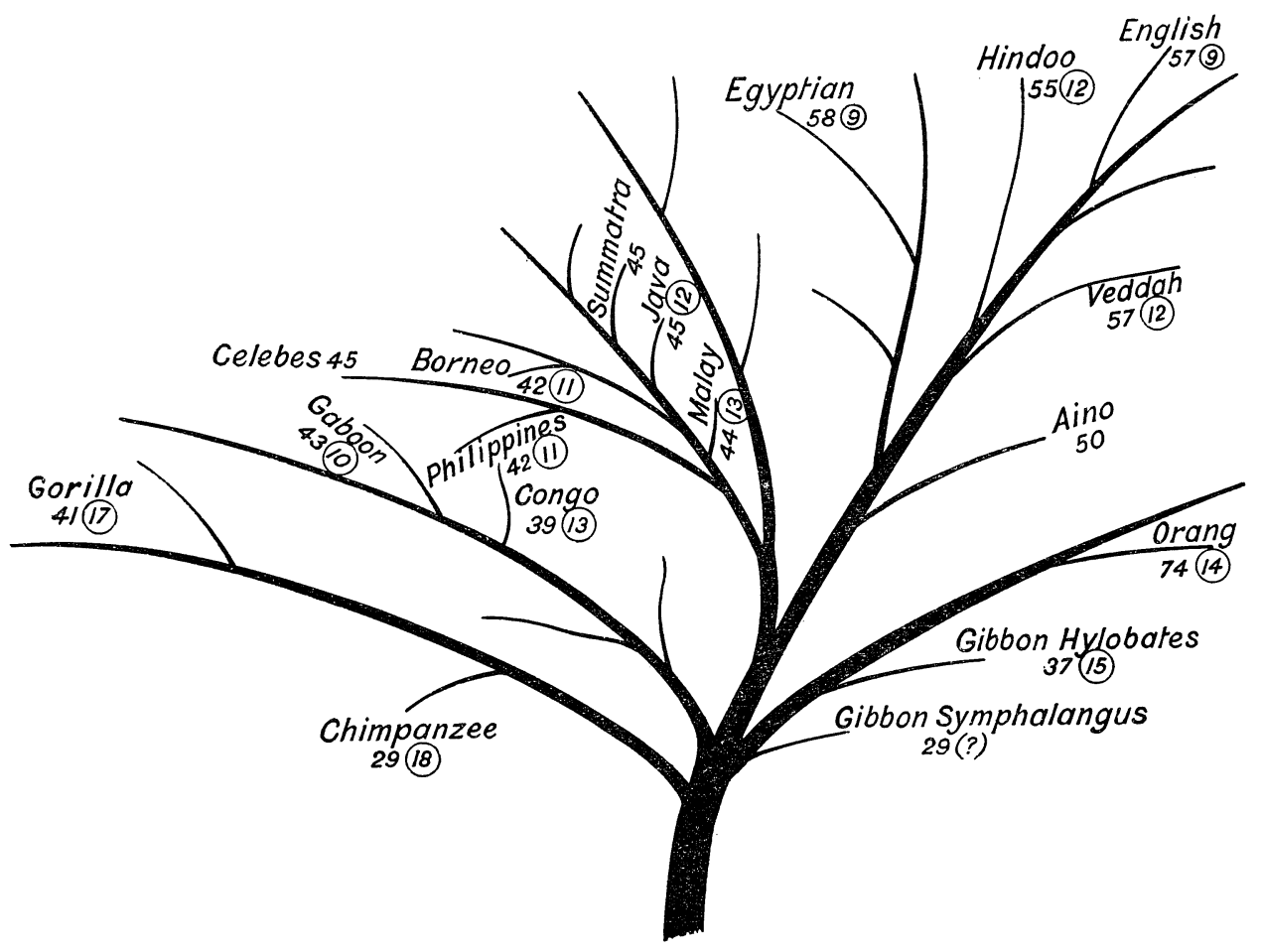

Tree. Mesodacryal Subtense Index and Average Variability for o's indicated. 


\section{A Study of the Nasal Bridge in the Anthropoid Apes}

On this tree we have placed the mean values of the mesodacryal subtense index $(\alpha)$ and the average variability of the mesodacryal lengths*, both for males to indicate the degree of correspondence suggested.

In such a tree as this we see the general tendency of the higher races to have (1) a more developed nasal bridge, and (2) a markedly lessened variability. The tree is merely diagrammatic and no great stress is of course laid on it, but it does suggest that the results reached both for mean values and variabilities may not be merely contradictory, but correspond to a real evolutionary order in the development of the nasal bridge.

\section{(9) On the Correlations of the Nasal Bridge Characters.}

The correlations of the two mesodacryal indices and the simotic index are given in Table XX.

TABLE XX.

Coefficients of Correlation. Nasal Bridge Indices.

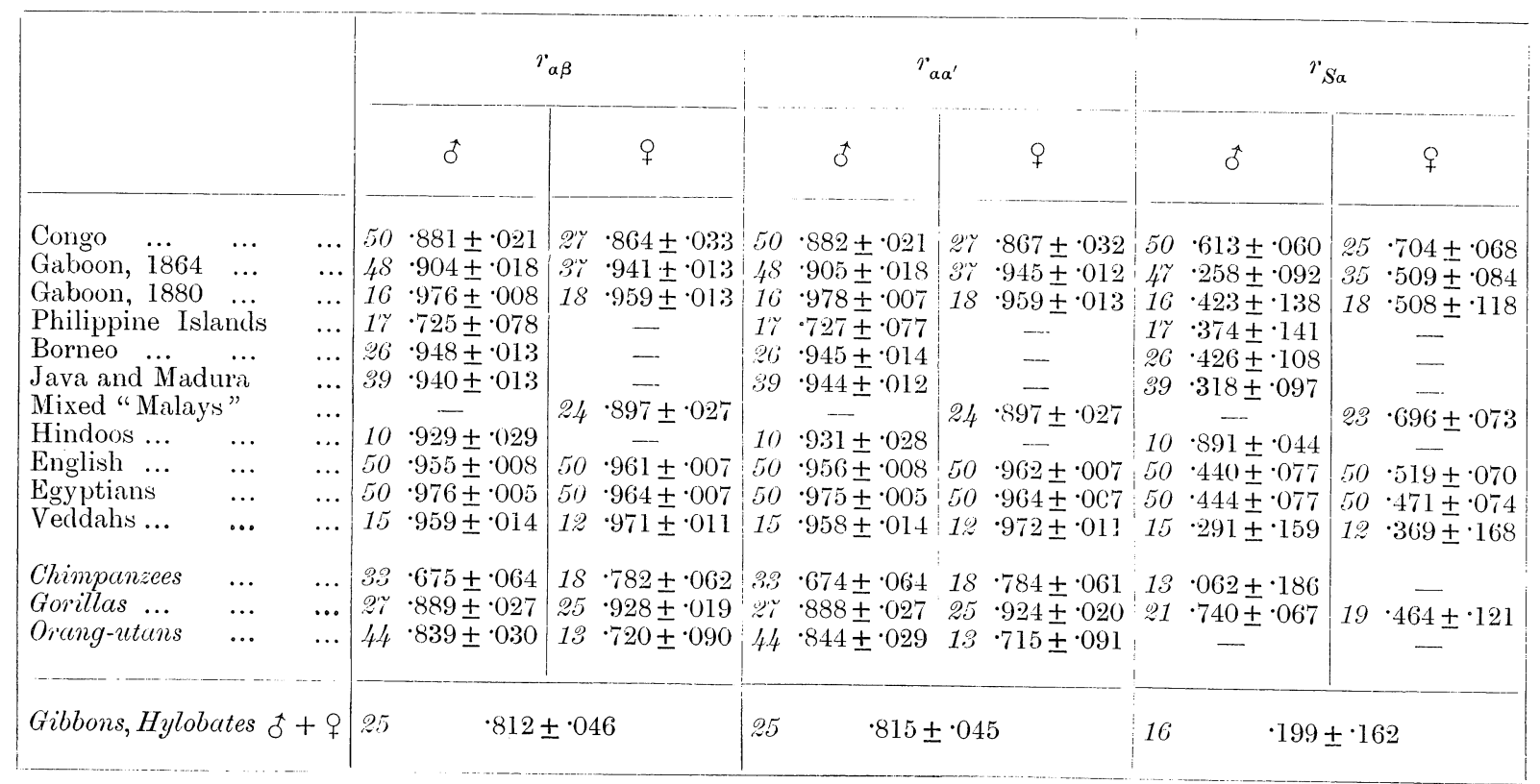

We have already (see pp. 399-401) discussed the relation of $\alpha$ to $\alpha^{\prime}$ and seen that it does not lead us to any very marked racial order. The correlation of the two mesodacryal indices gives a somewhat clearer result, if we group the correlations thus:

\footnotetext{
* Coefficients of variation of arc, chord and subtense.
} 
Kathleen V. Ryley and Julia Bell

$r_{\alpha \beta}$ in Groups.

\begin{tabular}{|c|c|c|c|}
\hline & & $\hat{o}$ & q \\
\hline $\begin{array}{l}\text { Apes ... } \\
\text { Eiast Asiatics } \\
\text { Negroes ... } \\
\text { Veddahs ... } \\
\text { Hindoos ... } \\
\text { Egyptians } \\
\text { English }\end{array}$ & $\begin{array}{l}\cdots \\
\cdots \\
\cdots \\
\cdots \\
\cdots \\
\cdots\end{array}$ & $\begin{array}{l}\cdot 801 \\
\cdot 871 \\
.920 \\
.959 \\
.929 \\
.965\end{array}$ & $\begin{array}{l}.810 \\
.897 \\
.931 \\
.971 \\
\cdot 962\end{array}$ \\
\hline All values, mea & ins & $\cdot 892$ & 899 \\
\hline
\end{tabular}

The suggestion is that there is increased correlation with higher civilisation, the Veddahs being somewhat out of rule. The females are slightly, but very probably not significantly, more highly correlated than the males. There is nothing out of keeping in this correlation order with that for the means and variations exhibited in the "tree" on p. 417, but it is too slender to give it much support. If we turn to the correlations of simotic and mesodacryal (subtense) indices $r_{s a}$ we find a greater range of variation and thus more possibility of getting an order of some racial interest.

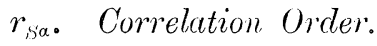

\begin{tabular}{|c|c|c|c|}
\hline & & o & ? \\
\hline Chimpances & $\ldots$ & $\cdot 06$ & - \\
\hline [Hylobates & $\ldots$ & $20(\hat{\sigma}+\hat{t})$ & $--]$ \\
\hline Gaboon, 1864 & $\ldots$ & $\cdot 26$ & 51 \\
\hline Veddahs ... & $\ldots$ & $\cdot 29$ & $\because 37$ \\
\hline Javanese... & $\ldots$ & $\cdot 32$ & - \\
\hline Philiploines & $\ldots$ & $\cdot 37$ & -- \\
\hline Gaboon, 1880 & $\ldots$ & $\cdot 42$ & 51 \\
\hline Borneo ... & $\ldots$ & $\cdot 43$ & - \\
\hline Malays ... & $\ldots$ & - & $\cdot 70$ \\
\hline English ... & $\ldots$ & $\cdot 44$ & .52 \\
\hline Egyptians & $\ldots$ & $\cdot 44$ & $\cdot 47$ \\
\hline Congo $\ldots$ & $\ldots$ & $\cdot 61$ & $\cdot 70$ \\
\hline Govillas ... & $\ldots$ & $\cdot 74$ & 46 \\
\hline Means & & $\cdot 40$ & 53 \\
\hline
\end{tabular}

With the single exception of the Gorilla the females have in every case, and often markedly, more correlation than the males. But the results are extremely irregular, even if we allow for the small numbers dealt with. Accordingly it seemed worth while to deal more at length with the relation between the simotic and mesodacryal characters, and further correlations were worked out. It must 


\section{A Study of the Nasal Bridge in the Anthropoid Apes}

be borne in mind that the mesodacryal subtense consists of two portions, the first part due to the nasal bones is the simotic subtense, the second part is due to the maxillary bones. If we subtract the simotic subtense from the mesodacryal subtense $(D S)-(S S)$, we have a measure of the part of the nose due solely to the maxillary bones, and we may correlate this with (SS) the part due to the nasal bones. There will be no spurious correlation in this as in correlating $(D S)$ and (SS) directly. Further we may form an index $\{(D S)-(S S)\} /(D C)$ and correlate this with the simotic index $(S S) /(S C)$, although in doing this $(S C)$ must be considered in a certain sense as contained in $(D C)$. The spurious correlation, however, is unlikely to be as great in this as in $(S S)$ and $(D S)$, for the maxillary walls of the nose can approach so close that there is no $(S C)$ at all, as in the case of many Orangs and in some Negro skulls*.

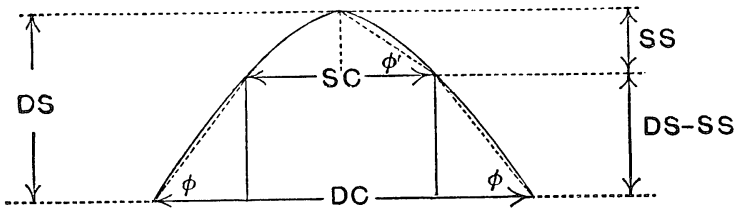

FIG. (i).

(10) The Maxillary and Simotic Nasal Angles, $\phi$ and $\phi^{\prime}$.

The value of $D C-S C$ may be used to obtain a measure of the flatness of the maxillary walls of the nose. Clearly (see figure above)

$$
\tan \phi=(D S-S S) / \frac{1}{2}(D C-S C) .
$$

We term $\phi$ the maxillary nasal angle and its complement $90^{\circ}-\phi$ measures approximately the angle the maxillary wall of the nose makes with the median plane of the skull. Table XXI records the values of the nasal maxillary angle $\phi$ for the races dealt with; they are obtained not from the calculation of $\phi$ from individual crania, but by the rougher process of using the mean values of the mesodacryal and simotic subtenses and chord in the above formula $\uparrow$. The table emphasises again the relation of the Veddahs and the higher races to Orang and Hylobates, while it indicates the relation of the Negro races to the African anthropoids. At some points the female order is not in accord with the male, but the smallness of many of the scries dealt with seems sufficient to explain the source of these differences. Some races have clearly a marked sexual difference, but it is not always one way and the means show no very great difference; more data and longer series would be needful to be certain of a persistent sexual differentiation.

\footnotetext{
* E.g. Gaboon 1864, Nos. 10, 11, 81, and Congo 70 : see Biometrika, Vol. virr. p. 319, and see especially the remarks in Tables of measurements. In one gibbon the simotic subtense was actually negative or the nasal bones depressed.

+ Table XXIV A gives the values of $\phi$ and their variabilities for a small number of selected races. It will be seen that the differences due to the two methods are not great. The short method will give results close enough for any conclusions which are in the least likely to be drawn from such small series.
} 
Kathleen V. Riley and Julia Bell

TABLE XXI.

Maxillary Nasal Angle $\phi$.

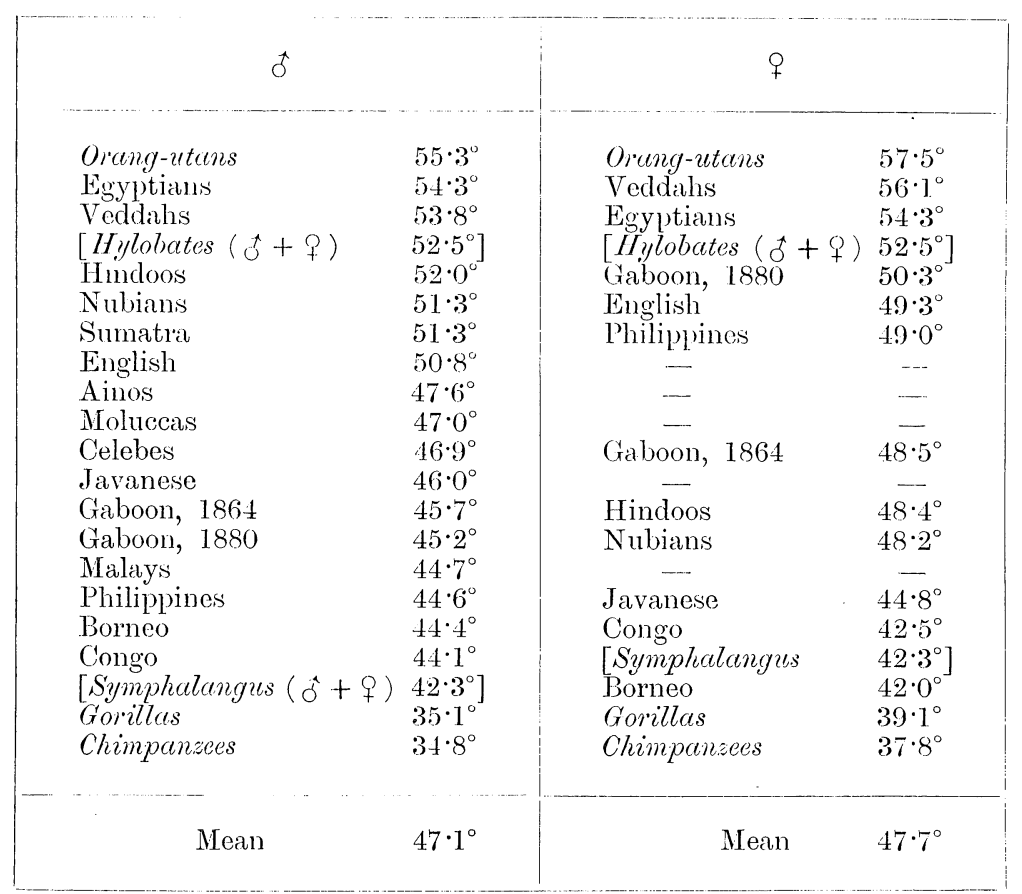

The smaller $\phi$, the flatter the maxillary part of nasal bridge.

If we now turn to Table XXII we find a number of additional correlations, which are sufficiently interesting to make one appreciate how much more valuable they would have been had we had longer series and more variety of races available. We have first correlated the mesodacryal and simotic portions, $D S-S S$ and $S S$, of the whole subtense of the nasal bridge. In every case dealt with, male and female, these subtenses are negatively correlated. On the other hand the correlation of the mesodacryal subtense with the simotic subtense is always positive and often substantial*. This positive correlation is therefore due to the appearance of $S S$ in both variates, i.e. it is a spurious correlation. Actually when the maxillary part of the nasal bridge is larger, then the simotic part is smaller. Intraracially-that is among individuals of the same race-there is a compensatory growth of the nasal bridge and those who develop large nasal bones have a smaller maxillary nasal development. This point seems to us of very great importance; the tendency now-a-days is to insist on the importance of anatomical unities. This has largely arisen from two sources. In the first place craniology

* For the mesodacryal subtense with the simotic subtense, all the correlations except that for the male Chimpanzee are positive and often substantial, the intraracial correlation amounting to $+\cdot 34$ to $+\cdot 38$. Further the interracial correlation is high indeed, being $+\cdot 81$ to $+\cdot 87$. But as we see these results are in part spurious.

Biometrika Ix 
TABLE XXII

Additional Correlations. Nasal Bridge Characters.

\begin{tabular}{|c|c|c|c|c|c|c|c|c|c|c|}
\hline & \multicolumn{2}{|c|}{$r_{D S, S S}$} & \multicolumn{2}{|c|}{$r_{D S-S S, S S}$} & \multicolumn{2}{|c|}{$\frac{D S-S S}{D C}, \frac{S S}{S C}$} & \multicolumn{2}{|c|}{$\hat{i}_{D C, S C}$} & \multicolumn{2}{|c|}{$v_{D C-S C, S C}$} \\
\hline & $\hat{d}$ & P & 0 & q & o & q & $\hat{0}$ & $q$ & ot & q \\
\hline Congo $\ldots$ & $+\cdot 467 \pm 075$ & $+\cdot 632 \pm \cdot 081$ & $-\cdot 143 \pm \cdot 093$ & $-\cdot 138 \pm \cdot 109$ & $-.074 \pm .095$ & $+\cdot 092 \pm \cdot 134$ & $+275 \pm \cdot 088$ & $+\cdot 217 \pm \cdot 129$ & $-\cdot 501 \pm \cdot 071$ & $-.729 \pm .063$ \\
\hline Gaboon, $1864 \ldots$ & $+\cdot 295 \pm \cdot 090$ & $+\cdot 437 \pm 092$ & $-\cdot 487 \pm \cdot 075$ & $-\cdot 20 \tau \pm \cdot 109$ & $-\cdot 22.9 \pm \cdot 093$ & $+\cdot 026 \pm \cdot 114$ & $+\cdot 345 \pm \cdot 087$ & $+.536 \pm .081$ & $-\cdot 745 \pm \cdot 044$ & $-\cdot 387 \pm \cdot 097$ \\
\hline Java and Madura & $+\cdot 658 \pm \cdot 061$ & - & $-.035 \pm \cdot 108$ & - & $-\cdot 165 \pm \cdot 105$ & - & $+\cdot 266 \pm \cdot 100$ & - & $-\cdot 589 \pm \cdot 071$ & - \\
\hline English $\ldots$ & $+\cdot 355 \pm \cdot 083$ & $+\cdot 505 \pm .071$ & $-\cdot 480 \pm \cdot 073$ & $-\cdot 130 \pm \cdot 094$ & $-\cdot 102 \pm \cdot 094$ & $+\cdot 274 \pm \cdot 088$ & $+\cdot 446 \pm \cdot 076$ & $+\cdot 611 \pm .060$ & $-\cdot 386 \pm \cdot 081$ & $-\cdot 328 \pm .085$ \\
\hline Egyptians & $+\cdot 416 \pm \cdot 079$ & $+\cdot 2 \cdot 30 \pm \cdot 090$ & $-\cdot 457 \pm .075$ & $-\cdot 465 \pm \cdot 075$ & $-\cdot 132 \pm \cdot 094$ & $-\cdot 169 \pm \cdot 093$ & $+\cdot 172 \pm .093$ & $+.520 \pm 070$ & $-.571 \pm .064$ & $-\cdot 138 \pm \cdot 094$ \\
\hline Gorillas ... & $+327 \pm \cdot 131$ & $+\cdot 120 \pm \cdot 153$ & $-\cdot 138 \pm \cdot 144$ & $-\cdot 468 \pm \cdot 121$ & $+\cdot 624 \pm \cdot 090$ & $-.079 \pm \cdot 154$ & $+\cdot 512 \pm \cdot 109$ & $+\cdot 303 \pm \cdot 141$ & $-\cdot 10 \bar{i} \pm \cdot 146$ & $-\cdot 137 \pm \cdot 152$ \\
\hline Chimpanzees & $-\cdot 153 \pm \cdot 183$ & $+\cdot 364 \pm \cdot 195$ & $-587 \pm \cdot 123$ & $-\cdot 042 \pm \cdot 224$ & 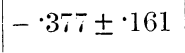 & $-\cdot 079 \pm \cdot 223$ & $-\cdot 039 \pm \cdot 187$ & $+\cdot 425 \pm \cdot 184$ & $-\cdot 613 \pm \cdot 117$ & $+\cdot 222 \pm \cdot 214$ \\
\hline [Hylobates & $+\cdot 116 \pm \cdot 166$ & for $\hat{c}+q$ & $-\cdot 220 \pm \cdot 161$ & for $\hat{c}+q$ & $-\cdot 112 \pm \cdot 166$ & for $\hat{\sigma}+q$ & $-\cdot 195 \pm \cdot 162$ & for $\hat{d}+q$ & $-730 \pm \cdot 079$ & for $\left.\begin{array}{c}0 \\
+\end{array}\right]$ \\
\hline $\begin{array}{c}\text { Interracial } \\
\left.\text { (omitting } O r^{*} \text { angs }\right)\end{array}$ & $+\cdot 868 \pm .039$ & $+\cdot 806 \pm .066$ & $+\cdot 581 \pm \cdot 105$ & $+\cdot 501 \pm \cdot 140$ & $+\cdot 370 \pm \cdot 137$ & $+\cdot 393 \pm \cdot 158$ & $+\cdot 344 \pm \cdot 140$ & $+\cdot 612 \pm \cdot 117$ & $-\cdot 413 \pm \cdot 132$ & $-\cdot 332 \pm \cdot 167$ \\
\hline Intraracial mean* & $+\cdot 338$ & +381 & $-\cdot 333$ & $-\cdot 226$ & -.065 & $+\cdot 011$ & $+\cdot 283$ & $+\cdot 43 \tilde{5}$ & -.502 & $-\cdot 250$ \\
\hline
\end{tabular}

* Hylubates excluded. 


\section{Kathleen V. Ryley and Julia Bell}

has been chiefly in the hands of the pure anatomist rather than in those of the student of philosophical evolution. The former has insisted on the importance of growth centres and anatomical unity of measurement; he has usually no appreciation of the relatively high correlations of the parts of the bony structure. $\mathrm{He}$ is thus liable to overlook the fact that from the standpoint of evolution a complex anatomical organ may be of far more importance to the race and to the individual than one factor of it which may be an anatomical unity. In the second place Mendelism has become the mode, and to surmount difficulties about characters which do not "mendelise," it has been customary to assert that they consist of a complex of simple Mendelian units*. On the original Mendelian theory such "units" were asserted to be independent, although as such a theory was found to be unworkable, a crude theory of "coupling," as a measurable association of anatomically or physiologically simple unities, was evolved to cover the real facts of correlation. In this manner there has arisen a conscious or unconscious association of anatomical and Mendelian units, and it has been supposed that an anatomical unity would be more likely to "mendelise" than a combination of such unitiesa single bone like the femur than a measurement like the leg length or the stature. The present result seems an illustration of the futility of neglecting the correlation of characters or treating them as compounded of independent Mendelian or even anatomical unities. The bridge of the nose consists of parts which are distinct anatomical unities, but the evolutionary factor is probably far better represented by the physiognomic factor-the whole bridge of the nose-than by any anatomical unit. When one part exceeds there is a correlated defect in the other part, and this rule extends practically through all the races examined. It is thus quite conceivable that a single measurement like the sagittal arc is from the evolutionary standpoint far more important than any of the simple ares-opisthion to lambda, lambda to bregma, and bregma to nasion-into which we may reduce it by aiming at the measurement of anatomical unities. There is such a thing as an evolutionary factor, a determinant which controls the development of a whole series of anatomical unities, and the heredity brought into evidence by such a factor may be far more important from the standpoint of evolution than the heredity of any simple anatomical character. What group of anatomical units go to form any such determinant can only be appreciated by a thorough study of the correlations of simple anatomical parts.

Especially in the nasal bridge is this matter of very great importance, for while within the race an individual with small maxillary height $(D S-S S)$ has a large simotic height (SS), interracially this is no longer true, the race with a small maxillary height will have a small simotic height and the positive correlation interracially is very substantial $(+\cdot 581)$ - this must be compared with the mean intraracial correlation which is $-\mathbf{3 3 3}$. Both these results are for males, for females the numbers are +.501 and -.226 respectively. This reversal of sign

\footnotetext{
* Of course when it is convenient a vast congeries of factors, such as "Albinism" or "Jewishuess," are illogically treated as a simple Mendelian "unit"!
} 


\section{A Study of the Nasal Bridge in the Anthropoid Apes}

when we pass from intraracial to interracial correlations is a thing previously not unknown. Thus in 1903 in a paper* on interracial and intraracial correlations, Jacob, Lee and Pearson showed that while with individuals a long cranium is likely to be a broad cranium, yet interracially a compensating factor comes in, a longheaded race is likely to be a narrow-headed race. Thus it is quite conceivable that capacity of the cranium-depending on many anatomical units-may be of far more evolutionary importance than the measure of any single "anatomical unit" of the skull. We have referred at length to these matters here, because there is a growing idea-fostered probably by the idea of Mendelian "units," that the measurement of "anatomical units"--or the measurement between "anatomical points" - is of primary importance in craniology. Whether craniologists measure the same thing or not is immensely important, the correlation between anatomical units is also of great value as determining what combinations of simple units form evolutionary factors. But very little service is done by insisting too largely on anatomical unity in and for itself. Evolution depends largely on physiological fitness, and organs of physiological importance are rarely compounded of either single anatomical or of single Mendelian units.

If we now turn to the index correlations of $(D S-S S) / D C$-i.e. height of maxillary portion of nose by its breadth - with $S S / S C$-i.e. height of nasal bones portion by its breadth-—our results are less uniform. Putting the male Gorillas on one side for a moment there are only two of the correlations which can be said to be significant, namely, possibly the male Chimpanzee and the female English, and these are of opposite signs. The means for male races and for female races are -065 and +.011 , and these would be of no service for prediction. With regard to the Gorilla result, this arises principally from three males with the very high simotic indices of 88,106 and 108 . It is conceivable that the material is not really homogeneous; the arithmetic has been carefully repeated without change in values. If we take these indices to measure the cuneal or wedge-shaped properties of the two portions of the nose, we should say that individually there is very little relation between the ratio of height to breadth in the simotic and maxillary portions of the nasal bridge; the only exception to this rule being the male Gorilla. On the other hand the cuneal characters are positively and sensibly correlated $(+.370$ to +.393$)$ interracially, an obtuso-cuneal nasal part being also associated with an obtuso-cuneal maxillary part and an acuto-cuneal nasal part with an acuto-cuneal maxillary part.

We have already discussed the maxillary nasal angle $\phi$, the complement of which roughly measures the angle between the maxillary wall of the nose at the bridge and the sagittal plane of the skull. We can introduce a similar angle $\phi^{\prime}$ to measure roughly the angle between the nasal bone and the simotic chord. We may take (see Fig. (i), p. 420):

$$
\begin{aligned}
\tan \phi^{\prime} & =S S /\left(\frac{1}{2} S C\right) \\
& =2 \text { Simotic Index. }
\end{aligned}
$$

* Biometrika, Vol. Ir. p. 355. For the first introduction of the ideas of intraracial and interracial correlation, see Biometrika, Vol. I. p. 460. 
Kathleen V. Ryley and Julia Bell

It will be of interest to investigate whether the correlations of $\phi$ and $\phi^{\prime}$ are higher than those of the cuneal indices. The following table* (XXIII) gives the

TABLE XXIII. Simotic Nasal Angle $\phi^{\prime}$.

\begin{tabular}{|c|c|c|c|}
\hline \multicolumn{2}{|l|}{$\delta$} & \multicolumn{2}{|l|}{$q$} \\
\hline Gorillas & $48 \cdot 6^{\circ}$ & Goritlas & $47 \cdot 8^{\circ}$ \\
\hline English & $45 \cdot 5^{\circ}$ & English & $430^{\circ}$ \\
\hline Hindoos & $41 \cdot 8^{\circ}$ & Hindoos & $38 \cdot 0^{\circ}$ \\
\hline Egyptians & $41 \cdot 6^{\circ}$ & Egyptians & $36 \cdot 5^{\circ}$ \\
\hline Veddahs & $41 \cdot 1^{\circ}$ & Veddahs & $36 \cdot 4^{\circ}$ \\
\hline Ainos & $40 \cdot 9^{\circ}$ & - & - \\
\hline Nubians & $34 \cdot 3^{\circ}$ & Borneo & $34^{\circ} 8^{\circ}$ \\
\hline Javanese & $34 \cdot 1^{\circ}$ & Javanese & $33 \cdot 2^{\circ}$ \\
\hline Malays & $34 \cdot 0^{\circ}$ & - & 一. \\
\hline Gaboon, 1864 & $31 \cdot 7^{\circ}$ & Philippines & $30 \cdot 1^{\circ}$ \\
\hline Philippines & $31 \cdot 3^{\circ}$ & Gaboon, 1864 & $29 \cdot 0^{\circ}$ \\
\hline Borneo & $31 \cdot 1^{\circ}$ & Comgo & $27 \cdot 2^{\circ}$ \\
\hline Celebes & $30 \cdot 7^{\circ}$ & - & - \\
\hline Sumatra & $30 \cdot 3^{\circ}$ & - & -- \\
\hline Gaboon, 1880 & $30 \cdot 1^{\circ}$ & Nubians & $25 \cdot 2^{\circ}$ \\
\hline Moluccas & $28 \cdot 0^{\circ}$ & - & - \\
\hline Congo & $27 \cdot 1^{\circ}$ & Gaboon, 1880 & $24 \cdot 6^{\circ}$ \\
\hline Ghimpanzees & $23 \cdot 2^{\circ}$ & Chimpanzees & $20 \cdot 3^{\circ}$ \\
\hline ts'ymphalangus & $11 \cdot 5^{\circ}$ & †Symphalangus & $11 \cdot 5^{\circ}$ \\
\hline$+H y l o b a t e s$ & $9 \cdot 8^{\circ}$ & +Hylobates & $9 \cdot 8^{\circ}$ \\
\hline Mean & $32 \cdot 3^{\circ}$ & Mean & $29 \cdot 8^{\circ}$ \\
\hline
\end{tabular}

The smaller $\phi^{\prime}$ the Alatter the simotic portion of the nasal bridge, i.e. the greater the simosis.

TABLE XXIV s. Maxillary Nasal Angle $\phi$. Mean and Variability.

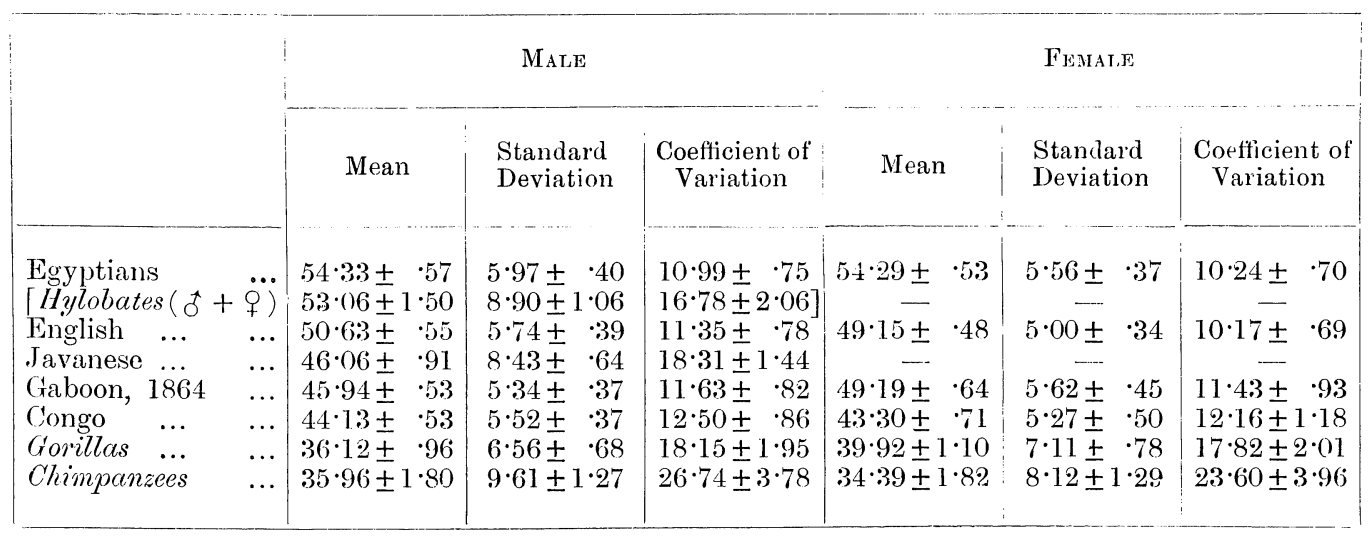

* These values of $\phi^{\prime}$ are calculated from the mean racial simotic index. In Table XXIV $\mathrm{B}$ the mean value of $\phi^{\prime}$ as obtained from averaging the simotic angles of the individual members of the race is given for a few races as well as the variabilities for these selected races. The agreement of the directly and indirectly calculated means is quite reasonable.

+ Both sexes together. 


\section{A Study of the Nasal Bridge in the Anthropoid Apes}

interracial values of $\phi^{\prime}$. It will be seen of course that the order must be the same as that of the simotic index, but if we compare this table with Table XXI some interesting points arise as we shall show in the next section. Tables XXIV A and XXIV $\mathrm{s}$ give the means and variabilities of the maxillary and simotic angles $\phi$ and $\phi^{\prime}$.

\section{TABLE XXIV $\mathrm{B}$.}

Simotic Nasal, Angle $\phi^{\prime}$. Mean and Variability.

\begin{tabular}{|c|c|c|c|c|c|c|}
\hline & \multicolumn{3}{|c|}{ MaLF } & \multicolumn{3}{|c|}{ FEMALE } \\
\hline & Mean & $\begin{array}{l}\text { Standard } \\
\text { Deviation }\end{array}$ & $\begin{array}{c}\text { Coefficient of } \\
\text { Variation }\end{array}$ & Mean & $\begin{array}{l}\text { Standard } \\
\text { Deviation }\end{array}$ & $\begin{array}{l}\text { Coeflicient of } \\
\text { Variation }\end{array}$ \\
\hline Egyptians & $41 \cdot 25 \pm \cdot 45$ & $4 \cdot 70 \pm \because 32$ & $11 \cdot 40 \pm .78$ & $35 \cdot 97 \pm .57$ & $6 \cdot 02 \pm \cdot 41$ & $16 \cdot 73+1 \cdot 16$ \\
\hline$[$ Hylobates $(\hat{b}+9)$ & $9.75 \pm .84$ & $4.97 \pm .59$ & $50.99 \pm 7.50]$ & - & - & $\ldots$ \\
\hline English $\quad \ldots \quad \ldots$ & $44.70 \pm \cdot 63$ & $6.58 \pm \cdot 44$ & $14 \cdot 73 \pm 1 \cdot 01$ & $42 \cdot 58 \pm \cdot 47$ & $4 \cdot 96 \pm \cdot 3 \cdot 3$ & $11 \cdot 65 \pm .80$ \\
\hline Javanese $\ldots$ & $33.23 \pm .88$ & $8 \cdot 15 \pm \cdot 62$ & $24.54 \pm 1.98$ & - & - & \\
\hline Gaboon, 1864 & $31 \cdot 15 \pm .72$ & $7 \cdot 34 \pm .51$ & $23 \cdot 56 \pm 1 \cdot 73$ & $28 \cdot 46 \pm .85$ & $7 \cdot 42 \pm \cdot 60$ & $26 \cdot 08 \pm 2 \cdot 24$ \\
\hline Congo $\quad \ldots$ & $26 \cdot 62 \pm \cdot 73$ & $7 \cdot 65 \pm .52$ & $28 \cdot 36 \pm 2 \cdot 10$ & $26 \cdot 48 \pm 1 \cdot 20$ & $8.91 \pm .85$ & $33 \cdot 63 \pm 3 \cdot 55$ \\
\hline Gorillas ... & $46 \cdot 48 \pm 1 \cdot 52$ & $10 \cdot 30 \pm 1 \cdot 07$ & $2 \cdot 2 \cdot 16 \pm 2 \cdot 42$ & $45 \cdot 63 \pm 1 \cdot 74$ & $112 ; \pm 1 \cdot 3$ & $24 \cdot 61 \pm 2 \cdot 85$ \\
\hline Chimpanzess & $22 \cdot 77 \pm 1 \cdot 37$ & $7 \cdot 31 \pm \cdot 97$ & $32 \cdot 10 \pm 4 \cdot 66$ & $20 \cdot 00 \pm 1 \cdot 73$ & $7 \cdot 70 \pm 1 \cdot 22$ & $38.51 \pm 6.97$ \\
\hline
\end{tabular}

It would appear from Tables XXI and XXIII that $\phi^{\prime}$ has a greater interracial range and from Tables XXIV A and $\mathrm{B}$ that it has a greater intraracial variability than $\phi$. What we need for a good racial character is a great interracial range and a small intraracial rariability. We cannot therefore say that $\phi^{\prime}$ is a letter racial character than $\phi$.

\section{(11) General Classification of Nasal Bridges by $\phi$ and $\phi^{\prime *}$.}

We need some new terms. We propose to term races which have high values or low values of both $\phi$ and $\phi^{\prime}$ homoclinic, while those which have low values of one and high of the other are heteroclinic. Among apes the Gorilla is markedly heteroclinic, and Hylobates is the same, but in the opposite direction. The Chimpanzee and Symphalangus are both homoclinic and so are the English, Egyptians, Hindoos and Veddahs.

Without regard to the exact numerical values and as merely descriptive terms the following types of Gephyrosis will indicate the nature of the characterisation, where it must be remembered that the reader has to fix his attention on the

* Professor G. D. Thane has kindly made the following suggestions for a more complete angle nomenclature of the nasal bridge (see Fig. (i), p. 420):

Lateral simotic angle =our simotic nasal angle $\phi^{\prime}$.

Mesial simotic angle $=\operatorname{our} 90^{\circ}-\phi^{\prime}=$ angle between simotic chord and median plane.

Simotic angle $($ median $)=$ our $180^{\circ}-2 \phi^{\prime}=$ internal angle between two simotic chords.

Lateral maxillary angle $=$ our $\phi=$ maxillary nasal angle.

Maxilli-simotic angle $=$ our $180^{\circ}-\phi+\phi^{\prime}=$ internal angle between simotic and maxillary chords.

The most important point here is the maxilli-simotic angle, the approach of which to $180^{\circ}$, i.e. the 
Katillelen V. Ryley and Julia Bhla

lower parts of the "bridge" from its "springings" at the dacrya to the strokes marking the naso-maxillary sutures.

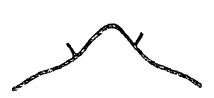

14

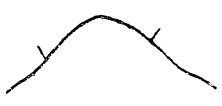

23

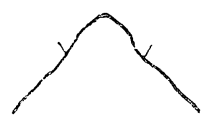

27

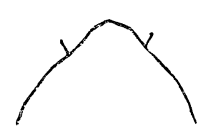

34

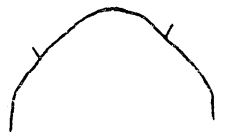

22

Hyperplatygephyreal Platygephyreal Mesogephyreal Leptogephyreal Hypoleptogephyreal (approaching Fig. (ii). Types of Gephyrosis.

Similarly we have for the part of the "bridge" from "haunch" to "haunch" i.e. the nasal bones, or part between the strokes marking the nas(o-maxillary sutures, the following characterisation:

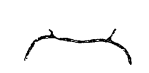

15

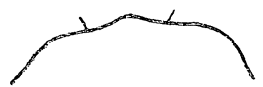

8

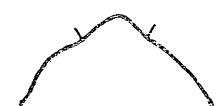

10

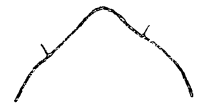

29

Stenotic

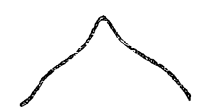

13

Iypersimotic

Simotic

Mrsotic

FIx. (iii). Types of Simosis.

For classificatory purposes it may be useful to divide $\phi$ into three classes: when $\phi$ is under $46^{\circ}$, the group shall be called platygephyreal, when $\phi$ lies between $46^{\circ}$ and $51^{\circ}$, the group is mesogepliyreal, and when $\phi$ is over $51^{\circ}$, the equality of $\phi$ and $\phi^{\prime}$, marks the "triangularity" of the bridge, or the unbroken character of the nasal wall.

$$
\text { Marilli-simotic angle } 180^{\circ}-\phi+\phi^{\prime} \text {. }
$$

\begin{tabular}{|c|c|c|c|}
\hline \multicolumn{2}{|l|}{$\hat{\sigma}$} & \multicolumn{2}{|l|}{ + } \\
\hline ... & $\ldots$ & $\cdots+\cdots$ & ... \\
\hline Gorillass & $193 \cdot 5^{\circ}$ & Gorillas & $188.7^{\circ}$ \\
\hline English & $17 \cdot 1 \cdot 7^{\circ}$ & Engrlish & $173 \cdot 7^{\circ}$ \\
\hline Ainos & $173 \cdot 3^{\circ}$ & - & - \\
\hline Mindoos & $169 \cdot 8^{\circ}$ & Borneo & $172 \cdot 8^{\circ}$ \\
\hline Malays & $169 \cdot 3^{\circ}$ & - & - \\
\hline Chimpanzess & $1(i s \cdot 10$ & Hindoos & $169 \cdot 6^{\circ}$ \\
\hline Javanese & $168 \cdot 1^{\circ}$ & Javanese & $168 \cdot 4^{\circ}$ \\
\hline Veddahs & $167 \cdot 3^{\circ}$ & Congo & $164 \cdot 7^{\circ}$ \\
\hline Egyptians & $167 \cdot 3^{\circ}$ & Chimpanzes & $162 \cdot 5^{\circ}$ \\
\hline Borneo & $166 \cdot 7^{\circ}$ & Egyptians & $1622^{\circ}$ \\
\hline Philippines & $166^{\circ} \cdot 7^{\circ}$ & Philippines & $161 \cdot 1^{\circ}$ \\
\hline Gahoon (1864) & $166 \cdot 0^{\circ}$ & Gaboon $(1864)$ & $160 \cdot 5^{\circ}$ \\
\hline Gaboon (1880) & $16 ! 9^{\circ}$ & Vedulahis & $160 \cdot 3^{\circ}$ \\
\hline Celebes & $163 \cdot 8^{\circ}$ & - & - \\
\hline Congo & $163 \cdot 0$ & Nulians & $1.57 \cdot 0^{\circ}$ \\
\hline Nubians & $163 \cdot 0^{\circ}$ & Gaboon $(1880)$ & $154 \cdot 3^{\circ}$ \\
\hline Moluccas & $161 \cdot 0^{\circ}$ & - & - \\
\hline Sumatra & $159 \cdot 0$ & ...... & - \\
\hline symphalangus & $149 \cdot 2^{\circ}$ & Symphulangus & $149 \cdot 2^{\circ}$ \\
\hline H'ylobates & $137 \cdot 3 \circ$ & IIylobates & $137 \cdot 3^{\circ}$ \\
\hline
\end{tabular}

Only the Gorillas have a re-entrant racial maxilli-simotic angle, althongh such angles oceur in individual cases of other races. Of the races considered the English appear to have most nearly an unbroken nasal wall. The racial order is not clearly marlied as Negroes and Asiatics are much intermixed. 


\section{A Study of the Nasal Bridge in the Anthropoid Apes}

TYPES OF THE NASAL BRIDGE.

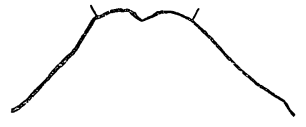

1

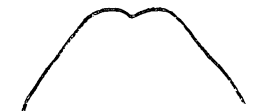

2

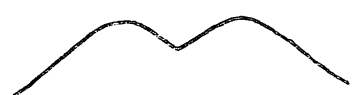

1 bis

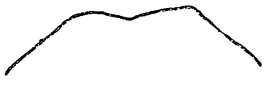

2 bis

Dog. Nasal Bridge.

Dog. Muzzle Section.

$1-2 b i s=$ Hypersimotic Platygephyrosis.

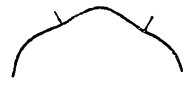

3

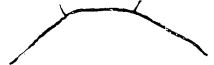

4

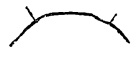

5

Chimpanzee.

Chimpanzee.

Symphalangus.

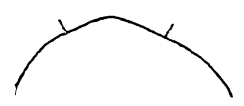

6

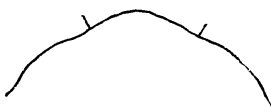

7

Congo Negroes.

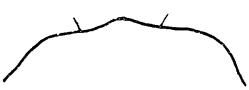

8

$3-9=$ Simotic Platygephyrosis.

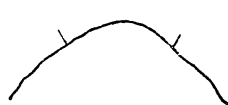

9 Gaboon Negroes.

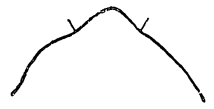

10

Malay.

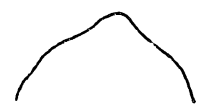

11

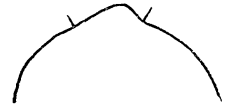

12

$10-12=$ Mesotic Platygephyrosis .

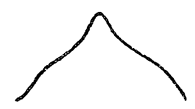

13

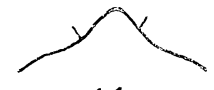

14

Gorilla.

13--14= Stenotic Platygephyrosis.

It has not always been possible to select a nasal bridge with the mean values of both $\phi$ and $\phi^{\prime}$, and the typical form will hardly be realised even from two or three cases. 


\section{Kathleen V. Ryley and Julia Bell}

TYPES OF THE NASAL BRIDGE.

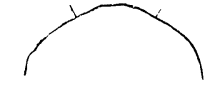

19

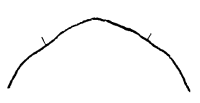

20

Natives of Moluccas.

19-20=Simotic Mesogephyrosis.

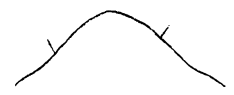

23

Aino.

$23--24=$ Mesotic Mesogephyrosis.

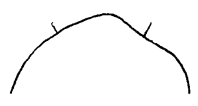

21

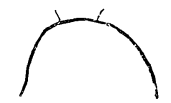

18
17

Orang-utan.

Hylobates.

$18=$ Simotic Leptogephyrosis.

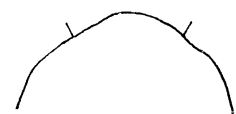

25

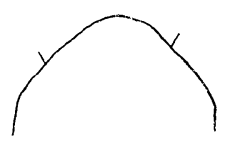

22

Natives of Sumatra.

$21-22=$ Simotic Leptogephyrosis.

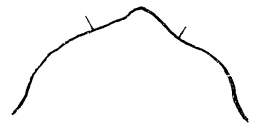

26

Nubian.

Nubian (Variant).

$25-26=$ Mesotic Leptogephyrosis.

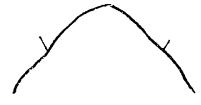

31

Egyptian.

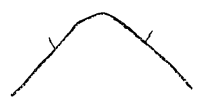

32

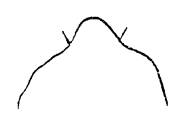

33
English.

Veddah.

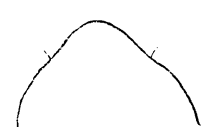

30
Hindoo.

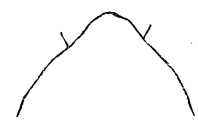

34

English.

Veddah.

Egyptian.

Hindoo.

27---28=Stenotic Mesogephyrosis. 29-34=Stenotic Leptogephyrosis.

It has not always been possible to select a nasal bridge with the mean values of both $\phi$ and $\phi^{\prime}$, and the typical form will hardly be realised even from two or three cases.

Biometrika Ix 


\section{A Study of the Nasal Bridge in the Anthropoid Apes}

group is leptogepliyreal. In the same way the simotic nasal angle $\phi^{\prime}$ may be classed as simotic when under $32^{\circ}$, mesotic between $32^{\circ}$ and $41^{\circ}$, and stenotic when over $41^{\circ}$. These limits should all be reduced by about $2^{\circ}$ in classifying the female simotic nasal angle, which differs sexually by at least this amount from the male. We have accordingly the following table, of which we give illustrations to indicate the type. The diagonal from simotic platygephyrosis to

\section{TABLE XXV.}

\begin{tabular}{|c|c|c|c|}
\hline & Under $46^{\circ}$ & $46^{\circ}$ to $51^{\circ}$ & Over $51^{\circ}$ \\
\hline $\begin{array}{c}\text { Under } \\
32^{\circ}\end{array}$ & $\begin{array}{l}\text { Simotic } \\
\text { Platygephyrosis } \\
\text { e.g. Chimpanzees } \\
\text { and Negroes }\end{array}$ & $\begin{array}{l}\text { Simotic } \\
\text { Mesogephyrosis } \\
\text { e.g. Natives of } \\
\text { Moluccas }\end{array}$ & $\begin{array}{c}\text { Simotic } \\
\text { Leptogephyrosis } \\
\text { e.g. Hylobates and } \\
\text { natives of Sumatra }\end{array}$ \\
\hline $32^{\circ}$ to $41^{\circ}$ & $\begin{array}{c}\text { Mesotic } \\
\text { Platygephyrosis } \\
\text { e.g. Malays }\end{array}$ & $\begin{array}{c}\text { Mesotic } \\
\text { Mesogephyrosis } \\
\text { e.g. Ainos }\end{array}$ & $\begin{array}{c}\text { Mesotic } \\
\text { Leptogephyrosis } \\
\text { e.g. Nubians }\end{array}$ \\
\hline Over $41^{\circ}$ & $\begin{array}{c}\text { Stenotic } \\
\text { Platygephyrosis } \\
\text { e.g. Gorillas }\end{array}$ & $\begin{array}{c}\text { Stenotic } \\
\text { Mesogephyrosis } \\
\text { e.g. English }\end{array}$ & $\begin{array}{c}\text { Stenotic } \\
\text { Leptogephyrosis } \\
\text { e.g. Egyptians and } \\
\text { Hindoos }\end{array}$ \\
\hline
\end{tabular}

stenotic plagygephyrosis marks the homoclinic groups. The simotic leptogephyrosis of the smaller gibbon and the stenotic platygephyrosis of the gorilla mark the heteroclinic extremes, which weaken the interracial correlation of $\phi$ and $\phi^{\prime}$. 'Table XXVI gives the values of $r_{\phi \phi}$.

With the exception of the Gorilla, which is as in the case of the cuncal indices (p. 424) again anomalous, we see that there is intraracially a small negative correlation between flatness of the maxillary and flatness of the nasal bones. But interracially it is otherwise; there is quite a moderate degree of positive correlation and a flat nasal part of the bridge is found in the same races as a flat maxillary part. This is another instance of the reversal of intraracial by interracial correlation.

(12) Discussion of Projections of Nasal and Maxillary Portions of Nose on the Base of the Nasal Bridge.

Having studied the relation of the subtenses, the indices and the angles, we now turn to the chords. The mesodacryal chord is positively correlated with the simotic chord for all races except male Chimpanzees and the mixed data for Hylobates, but in both these cases the correlations are insignificant having regard to their probable errors; see Table XXII, p. 422. Both interracially and intraracially a broad maxillary 
Kathlaen V. Ryley and Julia Beth

TABLE XXVI.

Correlation of Maxillary and Simotic Nasal Angles $\phi$ and $\phi^{\prime}$.

\begin{tabular}{|c|c|c|c|}
\hline & & ơ & f \\
\hline $\begin{array}{l}\text { Congo ... } \\
\text { Gaboon, } 1864 \\
\text { Javinese } \\
\text { English } \\
\text { Egyptians } \quad \cdots\end{array}$ & $\begin{array}{l}\cdots \\
\cdots \\
\cdots \\
\cdots \\
\cdots\end{array}$ & $\begin{array}{l}-.037 \pm \cdot 095 \\
-.338 \pm \cdot 087 \\
-.054 \pm \cdot 108 \\
-\cdot 169 \pm \cdot 093 \\
+\cdot 053 \pm \cdot 095\end{array}$ & $\begin{array}{r}-\cdot 127 \pm \cdot 133 \\
-.095 \pm \cdot 113 \\
- \\
-\cdot 005 \pm \cdot 095 \\
-\cdot 183 \pm \cdot 092\end{array}$ \\
\hline $\begin{array}{l}\text { Gorillas } \quad \ldots \\
\text { Chimpanzees } \quad \ldots \\
{[\text { Hylobates }(o++)}\end{array}$ & $\begin{array}{l}\cdots \\
\cdots \\
\cdots\end{array}$ & $\begin{array}{l}+\cdot 447 \pm \cdot 118 \\
-.329 \pm \cdot 167 \\
-.058 \pm \cdot 168\end{array}$ & $\begin{array}{l}-\cdot 217 \pm \cdot 117 \\
-\cdot 247 \pm .211 \\
-.058 \pm \cdot 168]\end{array}$ \\
\hline Intraracial Mean & $\ldots$ & $-\cdot 061$ & $-\cdot 146$ \\
\hline Interracial Value* & $\cdots$ & $+\cdot 353 \pm \cdot 139$ & $+\cdot 220 \pm \cdot 178$ \\
\hline
\end{tabular}

portion of the nose would thus signify a broad simotic portion. But the whole result is, as that for the subtenses, spurious and arises from the simotic portion recurring in the mesodacryal chord. If we subtract the simotic chord from the mesodacryal then the difference $(D C-S C)$ is negatively correlated with the simotic chord $S C$, and the correlation is fairly substantial both interracially and intraracially. In other words, whenever a race or an individual is found for which the nasal bones have a big projection on the base of the nasal bridge, then the maxillary bones have a small projection, and vice versâ. Thus individually and racially a principle of compensation appears at work. Now we have seen that intraracially $\phi$ is negatively correlated with $\phi^{\prime}$, or a steep maxillary portion is associated in the individual with a flat nasal bone portion of the bridge. Thus intraracially it is conceivable that even if the breadth of the nasal bone and the breadth of the maxillary wall of the nose were positively correlated, the projections might well be of opposite signs. But we cannot use this explanation to account for the negative interracial correlation of the projections, for here the maxillary and simotic nasal angles are positively correlated. In the case of intraracial correlations not only are the projections $\frac{1}{2} S C$ and $\frac{1}{2}(D C-S C)$ negatively correlated but also the subtenses $S S$ and $(D S-S S)$. Thus it is not improbable that in the individual a small nasal bone is associated with a large maxillary wall of the nose-a feature we may speak of as the Orang-utan character. But this does not hold interracially, for the subtenses $S S$ and $(D S-S S)$ are positively correlated (Table XXII) and substantially so for both sexes. It is of some interest to consider whether interracially the nasal bone and the maxillary wall of the nose are

$$
\text { * Hylobates excluded. }
$$




\section{A Study of the Nasal Bridge in the Anthropoid Apes}

positively correlated. In order to test this point a little more definitely, let us suppose $S B$ to be the breadth of a nasal bone and $D B$ the breadth of the maxillary wall at the bridge. Approximately:

$$
\begin{aligned}
& S B=\sqrt{\frac{1}{4}(S C)^{2}+(S S)^{2}}=(S S) / \sin \phi^{\prime}, \\
& D B=\sqrt{\frac{1}{4}(D C-S C)^{2}+(D S-S S)^{2}}=(D S-S S) / \sin \phi .
\end{aligned}
$$

Table XXVII gives the values of $S B$ and $D B$ found for each race from the means of that race for $S C, S S, D C$ and $D S$. Of course the nasal bone and the

TABLE XXVII.

Calculated* Values of $S B$, the breadth of either nasal bone at the bridge and $D B$, the breadth of the maxillary portion of the nasal wall at the bridge.

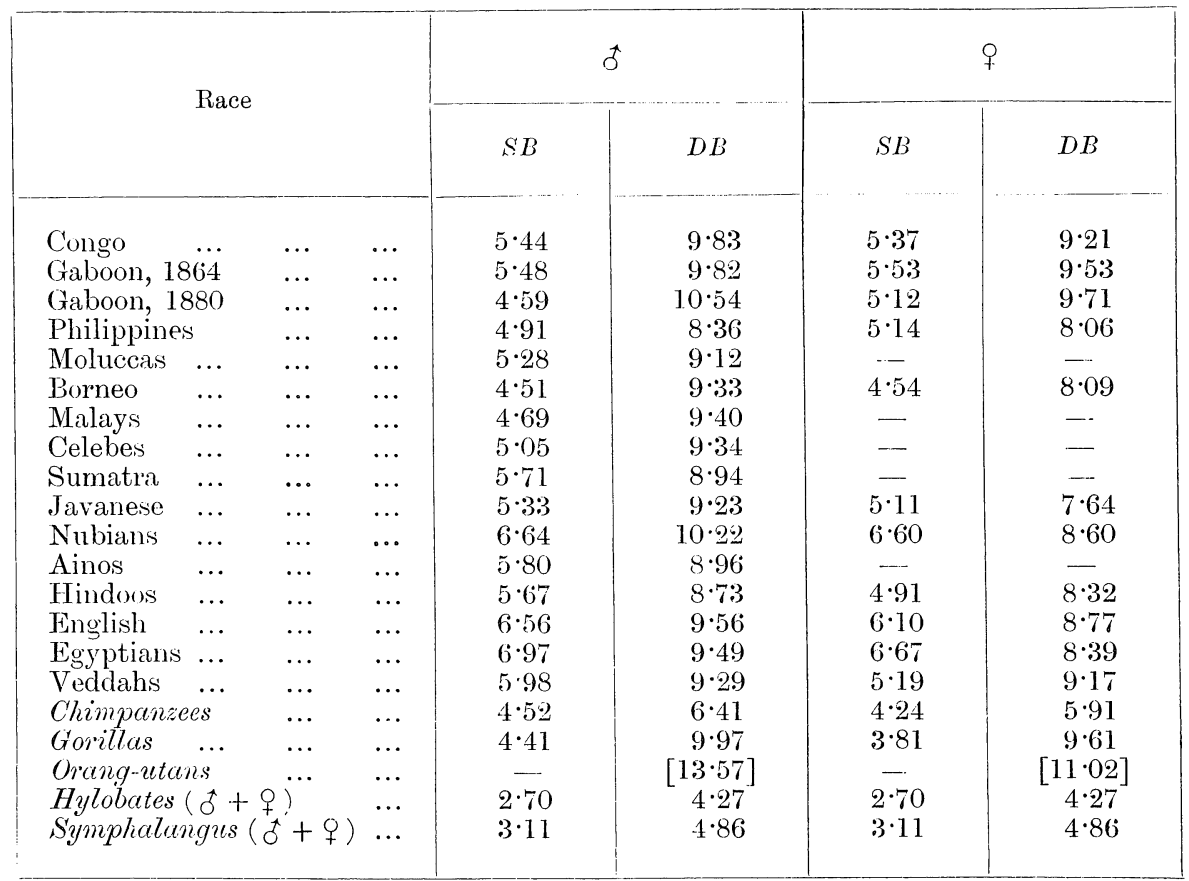

maxillary wall are often, as our contours (pp. 428-9) show, considerably curved, but the chord of these ares will indicate, at any rate approximately, what is the nature of the interracial correlations. Omitting Hylobates and Symphalangus as unsexed and the Orangs we find:

Interracial correlation of nasal bone and maxillary wall

$$
\text { Males }+\cdot 238, \quad \text { Females }+\cdot 215 \text {. }
$$

\footnotetext{
* These values are really the hypotenuses or chords corresponding to the nasal and maxillary portions of the bridge of the nose, and these portions are often curved.
} 


\section{Kathleen V. Ryley and Julia Bell}

It appears therefore reasonable to assume that racially, where the nasal portion is large, so also is the maxillary portion of the nose. Notwithstanding this and the positive correlation of the simotic and maxillary nasal angles, as well as of the subtenses, the projections of the nasal and maxillary portions on the base of the nasal bridge are negatively correlated. The algebraic explanation of this paradox is given below*, but it seems probable that its physiological explanation lies in the relative constancy of the mesodacryal chord. If the reader will examine Table XIV he will see that the variability of the simotic chord relative to its size is almost twice that of the mesodacryal chord, and although some of this may be due to the relatively greater difficulty of accurate measurement the bulk of it is not. The following results will indicate the relative stability of the mesodacryal chord. They are deduced from Tables VIII and XIII, males.

$\begin{array}{lcc} & \begin{array}{c}\text { Mesodacryal } \\ \text { Chord } \\ \text { Interracial Mean }\end{array} & \begin{array}{c}\text { Simotic } \\ \text { Chord }\end{array} \\ \text { Mean racial s. D. } & 21 \cdot 6 & 8 \cdot 47 \\ \text { Interracial s. D. } & 2 \cdot 44 & 1.97 \\ 100 \times \frac{\text { Mean racial s. D. }}{\text { Interracial Mean }} & 11 \cdot 3 & 1 \cdot 20 \\ 100 \times \frac{\text { Interracial s. D. }}{\text { Interracial Mean }} & 6 \cdot 34 & 23.3 \\ 100 \times \frac{\text { Racial Range }}{\text { Interracial Mean }} & 23 \cdot 5 & 14 \cdot 13\end{array}$

Whichever method we take to measure the variation we see that the mesodacryal chord is far less variable than the simotic chord. The breadth of the base of the nasal bridge is relatively constant. The nasal bridge has to span the nasal base, and whether we deal with the problem from the interracial or intraracial standpoint we realise that the nasal structure has to be considered as a whole, and that its anatomical units are very far from being necessarily evolutionary units, or in

* The problem is algebraically of the following kind: given two right angled triangles $A B C$ and $A^{\prime} B^{\prime} C^{\prime}$ with $C$ and $C^{\prime}$ for right angles, then with the usual notation $c^{2}=a^{2}+b^{2}, c^{\prime 2}=a^{\prime 2}+b^{\prime 2}$, is it possible for $c$ and $c^{\prime}, a$ and $a^{\prime}$ and $A$ and $A^{\prime}$ to be positively correlated together and yet $b$ and $b^{\prime}$ to be negatively correlated? Clearly if the means be denoted in the usual manner, we have approximately:

$$
\bar{l} \delta \delta=\bar{c} \delta c-\bar{a} \delta a, \quad \bar{b}^{\prime} \delta b^{\prime}=\bar{c}^{\prime} \delta c^{\prime}-\bar{a}^{\prime} \delta a^{\prime} .
$$

Hence multiplying together, summing for all possible pairs and dividing by their number, we have

$$
\bar{b} \bar{b}^{\prime} \sigma_{b} \sigma_{b^{\prime}} r_{b b^{\prime}}=\bar{c} \bar{c}^{\prime} \sigma_{c} \sigma_{c^{\prime}} r_{c c^{\prime}}+\bar{a} \bar{a}^{\prime} \sigma_{a} \sigma_{a^{\prime}} r_{a a^{\prime}}-\bar{c} \bar{a}^{\prime} \sigma_{c} \sigma_{a^{\prime}} r_{c a^{\prime}}-\bar{c}^{\prime} \bar{a} \sigma_{c^{\prime}} \sigma_{a} r_{c^{\prime} a}
$$

Hence if $r_{c c^{\prime}}$ and $r_{a a^{\prime}}$ are positive as the hypothesis supposes, and at least one or both $r_{c a^{\prime}}$ and $r_{c^{\prime} a}$ are positive also, the negative term or terms on the right may exceed the positive and $r^{\prime} b b^{\prime}$ be negative. In the case of the simotic and maxillary nasal triangles both $r_{c a^{\prime}}$ and $r_{c^{\prime} t a}$ are positive, and the last pair of terms on the right is wholly negative and in excess of the first pair. The above result depends of course on $c^{2}=\dot{a}^{2}+\bar{l}^{2}$ and $\bar{c}^{\prime 2}=\bar{a}^{\prime 2}+\bar{b}^{\prime 2}$ being nearly true. These give $\bar{c}^{2}=84 \cdot 83$ against actual $84 \cdot 64$ and $c^{\prime 2}=29 \cdot 68$ against $29 \cdot 16$. These are close enough to justify the use of the above formula, which on putting in the actual numbers gave $r_{b b^{\prime}}$ the correlation of the projections negative, as the direct investigation gave it. Thus the origin of the negative value for the projections' correlation lies in the negative terms involving the cross-correlations of nasal bone with maxillary height and simotic subtense with maxillary wall, which are themselves positive. 


\section{A Study of the Nasal Bridge in the Anthropoid Apes}

themselves primarily significant for interracial comparison or evolutionary history. The intimate correlations of anatomical units renders them also very frequently of small importance as hereditary characters, and a complex of anatomical units may be much closer to an evolutionary unit,-that entity which as a whole is the subject of selective action. For respiratory efficiency the mesodacryal arc may be of far more importance than either of its components, the maxillary or nasal bone portions. Thus we think it probable that the value of anatomical units in craniometric measurements is liable to be overrated, and in view of their complex and subtle intercorrelations their identification with independent "Mendelian units"whatever the latter may signify-is unjustifiable.

In the series of cuts on pp. 428-9, we have endeavoured to give "type" contours of the nasal bridge for various races on the basis of the classification adopted in Table XXV. The reader is warned that in any race individuals may be found with many of these types. Our "types" are those of individuals whose simotic and maxillary nasal angles, $\phi^{\prime}$ and $\phi$, are as near as we could get to the mean values of those angles in the race. Not too much weight must of course be placed on the classification of races thus reached, but the diagrams are not without suggestiveness. We have added the Dog with its negative simotic subtense, a condition which is just reached in one or two Gibbons. In the case of the dog, however, the dacryon to dacryon section seems to miss the physiognomic nasal bridge, and we have given also a lower section termed on p. 428 the muzzle section. The short strokes mark for each contour the limits of the nasal bone; the contours are in each case from dacryon to dacryon, and were traced after orientating the skull so that the two dacrya and the summit of the bridge were in one horizontal plane. Obviously larger numbers of many more races would provide a more adequate classification, especially if extended into the animal kingdom generally*.

* The Gibraltar skull is the only "ancient type" of man for which we have been able to obtain the nasal bridge constants. They are:

Mesodacryal Subtense $8 \cdot 6, \quad$ Simotic Subtense $2 \cdot 8$
," $\quad$ Chord $22 \cdot 0 ? \quad$ Arc $\quad 31 \cdot 0 ?$
These give $\quad a=39 \cdot 1, \quad a^{\prime}=44 \cdot 4, \quad \beta=40 \cdot 9, \quad S=25 \cdot 9, \quad \phi=46^{\circ} \cdot 0, \quad \phi^{\prime}=27^{\circ} \cdot 5$,

the nasal bridge is thus on the border of the simotic platygephyreal and simotic mesogephyreal groups. The difficulty, however, of determining the dacrya in the absence of the sutures in the cast used is very

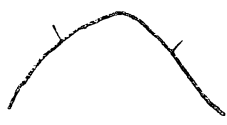

Gibraltar Skull.

considerable. The contour of the nasal bridge is shown above. It will be seen to be in no way markedly differentiated. If we accept it as approximating to that of the original, that original would have stood somewhere between the Negroes and the natives of the Moluccas for both the maxillary and simotic nasal angles, i.e. at the Chimpanzee and Symphalangus end of the scales. But the evidence is too fragile to lay any stress on this point. 


\section{Kathleen V. Ryley and Julia Bell}

(13) Concluding Remarks. We are aware how much of the present paper is open to criticism on account of the limited number of the racial series dealt with and the sparseness of the individual crania in those series. Notwithstanding we hope that the reader may find suggestive paths leading off from these preliminary researches. We believe that the time must come when in the larger Universities there will exist established schools of craniometry with adequate anatomical, physical and statistical training, and that such schools will carry on secular work in collecting and measuring. We have indicated in this paper that the study of the personal equation of craniometricians has hardly begun, but we look forward to the day when it will be as customary for one of the workers in an established craniometry laboratory to be adopted as a standard and his personal equation relative to other workers at home and abroad discussed, as it is for one astronomical observer to be tested against a second. The intercomparability of measurements is largely taken on blind trust by craniologists to-day. Only when relative personal equation has been studied will it be possible safely to pool the measurements of small series made by different laboratories.

Again, anatomical and zoological museums and collections are singularly defective at the present time. If it were desirable to make a thorough study of the cranium of any animal other than man-say dog or horse-is there any collection which could place at the disposal of the inquirer a hundred crania of definite sex, fairly uniform age and reasonable limits of race? We sadly fear not, and yet how much could be learnt of evolutionary descent by an exact study of a variety of species based on even a hundred crania from each! Take the plane of the foramen magnum, determined say by a plane through basion and opisthion perpendicular to the sagittal plane, and consider the angle this makes with the horizontal plane of the skull, as determined, say, by the Frankfurt Concordat. This angle -closely allied to Dauberton's angle--is of very great evolutionary importance, but who can say - on the basis of really numerically adequate measurements* and other than from mere impression gained on a few specimens-what its value is in the chief mammals, in the anthrepoid apes, in negroes and in the various other races of man? Comparative craniometry is almost at its origins if we refer, not to descriptions of "typical " † crania, but to the measurement of numerically adequate series. Not until investigations, only roughly foreshadowed in such a paper as the present, have been made on a far greater variety of species and on a wide range of cranial charactersand this will have to wait until adequate material accumulates in our museumswould any suggestion of evolutionary descent pass into comparative certainty. When the reader realises that some 25 gorilla skulls of one sex, but of all ages

* We do not wish for a moment to underrate Broca's work in this field; but besides his views as to the horizontal planes, his series are often unsexed, and, especially for the chief mammals, wholly inadequate numerically. 'Thus he uses two or three apes, dogs, cats, and so forth, where we need 50 to 100 of each breed and sex.

+ How few anatomists realise that nobody knows what a "typical" cranium is until a long series of the particular race has been measured! We remember seeing in one museum a skull, labelled "typical English," and this at a date when not 50 English crania from one district and period had been measured. 


\section{A Study of the Nasal Bridge in the Anthropoid Apes}

and all districts, are about all that the English worker has to rely upon at present, and that it may be doubted whether he could find the same number of dog skulls of known sex, of one breed and of fairly certain age, anywhere in the country, he will, we hope, pardon one source of the inadequacy of the present study.

In choosing the nasal bridge we had in view the importance of the nasal organs as a factor of survival, and we believe we have at least indicated that with caution the parts of the bridge can be measured and comparative results obtained. The measurements lead directly, we think, to the suggrestion of a racial scale and throw light on the importance of dealing with groups of correlated characters and not with isolated anatomical units. The classification we have suggested, both in the limits of its categories and its terminology, is of course not put forward as final, but we believe it will be helpful as a step to a good ultimate classification and as enabling meanwhile the characters of the nasal bridge of any other race to be associated with those treated in this paper. The needful measurements are simotic chord and simotic subtense, and again mesodacryal chord and subtense; from the first two the simotic nasal angle can be readily found and from all four the maxillary nasal angle. The two taken in conjunction will enable the recorder to classify the nose by aid of Table XXV.

On the whole we consider that Mérejkowsky broke fruitful ground, especially, if the discussion of the nasal bridge be extended to the mesodacryal chord and subtense, which appear of more evolutionary importance than his simotic chord and subtense; but there will undoubtedly have to be standardisation of individual craniometricians in a far higher degree than even for the macrometric measurements of the skull, if these micrometric measurements are to be dealt with confidently.

Addendum. Since this paper was written, it occurred to us that the Moriori crania from Chatham Island in the Royal College of Surgeons might be worth investigating from the standpoint of the nasal bridge-as they are undoubtedly worth investigating from their general craniometric importance.

The nasal bridges, however, turned out to be of no markedly primitive type, as the accompanying contours will indicate.

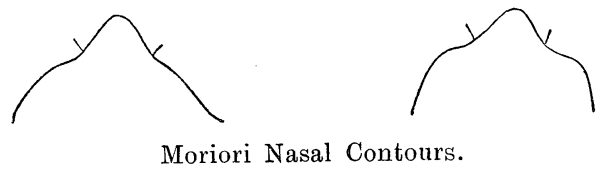

They are mesotic mesogephyreal, and stand between Malay and Aino with :

$\begin{array}{ccc} & 5 & q \\ \phi & 46.0^{\circ} & 49 \cdot 0^{\circ} \\ \phi^{\prime} & 40 \cdot 6^{\circ} & 34.3^{\circ}\end{array}$

48 crania were taken as male, 15 as female. 


\section{Kathleen V. Ryley and Julia Bell}

There is a somewhat noteworthy difference between male and female, but a still more remarkable feature of the results is that for the whole eleven characters discussed the male is more variable and in some cases no less than twice as variable as the female. Such exaggerated differences in variation in the sexes are so unusual, especially in primitive races, that we believe that the noteworthy cranial characters of this race, in which " maleness" seems almost a racial character, may have led to a far too stringent selection of female crania. Thus on the present sexing the female coefficient of variation of the mesodacryal subtense is $8 \cdot 0$, of the mesodacryal index $\alpha, 8 \cdot 0$, and of the simotic index $14 \cdot 4$, - all values much below any reached for females of the human races given in Table XIV. We consider it better to postpone publication of the Moriori results, until a fuller study has been made of all the craniological characters of the Royal College series, which we hope may soon be undertaken.

Tables A-D give the measurements made for the apes only. The tape measurements of the mesodacryal arc scarcely ever permitted of the determination to tenths of a millimetre, and this makes the tenths in the mesodacryal chord of small value, when we are determining the arcual index $\beta$. In the tables doubt as to a value is only expressed in the columns of the absolute measurements and not repeated in the index columns deduced from these absolute measurements. Of course the index values have no more weight than the data from which they are deduced.

Note. The Editor is responsible for the terminology used in this paper. $\mathrm{He}$ fully admits its barbarism. But no English form for the Greek adjective exists, and when a distinguished classical scholar fails to find one, science must take the matter into its own hands, and adjectives in -otic seem the only possibility. Simotic has practically Greek sanction; the pathologists have already adopted stenotic; thus the step to mesotic was not a very great one, and it is shorter than mesomorphic or mesorhinal,--were indeed compounds in rhinal not already allocated. 
438 A Study of the Nasal Bridge in the Anthropoid Apes

TABLE A. Characters of the

\begin{tabular}{|c|c|c|c|c|c|c|c|c|c|c|}
\hline \multirow{2}{*}{$\begin{array}{l}\text { Museum } \\
\text { Number }\end{array}$} & \multirow{2}{*}{ Sex } & \multirow{2}{*}{$\begin{array}{l}\text { Meso- } \\
\text { dacryal } \\
\text { Chord }\end{array}$} & \multirow{2}{*}{$\begin{array}{c}\text { Meso- } \\
\text { dacryal } \\
\text { Arc }\end{array}$} & \multirow{2}{*}{$\begin{array}{c}\text { Meso- } \\
\text { dacryal } \\
\text { Subtense }\end{array}$} & \multicolumn{4}{|c|}{ Mesodacryal Indices } & \multirow{2}{*}{$\begin{array}{c}\text { Simotic } \\
\text { Chord }\end{array}$} & \multirow{2}{*}{$\begin{array}{l}\text { Simotic } \\
\text { Subtense }\end{array}$} \\
\hline & & & & & $\alpha$ & $a^{\prime}$ & $a-a^{\prime}$ & $\beta$ & & \\
\hline 1011. S & 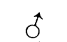 & $19 \cdot 5$ & 29 & $9 \cdot 1$ & $46 \cdot 7$ & $49 \cdot 4$ & $-2 \cdot 7$ & $48 \cdot 7$ & $6 \cdot 0$ & $3 \cdot 3$ \\
\hline 7. 1.8. 2 & $\delta$ & $21 \cdot 6$ & 30 & $9 \cdot 9$ & $45 \cdot 8$ & $43 \cdot 1$ & $+2 \cdot 7$ & $38 \cdot 9$ & $5 \cdot 8$ & $4 \cdot 3$ \\
\hline \%.1.8. 1 & ô & $29 \cdot 3$ & 34 & $7 \cdot 6$ & $25 \cdot 9$ & $25 \cdot 9$ & 0 & $16 \cdot 1$ & $8 \cdot 1$ & $1 \cdot 8$ \\
\hline- & $\hat{\jmath}$ & $33.5 ?$ & $41 ?$ & $7 \cdot 6 ?$ & $22 \cdot 7$ & $31 \cdot 2$ & $-8 \cdot 5$ & $22 \cdot 4$ & - & - \\
\hline 1011. u & o & $21 \cdot 1$ & 32 & $11 \cdot 4$ & $54 \cdot 0$ & $51 \cdot 3$ & $+2 \cdot 7$ & $51 \cdot 7$ & $5 \cdot 7$ & $2 \cdot 7$ \\
\hline 1011. c & $\hat{\sigma}$ & $16 \cdot 2$ & $2: 3$ & $7 \cdot 5$ & $46 \cdot 3$ & $45 \cdot 1$ & $+1 \cdot 2$ & $42 \cdot 0$ & - & - \\
\hline Olkwa & q & $25 \cdot 4$ & $31 \cdot 5$ & $8 \cdot 6$ & $33 \cdot 9$ & $32 \cdot 4$ & +15 & $24^{\circ} 0$ & - & - \\
\hline$\because 1.8 .4$ & T & $19 \cdot 1$ & $29 \cdot 2$ & $9 \cdot 2$ & $48 \cdot 2$ & $52 \cdot 1$ & $-3 \cdot 9$ & $52 \cdot 9$ & $3 \cdot 6$ & $2 \cdot 2$ \\
\hline$\% 1.8 .5$ & $\stackrel{+}{+}$ & $22 \cdot 2$ & $31 \cdot 7$ & $9 \cdot 6$ & $43 \cdot 2$ & $45 \cdot 6$ & $-2 \cdot 4$ & $42 \cdot 8$ & $5 \cdot 4$ & $3 \cdot 3$ \\
\hline \%. 1.8 .3 & $\stackrel{+}{q}$ & $25 \cdot 6 ?$ & $33 ?$ & $9 \cdot 0$ & $35 \cdot 2$ & $36 \cdot 1$ & -9 & $28 \cdot 9$ & $4 \cdot 7$ & $3 \cdot 8$ \\
\hline$\% 1.8 . \%$ & $\stackrel{+}{+}$ & $25 \cdot 0$ & 32 & $9 \cdot 2$ & $36 \cdot 8$ & $35 \cdot 4$ & $+1 \cdot 4$ & $28 \cdot 0$ & $5 \cdot 6$ & $2 \cdot 6$ \\
\hline \%. 1.8 .6 & $\stackrel{+}{+}$ & $21 \cdot 8 ?$ & $30 \cdot 6 ?$ & $10 \cdot \overline{3}$ & $47 \cdot 2$ & $44 \cdot 1$ & $+3 \cdot 1$ & $40 \cdot 4$ & $4 \cdot 0 ?$ & $1 \cdot 8 ?$ \\
\hline 64. 12. 1.1 & $\stackrel{+}{+}$ & $17 \cdot 8 ?$ & $28 ?$ & $10 \cdot 0$ & $56 \cdot 2$ & $54 \cdot 8$ & $+1 \cdot 4$ & $57 \cdot 3$ & $--\cdot$ & - \\
\hline 1011. d & $\stackrel{+}{q}$ & $21 \cdot 3$ & $32 \cdot 5$ & $10 \cdot 2$ & $47 \cdot 9$ & $51 \cdot 9$ & $-4 \cdot 0$ & $52 \cdot 6$ & $4 \cdot 2$ & $2 \cdot 6$ \\
\hline - & q & $21 \cdot 5 ?$ & $34 ?$ & $10 \cdot 1 ?$ & $47^{\circ} 0$ & $55 \cdot 3$ & $-8 \cdot 3$ & $58 \cdot 1$ & $7 \cdot 5 ?$ & $5 \cdot 7 ?$ \\
\hline 1011. b & $\stackrel{+}{+}$ & $16 \cdot 2$ & 23 & $7 \cdot 5$ & $46 \cdot 3$ & $45 \cdot 1$ & $+1 \cdot 2$ & $42 \cdot 0$ & $3 \cdot 0$ & $2 \cdot 0$ \\
\hline $\mathscr{2} \mathbb{2}$ & t. & $16 \cdot 8$ & $27 ?$ & $11 \cdot 0$ & $65 \cdot 5$ & $56 \cdot 9$ & $+8 \cdot 6$ & $60 \cdot 7$ & $4 \cdot 1$ & $3 \cdot 6$ \\
\hline 20 & $\hat{\sigma}$ & $18 \cdot 7$ & 23 & $5 \cdot 3$ & $28 \cdot 3$ & $31 \cdot 6$ & $-3 \cdot 3$ & $23 \cdot 0$ & - & - \\
\hline $\mathscr{Q} 1$ & $s$ & $25 \cdot 9$ & 37 & $11 \cdot 4$ & $44 \cdot 0$ & $45 \cdot 7$ & $-1 \cdot 7$ & $42 \cdot 9$ & $8 \cdot 8$ & $3 \cdot 7$ \\
\hline $\mathscr{Q S}$ & $\hat{0}$ & $22 \cdot 6$ & 30 & $8 \cdot 7$ & $38 \cdot 5$ & $38 \cdot 8$ & -3 & $32 \cdot 7$ & $5 \cdot 0$ & $2 \cdot 4$ \\
\hline 25 & c & $22 \cdot 0$ & 33 & $8 \cdot 6$ & $39 \cdot 1$ & $50 \cdot 3$ & $-11 \cdot 2$ & $50 \cdot 0$ & $3 \cdot 8$ & $2 \cdot 7$ \\
\hline 21. a & o & $25 \cdot 0$ & 30) & $7 \cdot 2$ & $28 \cdot 8$ & $29 \cdot 2$ & $-\quad \cdot 4$ & $20 \cdot 0$ & $8 \cdot 2$ & $3 \cdot 6$ \\
\hline 93 & Q & $23 \cdot 8 ?$ & $34 ?$ & $10 \cdot 5 ?$ & $44 \cdot 1$ & $45 \cdot 7$ & $-1 \cdot 6$ & $42 \cdot 9$ & $6 \cdot 4$ & $2 \cdot 0$ \\
\hline 96 & $\stackrel{+}{q}$ & $24 \cdot 2$ & 31 & $8 \cdot 3$ & $34 \cdot 2$ & $3 \tilde{5} \cdot 5$ & $-1 \cdot 3$ & $28 \cdot 1$ & $6 \cdot 0$ & $2 \cdot 6$ \\
\hline $\mathscr{2} y$ & q & $12 \cdot 5 ?$ & 19 ? & $6 \cdot 2 ?$ & $49 \cdot 6$ & $45 \cdot 7$ & $+3 \cdot 9$ & $52 \cdot 0$ & - & - \\
\hline 94 & q & $22 \cdot 0$ & 28 & $8 \cdot 4$ & $38 \cdot 2$ & $34 \cdot 9$ & $+3 \cdot 3$ & $27 \cdot 3$ & $9 \cdot 1$ & $2 \cdot 2$ \\
\hline 93 & $\hat{\sigma}$ & $20 \cdot 3$ & 29 & $8 \cdot 4$ & $41 \cdot 4$ & $45 \cdot 7$ & $-4 \cdot 3$ & $42 \cdot 9$ & $8 \cdot 7$ & $3 \cdot 9$ \\
\hline- & ô & $26 \cdot 5$ & 32 & $8 \cdot 9$ & $33 \cdot 6$ & $29 \cdot 9$ & $+3 \cdot 7$ & $20 \cdot 8$ & $6 \cdot 0$ & $3 \cdot 1$ \\
\hline 'T & $\hat{\sigma}$ & $23 \cdot 2$ & 30 & $9 \cdot 2$ & $39 \cdot 7$ & $36 \cdot 4$ & $+3 \cdot 3$ & $29 \cdot 3$ & $8 \cdot 2$ & $3 \cdot 7$ \\
\hline 'T' & q & $21 \cdot 7$ & 32 & $10 \cdot 7$ & $49 \cdot 3$ & $48 \cdot 7$ & +6 & $47 \cdot 5$ & $7 \cdot 0$ & $1 \cdot 5 ?$ \\
\hline- & $\stackrel{+}{q}$ & $21 \cdot 2$ & 34 & $11 \cdot 2$ & $52 \cdot 8$ & $56 \cdot 7$ & $-3 \cdot 9$ & $60 \cdot 4$ & $5 \cdot 4$ & $2 \cdot 7$ \\
\hline 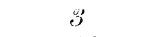 & $\stackrel{+}{+}$ & $19 \cdot 0$ & 23 & $5 \cdot 4$ & $28 \cdot 4$ & $30 \cdot 1$ & $-1 \cdot 7$ & $21 \cdot 1$ & $4 \cdot 2$ & $1 \cdot 1$ \\
\hline 6. 194 & q & $11 \cdot 8$ & 17 & $6 \cdot 4$ & $54 \cdot 2$ & $46 \cdot \tilde{J}$ & $+7 \cdot 7$ & $44 \cdot 1$ & $5 \cdot 6$ & $3 \cdot 3$ \\
\hline 4 & q & $19 \cdot 5$ & 31 & $11 \cdot 6$ & $59 \cdot \tilde{5}$ & $55 \cdot 8$ & $+3 \cdot 7$ & $59 \cdot 0$ & $5 \cdot 6$ & $3 \cdot 5$ \\
\hline 43.5 & $\stackrel{+}{q}$ & $24 \cdot 8 ?$ & $30 ?$ & $8 \cdot 1$ & $32 \cdot 7$ & $30 \cdot 0$ & $+2 \cdot 7$ & $21 \cdot 0$ & - & - \\
\hline "Gerrard" & $\stackrel{+}{q}$ & $21 \cdot 7$ & 26 & $7 \cdot 6$ & $35 \cdot 0$ & $29 \cdot 1$ & +5.9 & $19 \cdot 8$ & - & - \\
\hline 5 xii. 05 & O & $28 \cdot 0 ?$ & $29 ?$ & $10 \cdot 2$ & $36 \cdot 4$ & - & - & $3 \cdot 6$ & - & - \\
\hline 16 & q & $16 \cdot 2 ?$ & $28 ?$ & $9 \cdot 9$ & $61 \cdot 1$ & $64 \cdot 1$ & $-3 \cdot 0$ & $72 \cdot 8$ & $3 \cdot 2$ & $3 \cdot 2$ \\
\hline Q & Q & $17 \cdot 6 ?$ & $25 ?$ & $7 \cdot 6$ & $43 \cdot 2$ & $45 \cdot 2$ & $-2 \cdot 0$ & $42 \cdot 1$ & - & - \\
\hline 3 & t & $25 \cdot 4$ & 34 & $9 \cdot 4$ & $37 \cdot 0$ & $39 \cdot 6$ & $-2 \cdot 6$ & $33 \cdot 9$ & $9 \cdot 2$ & $3 \cdot 8$ \\
\hline $1^{\mathrm{a}}$ & $\hat{0}$ & $22 \cdot 0 ?$ & $30 ?$ & $9 \cdot 8$ & $44 \cdot 6$ & $41 \cdot 4$ & $+3 \cdot 2$ & $36 \cdot 4$ & $-\ldots$ & - \\
\hline 1161. F & o & $18 \cdot 2$ & 28 & $9 \cdot 6$ & $52 \cdot 8$ & $52 \cdot 7$ & $+\cdot 1$ & 53.9 & $4 \cdot 2$ & $3 \cdot 1$ \\
\hline 1161. A & ô & $24 \cdot 7$ & $36 \cdot 5$ & $12 \cdot 9$ & $52 \cdot 2$ & $48 \cdot 9$ & +3.3 & $47 \cdot 8$ & $3 \cdot 2$ & $3 \cdot 4$ \\
\hline 423.5 & $\hat{o}$ & $17 \cdot 0$ & 23 & $7 \cdot 2$ & $42 \cdot 4$ & $40 \cdot 6$ & $+1 \cdot 8$ & $35 \cdot 3$ & $3 \cdot 0$ & $2 \cdot 2$ \\
\hline 7 & to & $23 \cdot 8 ?$ & $33 ?$ & $10 \cdot 0$ & $42 \cdot 0$ & $42 \cdot 9$ & -9 & $38 \cdot 7$ & $6 \cdot 0$ & $2 \cdot 9$ \\
\hline $\mathrm{L}$ & $\hat{0}$ & $30 \cdot 0$ & $36 \cdot 5$ & $8 \cdot 5$ & $28 \cdot 3$ & 3.) \cdot 6$ & $-2 \cdot 3$ & $21 \cdot 7$ & $8 \cdot 8$ & $2 \cdot 9$ \\
\hline 8 & $\hat{\sigma}$ & $20 \cdot 9$ & $32 \cdot 5$ & $11 \cdot 6$ & $55 \cdot 5$ & $53 \cdot 7$ & $+1 \cdot 8$ & $55 \cdot 5$ & $4 \cdot 0$ & $4 \cdot 1$ \\
\hline 10 & f & $19 \cdot 7$ & 28 & $9 \cdot 0$ & $45 \cdot 7$ & $45 \cdot 2$ & $+\quad 5$ & $42 \cdot 1$ & $6 \cdot 5$ & $5 \cdot 0$ \\
\hline 1 & o & $21 \cdot 0$ & 30 & $8 \cdot 9$ & $42 \cdot 4$ & $45 \cdot 7$ & $-3 \cdot 3$ & $42 \cdot 9$ & $8 \cdot 0$ & $3 \cdot 5$ \\
\hline 1 & ô & $25 \cdot 0 ?$ & $32 \cdot 5 ?$ & $8 \cdot 9$ & $35 \cdot 6$ & $36 \cdot 9$ & $-1 \cdot 3$ & $30 \cdot 0$ & - & - \\
\hline 2052 & oे & $21 \cdot 8 ?$ & $28 ?$ & $6 \cdot 5$ & $29 \cdot 8$ & $35 \cdot 8$ & $-6 \cdot 0$ & $28 \cdot 5$ & $8 \cdot 8$ & $3 \cdot 0$ \\
\hline 982 & o & $21 \cdot 0 ?$ & $27 ?$ & $9 \cdot 7$ & $46 \cdot 2$ & $35 \cdot 9$ & $+10 \cdot 3$ & $28 \cdot 6$ & - & - \\
\hline $\mathscr{2 0 5 1}$ & o & $15 \cdot 4$ & 23 & $6 \cdot 9$ & $44 \cdot 8$ & $49 \cdot 9$ & $-5 \cdot 1$ & $49 \cdot 4$ & $6 \cdot 2$ & $4 \cdot 3$ \\
\hline
\end{tabular}




\section{Kathleen V. Rilley and Julia Bell}

Nasal Bridge in the Gorilla.

\begin{tabular}{|c|c|c|c|c|c|c|c|}
\hline $\begin{array}{l}\text { Simotic } \\
\text { Index }\end{array}$ & \multicolumn{6}{|c|}{ Locus } & \multirow[t]{2}{*}{ Remarks } \\
\hline $55 \cdot 0$ & Natural & History & Mus & um & $\ldots$ & $\ldots$ & \\
\hline $74 \cdot 1$ & $"$ & " & , & & $\ldots$ & $\ldots$ & From Okuni district. Sutures clear \\
\hline $22 \cdot 2$ & $"$ & $"$ & & & ... & ... & From Okuni district. Sutures vague [specimen mounted in case \\
\hline- & $"$ & $"$ & & & $\ldots$ & .. & Measurements uncertain owing to bad light and position of \\
\hline $47 \cdot 4$ & $"$ & " & & & $\ldots$ & $\ldots$ & Very large and heavy skull. Sutures not clear \\
\hline - & $"$ & ", & & & .. & $\ldots$ & Permanent teeth not quite erupted. Nasal bones too narrow to \\
\hline$=$ & " & $"$ & & & $\ldots$ & $\ldots$ & Nasal bones too narrow to measure [measure \\
\hline $47 \cdot 4$ & " & $"$ & & & $\ldots$ & $\ldots$ & From Okuni district. Sutures vague \\
\hline $61 \cdot 1$ & " & $"$ & & & $\ldots$ & $\ldots$ & From Okuni district. Sutures clear \\
\hline $80 \cdot 9$ & $"$ & $"$ & , & & $\ldots$ & $\ldots$ & From Okuni district. Sutures vague \\
\hline $46 \cdot 4$ & $"$ & $"$ & & & $\ldots$ & $\ldots$ & From Okuni district. Sutures very vague \\
\hline $45 \cdot 0$ & , & $"$ & & &.. & $\ldots$ & From Okuni district. Sutures vague \\
\hline- & $"$ & $"$ & , & & $\ldots$ & ... & In the Du Chaillu collection. Sutures obliterated \\
\hline $61 \cdot 9$ & $"$ & $"$ & & & $\ldots$ & $\ldots$ & $\begin{array}{l}\text { Sutures clear } \quad[\text { specirnen mounted in case } \\
\text {. }\end{array}$ \\
\hline $76 \cdot 0$ & $"$ & $"$ & , & & $\cdots$ & $\cdots$ & Measurements uncertain owing to bad light and position of \\
\hline $66 \cdot 7$ & Royal C & college of & & & $\cdots$ & $\ldots$ & Young. Permanent teeth not quite erupted. Nasal bones \\
\hline $87 \cdot 8$ & & & & eons & $\ldots$ & $\ldots$ & $\begin{array}{l}\text { Sutures clear } \\
\text { [very narrow }\end{array}$ \\
\hline - & $"$ & $"$ & , & & $\cdots$ & $\ldots$ & $\begin{array}{l}\text { Sutures clear. Split skull and therefore measurements un- } \\
\text { certain. Nasal bone abnormal on one side }\end{array}$ \\
\hline $42 \cdot 1$ & $"$ & $"$ & , & & $\cdots$ & $\cdots$ & $\begin{array}{l}\text { Heavily made skull. Sutures clear. Nasal and maxillary } \\
\text { bones large, lacrymal bones very small }\end{array}$ \\
\hline $48 \cdot 0$ & & $"$ & , & & ... & $\cdots$ & Young. Permanent teeth erupting \\
\hline $71 \cdot 1$ & " & $"$ & , & & $\ldots$ & $\ldots$ & Split skull \\
\hline $43 \cdot 9$ & $"$ & $"$ & , & & .. & $\ldots$ & [sutures are rague \\
\hline $31 \cdot 3$ & $"$ & $"$ & , & & $\ldots$ & $\ldots$ & Difficult to measure as skull is attached to skeleton in case and \\
\hline $43 \cdot 3$ & " & $"$ & , & & ... & $\ldots$ & Sutures vague \\
\hline- & $"$ & $"$ & & & $\cdots$ & $\cdots$ & Adolescent. Split skull with badly fitting halves. Sutures \\
\hline $\begin{array}{l}2+\cdot 2 \\
44 \cdot 8\end{array}$ & Univers & ity Colleg & se, Zo & $\log y \mathrm{l}$ & eparts & nent & $\begin{array}{l}\text { Perfect sutures } \\
\text { Young adult. Sutures clear }\end{array}$ \\
\hline $51 \cdot 7$ &, & 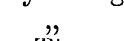 & 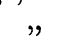 & , & , & & $\begin{array}{l}\text { Young adut. Sutures clear } \\
\text { Sutures rather vague }\end{array}$ \\
\hline $45 \cdot 1$ & Professo & or T'hane & & $\ldots$ & $\ldots$ & $\ldots$ & Sutures vague \\
\hline $21 \cdot 4$ & ," &, & & & $\ldots$ & & Sutures very vague \\
\hline $50 \cdot 0$ & Protesso & or Pearson & , Biol & netric & abora & ory & Sutures rague \\
\hline $26 \cdot 2$ & Cambrid & dge Anth & ropol & gical & abora & ory & Sutures clear \\
\hline $58 \cdot 9$ & $"$ & $"$ & $"$ & , & , & & Young adult. Sutures clear \\
\hline $62 \cdot 5$ & $"$ & $"$ & $"$ & ", & , & & Sutures clear \\
\hline$\cdots$ & " & $"$ & $"$ & " & , & & Sutures obliterated. Skull varnished \\
\hline- & $"$ & $"$ & $"$ & ", & , & & Sutures obliterated \\
\hline (100. & $"$ & " & $"$ & $"$ & , & & $\begin{array}{l}\text { Young. Third molar and canmes not yed from statistical } \\
\text { apparently damaged and deformed. Omitted from stat. }\end{array}$ \\
\hline $100 \cdot 0$ & $"$ & $"$ & $"$ & " & , & & Sutures obliterated. A high, narrow nose. [reductions \\
\hline- & $"$ & $"$ & $"$ & $"$ & $?$ & & Sutures obliterated. Fourth molar appearing on right side \\
\hline $41 \cdot 3$ & " & $"$ & , & " & , & & Sutures clear. Bicuspids out of place on right side \\
\hline$\overline{73 \cdot 8}$ & Cambrid & dge "Zoolo & gical & Labor & tory & $\cdots$ & $\begin{array}{l}\text { Sutures very vague } \\
\text { Sutures clear }\end{array}$ \\
\hline $106 \cdot 3$ & ", & , &, & & & $\ldots$ & Sutures clear. Very narrow nasal bones and large maxillary \\
\hline $\begin{array}{l}73 \cdot 3 \\
48 \cdot 3\end{array}$ & Dr $W$ & L. H. Di & uckwo & orth & $\ldots$ & $\ldots$ & Young. Third molars and canines erupting \\
\hline $\begin{array}{l}48 \cdot 3 \\
33 \cdot 0\end{array}$ & ” & $"$ & $"$ & & $\ldots$ & $\cdots$ & Sutures obliterated \\
\hline $\begin{array}{r}33 \cdot 0 \\
102 \cdot 5\end{array}$ & $"$ & $"$ & $"$ & & $\cdots$ & $\cdots$ & Sutures clear but complex. Heavily developed skull \\
\hline $102 \cdot 5$ & $"$ & $"$ & $"$ & & $\cdots$ & $\cdots$ & $\begin{array}{l}\text { Sutures clear, but measurements rather uncertain on account } \\
\text { of ossicles in naso-maxillary suture }\end{array}$ \\
\hline $76 \cdot 9$ & $"$ & $"$ & $"$ & & .. & $\ldots$ & Sutures obliterated. Much developed crest \\
\hline $43 \cdot 8$ & Oxford & ", & $"$ & & ... & $\ldots$ & Sutures clear. Heavily developed skull \\
\hline$\overline{34 \cdot 1}$ & Uxford & Museum & .. & $\cdots$ & .. & $\ldots$ & Sutures obliterated. Cleft in sagittal cres \\
\hline $34 \cdot 1$ & $"$ & " & ... & ... & $\ldots$ & $\ldots$ & Sutures obliterated \\
\hline & $"$ & " & & $\cdots$ & ... & $\cdots$ & Aged. Sutures obliterated \\
\hline 69.4 & & , & & .. & ... & & Nearly adult. Sutures clear. Third molar nearly erupted \\
\hline
\end{tabular}


440 A Study of the Nasal Bridge in the Anthropoid Apes

TABLE B. Characters of the

\begin{tabular}{|c|c|c|c|c|c|c|c|c|c|c|}
\hline \multirow{2}{*}{$\begin{array}{l}\text { Museum } \\
\text { Number }\end{array}$} & \multirow{2}{*}{ Sex } & \multirow{2}{*}{$\begin{array}{l}\text { Meso- } \\
\text { dacryal } \\
\text { Chord }\end{array}$} & \multirow{2}{*}{$\begin{array}{c}\text { Meso- } \\
\text { dacryal } \\
\text { Arc }\end{array}$} & \multirow{2}{*}{$\begin{array}{c}\text { Meso- } \\
\text { dacryal } \\
\text { Subtense }\end{array}$} & \multicolumn{4}{|c|}{ Mesodacryal Indices } & \multirow{2}{*}{$\begin{array}{l}\text { Simotic } \\
\text { Chord }\end{array}$} & \multirow{2}{*}{$\begin{array}{c}\text { Simotic } \\
\text { Subtense }\end{array}$} \\
\hline & & & & & $a$ & $a^{\prime}$ & $a-a^{\prime}$ & $\beta$ & & \\
\hline y & t & $20 \cdot 0$ & 27 & $7 \cdot 1$ & $35 \cdot 5$ & $40 \cdot 4$ & $-4 \cdot 9$ & $35 \cdot 0$ & $6 \cdot 0$ & $\cdot 8$ \\
\hline 10 & ot & $14 \cdot 8$ & $16 \cdot 8$ & $3 \cdot 8$ & $25 \cdot 7$ & $23 \cdot 5$ & $+2 \cdot 2$ & $13 \cdot 5$ & $8 \cdot 6$ & $2 \cdot 5$ \\
\hline 11. A & t & $15 \cdot 2$ & 19 & $4 \cdot 8$ & $31 \cdot 6$ & $33 \cdot 2$ & $-1 \cdot 6$ & $25 \cdot 0$ & $5 \cdot 0$ & $1 \cdot 3$ \\
\hline 11. 2 & 0 & $15 \cdot 1$ & $18 \cdot 5$ & $2 \cdot 7$ & $17 \cdot 9$ & $31 \cdot 2$ & $-13 \cdot 3$ & $22 \cdot 5$ & $9 \cdot 8$ & $1 \cdot 8$ \\
\hline 10. A & o & $17 \cdot 2$ & 21 & $4 \cdot 6$ & $26 \cdot 7$ & $30 \cdot \overline{9}$ & $-\quad 4 \cdot 2$ & $22 \cdot 1$ & - & - \\
\hline 8 & o & $16 \cdot 0$ & 19 & $3 \cdot 9$ & $24 \cdot 4$ & $28 \cdot 3$ & $-3 \cdot 9$ & $18 \cdot 8$ & $8 \cdot 2$ & $2 \cdot 1$ \\
\hline 9 & ô & $19 \cdot 9$ & 23 & $5 \cdot 5$ & $27 \cdot 6$ & $25 \cdot 5$ & $+2 \cdot 1$ & $15 \cdot 6$ & $7 \cdot 7$ & $\cdot 6$ \\
\hline $1 \%$ & o & $21 \cdot 1$ & 27 & $5 \cdot 5$ & $26 \cdot 1$ & $35 \cdot 4$ & $-9 \cdot 3$ & $28 \cdot 0$ & $10 \cdot 0$ & $1 \cdot 0$ \\
\hline 3 & ô & $19 \cdot 0$ & 24 & $5 \cdot 5$ & $29 \cdot 0$ & $34 \cdot 2$ & $-5 \cdot 2$ & $26 \cdot 3$ & $8 \cdot 0$ & $1 \cdot 8$ \\
\hline 1 & t & $19 \cdot 2 ?$ & $22 ?$ & $4 \cdot 9 ?$ & $25 \cdot 5$ & $24 \cdot 6$ & +9 & $14 \cdot 6$ & - & - \\
\hline $\mathscr{2}$ & i & $19 \cdot 0 ?$ & $20 \cdot 2 ?$ & $4 \cdot 0$ & $21 \cdot 1$ & $15 \cdot 7$ & $+5 \cdot 4$ & $6 \cdot 3$ & - & -- \\
\hline 11 & q & $23 \cdot 0$ & 25 & $5 \cdot 4$ & $23 \cdot 5$ & $18 \cdot 6$ & $+4 \cdot 9$ & $8 \cdot 7$ & $8 \cdot 7$ & $2 \cdot 4$ \\
\hline 11. 1 & $\dot{\phi}$ & $19 \cdot 0$ & $22 ?$ & $5 \cdot 0$ & $26 \cdot 3$ & $25 \cdot 6$ & +7 & $15 \cdot 8$ & $9 \cdot 0$ & $1 \cdot 6$ \\
\hline 11. $\mathrm{B}$ & $\phi_{+}^{+}$ & $12 \cdot 0$ & 15 & $3 \cdot 8$ & $31 \cdot 7$ & $33 \cdot 2$ & $-1 \cdot 5$ & $25 \cdot 0$ & $7 \cdot 0$ & $1 \cdot 0$ \\
\hline 4 & ơ & $17 \cdot 0$ & $19 \cdot 5$ & $2 \cdot 7$ & $15 \cdot 9$ & $24 \cdot 7$ & $-8 \cdot 8$ & $14 \cdot 7$ & $8 \cdot 7$ & 6 \\
\hline 94 & $? 0^{+}$ & $22 \cdot 3$ & 26 & $5 \cdot 2$ & $2: 3 \cdot 3$ & $26 \cdot 4$ & $-3 \cdot 1$ & $16 \cdot 6$ & -- & - \\
\hline \%. $\% .19$ & 0 & $25 \cdot 0 ?$ & 31 & $6 \cdot 8$ & $27 \cdot 2$ & $32 \cdot 4$ & $-5 \cdot 2$ & $24 \cdot 0$ & - & - \\
\hline 94.7 .25 .2 & o & $21 \cdot 0$ & $23 \cdot 7$ & $6 \cdot 4$ & $30 \cdot 5$ & $23 \cdot 0$ & $+7 \cdot 5$ & $12 \cdot 9$ & $8 \cdot 0$ & $3 \cdot 0$ \\
\hline $64.12 .1 \%$ & $?$ & $19 \cdot 0$ & 22 & $5 \cdot 4$ & $28 \cdot 4$ & $25 \cdot 6$ & $+2 \cdot 8$ & $15 \cdot 8$ & $9 \cdot 0$ & 9 \\
\hline $8 \% 12.1 .1$ & f & $14 \cdot 1$ & 17 & $4 \cdot 8$ & $34 \cdot 0$ & $29 \cdot 7$ & +43 & $20 \cdot 6$ & $7 \cdot 4$ & $1 \cdot 5$ \\
\hline פ. e & $?$ & $20 \cdot 0$ & 27 & $7 \cdot 6$ & $38 \cdot 0$ & $40 \cdot 4$ & $-2 \cdot 4$ & $35 \cdot 0$ & $8 \cdot 2$ & $1 \cdot 7$ \\
\hline 8.9. 9.18.1 & ? & $22 \cdot 0$ & $25 ?$ & $3 \cdot 7 ?$ & $16 \cdot 8$ & $23 \cdot 6$ & -6.8 & $13 \cdot 6$ & - & - \\
\hline 64.19 .1 .6 & $?$ ? & $18 \cdot 2$ & 22 & $6 \cdot 3 ?$ & $34 \cdot 6$ & $30 \cdot 0$ & $+4 \cdot 6$ & $20 \cdot 9$ & $8 \cdot 4$ & $2 \cdot 0$ \\
\hline Koo Loo 2.1 & ? & $2(1) \cdot 5$ & $26.5 ?$ & $7 \cdot 8$ & $38 \cdot 1$ & $36 \cdot 4$ & +1.7 & $29 \cdot 3$ & $\ldots$ & - \\
\hline 'Talbot 39' & ? & $18 \cdot 2$ & $24 ?$ & $6 \cdot 1$ & $33 \cdot 5$ & $38 \cdot 2$ & -47 & $31 \cdot 9$ & - & -- \\
\hline 90.6 .8 .1 & o & $19 \cdot 2$ ? & $24 \cdot 2 ?$ & $6 \cdot 5$ & $33 \cdot 9$ & $33 \cdot 9$ & $\cdot 0$ & $26 \cdot 0$ & -- & - \\
\hline $65 / 11(\mathrm{~b})$ & ? & $16 \cdot 0$ & 18 & $3 \cdot 7$ & $23 \cdot 1$ & $22 \cdot 6$ & +5 & $12 \cdot 5$ & -.- & - \\
\hline $65 / 11(\mathrm{a})$ & $?$ & $22 \cdot 0$ & $28 \cdot 5$ & $6 \cdot 2$ & $28 \cdot 2$ & $36 \cdot 5$ & $-8 \cdot 3$ & $29 \cdot \check{5}$ & $\ldots$ & - \\
\hline 1.8 .9 .84 & ${ }^{+}$ & $15 \cdot 2$ & 21 & $6 \cdot 0$ & $39 \cdot 5$ & $42 \cdot 6$ & $-3 \cdot 1$ & $38 \cdot 2$ & - & - \\
\hline 7.1 .8 .8 & r & $18 \cdot 0$ & $21 \cdot 5$ & $5 \cdot 4$ & $30 \cdot 0$ & $28 \cdot 7$ & $+1 \cdot 3$ & $19 \cdot 4$ & - & - \\
\hline 1.8 .9 .10 & to & $21 \cdot 0$ & 25 & $5 \cdot 9$ & $28 \cdot 1$ & $28 \cdot 5$ & $-\quad \cdot 4$ & $19 \cdot 1$ & - & -- \\
\hline 94.7 .25 .3 & $? \%$ & $20 \cdot 0$ & $2.5 \cdot 5$ & $7 \cdot 3$ & $36 \cdot 5$ & $35 \cdot 1$ & $+1 \cdot 4$ & $27 \cdot 5$ & $7 \cdot 0$ & $2 \cdot 0$ \\
\hline $95 \cdot 4 \cdot 11$ & $O_{+}^{+}$ & $21 \cdot 0$ & 26 & $7 \cdot 3$ & $34 \cdot 8$ & $32 \cdot 3$ & +2.5 & $23 \cdot 8$ & $\ldots$ & - \\
\hline Q. a & o & $19 \cdot 8$ & 24 & $6 \cdot 2$ & $31 \cdot 3$ & $30 \cdot 2$ & $+\overline{1} \cdot 1$ & $21 \cdot 2$ & - & - \\
\hline 83 & $q$ & $11 \cdot 0$ & 13 & $2 \cdot 4$ & $21 \cdot 8$ & $27 \cdot 7$ & -5.9 & $18 \cdot 2$ & $8 \cdot 2$ & $1 \cdot 8$ \\
\hline 90.6 .8 .2 & $q$ & $14 \cdot 3$ & 18 & $4 \cdot 5 ?$ & $31 \cdot 5$ & $33 \cdot 9$ & $-2 \cdot 4$ & $25 \cdot 9$ & $7 \cdot 0$ & $1 \cdot 9$ \\
\hline 61.\%.29.12 & t & $23 \cdot 2$ & 28 & $4 \cdot 9$ & $21 \cdot 1$ & $29 \cdot 8$ & $-8 \cdot 7$ & $20 \cdot 7$ & - & - \\
\hline 83.\%.98. 18 & $q$ & $18 \cdot 8$ & $25 \cdot 5 ?$ & $5 \cdot 8$ & $30 \cdot 9$ & $40 \cdot 8$ & $-9 \cdot 9$ & $35 \cdot 6$ & - & - \\
\hline $8 \%$ 1. 1. 12 & ot & $19 \cdot 0$ & $24 \cdot 5$ & $7 \cdot 3$ & $38 \cdot 4$ & $36 \cdot 1$ & $+2 \cdot 3$ & $28 \cdot 9$ & - & - \\
\hline A & o & $19 \cdot 0$ & 23 & $5 \cdot 3$ & $27 \cdot 9$ & $30 \cdot 1$ & $-2 \cdot 2$ & $21 \cdot 1$ & $8 \cdot 0$ & $1 \cdot 0$ \\
\hline B & ? के & $16 \cdot 2$ & 20 & $5 \cdot 3$ & $32 \cdot 7$ & $32 \cdot 0$ & $+\cdot 7$ & $23 \cdot 5$ & $12 \cdot 8$ & $3 \cdot 0$ \\
\hline C & $?$ & $21 \cdot 0 ?$ & $24 ?$ & $5 \cdot 3$ & $25 \cdot 2$ & $24 \cdot 3$ & $+\quad 9$ & $14 \cdot 3$ & $\ldots$ & - \\
\hline D & f & $8 \cdot 8$ & 13 & $3 \cdot 5$ & $39 \cdot 8$ & $48 \cdot 8$ & $-9 \cdot()$ & $47 \cdot 7$ & - & - \\
\hline $\mathrm{K}$ & o & $20 \cdot 0 ?$ & $25 ?$ & $6 \cdot 0$ & $30 \cdot 0$ & $33 \cdot 2$ & $-3 \cdot 2$ & $25 \cdot 0$ & - & - \\
\hline 5 & o & $13 \cdot 2$ & 19 & $5 \cdot 1$ & $38 \cdot 6$ & $46 \cdot 4$ & $-7 \cdot 8$ & $43 \cdot 9$ & - & - \\
\hline $\mathrm{E}$ & f & $19 \cdot 6$ ? & $23 \cdot 5 ?$ & $6 \cdot 3 ?$ & $32 \cdot 1$ & $29 \cdot 2$ & $+2 \cdot 9$ & $19 \cdot 9$ & - & - \\
\hline 1169 & $? 0^{+}$ & $22 \cdot 8 ?$ & $28 \cdot 5 ?$ & $7 \cdot 0 ?$ & $30 \cdot 7$ & $33 \cdot 2$ & $-2 \cdot 5$ & $25 \cdot 0$ & - & -- \\
\hline 1 & $0^{t}$ & $19 \cdot 5$ & 21 & $3 \cdot 9$ & $20 \cdot 0$ & $17 \cdot 4$ & $+2 \cdot 6$ & $7 \cdot 7$ & -- & - \\
\hline 2 & $? \hat{o}^{+}$ & $13 \cdot 0$ & 18 & $4 \cdot 6$ & $35 \cdot 4$ & $42 \cdot 8$ & $-7 \cdot 4$ & $38 \cdot 5$ & - & - \\
\hline 1 & $? \sigma^{*}$ & $15 \cdot 0$ & 18 & $3 \cdot 6$ & $24 \cdot 0$ & $29 \cdot 2$ & $-5 \cdot 2$ & $20 \cdot 0$ & - & - \\
\hline $2049^{b}$ & q & $14 \cdot 8$ & $17 \cdot 4$ & $4 \cdot 7$ & $31 \cdot 8$ & $27 \cdot 2$ & $+4 \cdot 6$ & $17 \cdot 6$ & - & - \\
\hline 979 & ô & $19 \cdot 1$ ? & $21 \cdot 5$ ? & $5 \cdot 2 ?$ & $27 \cdot 2$ & $22 \cdot 7$ & $+4 \cdot 5$ & $12 \cdot 6$ & - & - \\
\hline
\end{tabular}


Kathleen V. Ryley and Julia Bell

Nasal Bridge in the Chimpanzee.

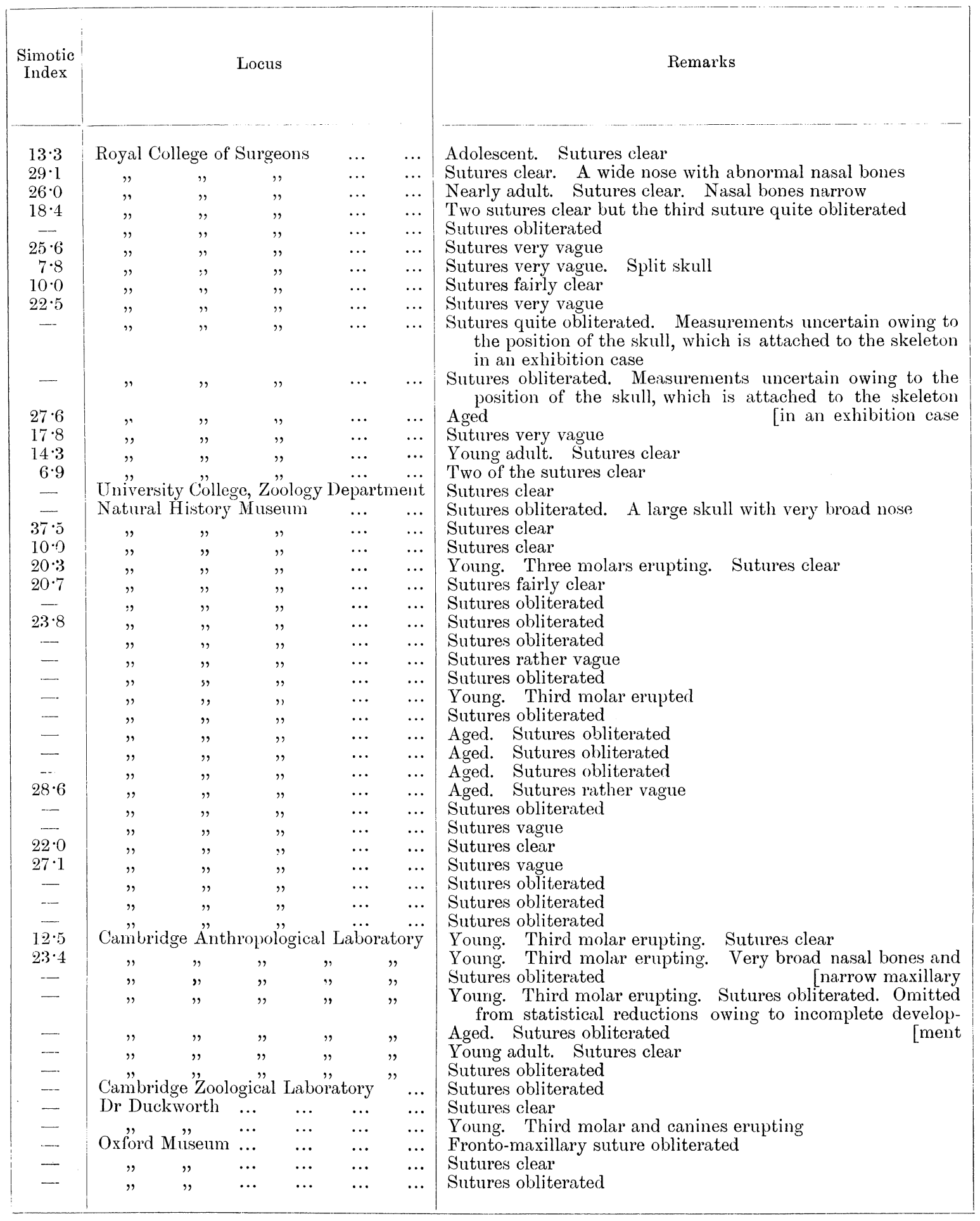


442 A Study of the Nasal Bridge in the Anthropoid Apes

'I'ABLE C. Characters of the

\begin{tabular}{|c|c|c|c|c|c|c|c|c|}
\hline \multirow{2}{*}{$\begin{array}{l}\text { Museum } \\
\text { Number }\end{array}$} & \multirow{2}{*}{ Sex } & \multirow{2}{*}{$\begin{array}{l}\text { Meso- } \\
\text { dacryal } \\
\text { Chord }\end{array}$} & \multirow{2}{*}{$\begin{array}{c}\text { Meso- } \\
\text { dacryal } \\
\text { Arc }\end{array}$} & \multirow{2}{*}{$\begin{array}{c}\text { Meso- } \\
\text { dacryal } \\
\text { Subtense }\end{array}$} & \multicolumn{4}{|c|}{ Mesodacryal Indices } \\
\hline & & & & & $a$ & $a^{\prime}$ & $a-a^{\prime}$ & $\beta$ \\
\hline 89 & o & $18 \cdot() ?$ & 36 & $11 \cdot 8$ ? & $65 \cdot 6$ & $79 \cdot 6$ & $-14 \cdot 0$ & $100 \cdot 0$ \\
\hline 41 & o & $16 \cdot 8$ & $59 ?$ & $12 \cdot 6$ & $75 \cdot 0$ & $160 \cdot 1$ & $-85 \cdot 1$ & $251 \cdot 2$ \\
\hline 37 & to & $15 \cdot 2$ & $34 \cdot 2$ & $10 \cdot 7$ & $70 \cdot 4$ & $93 \cdot 4$ & $-23 \cdot 0$ & $125 \cdot 0$ \\
\hline 38 & oे & $13 \cdot 8$ & $37 ?$ & $12 \cdot 9 ?$ & $93 \cdot 5$ & $116 \cdot 6$ & $-23 \cdot 1$ & $168 \cdot 1$ \\
\hline 38. A & o & $17 \cdot 5$ & 35 & $8 \cdot 6$ & $49 \cdot 1$ & $79 \cdot 6$ & $-30 \cdot 5$ & $100 \cdot 0$ \\
\hline 4.5 & o & $11 \cdot 8$ & 33 ? & $11 \cdot 4$ & $96 \cdot 6$ & $122 \cdot 7$ & $-26 \cdot 1$ & $179 \cdot 7$ \\
\hline 42 & t & $16 \cdot 8$ & $38 ?$ & $11 \cdot 0$ & $65 \cdot 5$ & $94 \cdot 1$ & $-28 \cdot 6$ & $126 \cdot 2$ \\
\hline $40 . \mathrm{A}$ & O & $10 \cdot 0$ & $25 \cdot 3$ & $7 \cdot 7$ & $77 \cdot 0$ & $108 \cdot 5$ & $-31 \cdot 5$ & $153 \cdot 0$ \\
\hline $40 . \mathrm{B}$ & $\stackrel{+}{+}$ & $13 \cdot 4$ & $35 \cdot 5$ & $9 \cdot 1$ & $67 \cdot 9$ & $114 \cdot 9$ & $-47 \cdot 0$ & $164 \cdot 9$ \\
\hline $40 . \mathrm{E}$ & 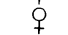 & $11 \cdot 6$ & 23 & $6 \cdot 8$ & $58 \cdot 6$ & $78 \cdot 7$ & $-20 \cdot 1$ & $98 \cdot 3$ \\
\hline 44 & $\stackrel{+}{+}$ & $13 \cdot 8$ & $27 \cdot 3$ & $9 \cdot 2$ & $66 \cdot 7$ & $78 \cdot 4$ & $-11 \cdot 7$ & $97 \cdot 8$ \\
\hline 44. A & $\stackrel{+}{+}$ & $12 \cdot 7$ & 27 & $9 \cdot \overline{7}$ & $76 \cdot 4$ & $86 \cdot 6$ & $-10 \cdot 2$ & $112 \cdot 6$ \\
\hline 46 & $q$ & $12 \cdot 0$ & $28 \cdot 2$ & $9 \cdot 3$ & $77 \cdot 5$ & $98 \cdot 9$ & $-21 \cdot 4$ & $135 \cdot 0$ \\
\hline- & to & $16 \cdot 6$ & 29 & $8 \cdot 5$ & $51 \cdot 2$ & $65 \cdot 2$ & $-14 \cdot 0$ & $74 \cdot 7$ \\
\hline 59.8 .16 .2 & 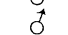 & $11 \cdot 0$ & $3: 3$ & $12 \cdot 7$ & $115 \cdot \tilde{5}$ & $133 \cdot 4$ & $-17 \cdot 9$ & $200 \cdot 0$ \\
\hline 1101 & t & $12 \cdot 0$ & 38 & $14 \cdot 7$ & 122.5 & $142 \cdot 2$ & $-19 \cdot 7$ & $216 \cdot 7$ \\
\hline 9Q. 11.5 .14 & o & $18 \cdot 8$ & 31 & $9 \cdot 7$ & $51 \cdot 6$ & $59 \cdot 4$ & $-7 \cdot 8$ & $64 \cdot 9$ \\
\hline 55 & $\hat{0}$ & $17 \cdot 1$ & 26 & $7 \cdot 7$ & $45 \cdot 0$ & $51 \cdot 6$ & $-6 \cdot 6$ & $52 \cdot 1$ \\
\hline $108 \%$ & $q$ & $11 \cdot 4$ & 31 & $10 \cdot 9$ & $95 \cdot 6$ & $118 \cdot 6$ & $-2: 3 \cdot 0$ & $171 \cdot 9$ \\
\hline 1179. a & to & $10 \cdot 2$ & 29 & $10 \cdot 5$ & $102 \cdot 9$ & $125 \cdot 2$ & $-22 \cdot 3$ & $184 \cdot 3$ \\
\hline $3 . \mathrm{b}$ & o & $13 \cdot 8$ & $31 !$ & $10 \cdot 0$ & $72 \cdot 5$ & $93 \cdot 2$ & $-20 \cdot 7$ & $124 \cdot 6$ \\
\hline -.. & $? \hat{0}$ & $14 \cdot 0$ & $35 ?$ & $14 \cdot 5$ & $103 \cdot 6$ & $106 \cdot 9$ & $-3 \cdot 3$ & $150 \cdot 0$ \\
\hline 3. $\mathrm{i}$ & o & $15 \cdot 2$ & $30 \cdot \tilde{5}$ & $11 \cdot 2$ & $73 \cdot 7$ & $80 \cdot 0$ & $-6: 3$ & $100 \cdot 7$ \\
\hline 92.11 .5 .4 & o & $17 \cdot 0$ & 35 & $11 \cdot 6$ & $68 \cdot 2$ & $82 \cdot 9$ & $-14 \cdot 7$ & $105 \cdot 9$ \\
\hline ภ. $\mathrm{b}^{2}$ & ? के & $14 \cdot 0$ & 33 & $12 \cdot 4$ & $88 \cdot 6$ & $99 \cdot 3$ & $-10 \cdot 7$ & $135 \cdot 7$ \\
\hline$\because \mathrm{m}$ & o & $13 \cdot 4$ & 24 & $10 \cdot 5$ & $78 \cdot 4$ & $67 \cdot 8$ & $+10 \cdot 6$ & $79 \cdot 1$ \\
\hline 3⿻ & o & $17 \cdot 7$ & 40 & $13 \cdot 1$ & $74 \cdot 0$ & $94 \cdot 0$ & $-20 \cdot 0$ & $126 \cdot 0$ \\
\hline Y9. 11. 21.24 & 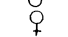 & $13 \cdot 0 ?$ & $333 \cdot 5 ?$ & $11 \cdot 1$ & $85 \cdot 4$ & $111 \cdot 1$ & $-25 \cdot 7$ & $157 \cdot 7$ \\
\hline 52. 12.26 & $\hat{o}$ & $160 ?$ & $35 ?$ & $9 \cdot 6$ & $60 \cdot 0$ & $90 \cdot 0$ & $-30 \cdot 0$ & $118 \cdot 8$ \\
\hline 8. \%. $1 \% .1$ & के & $14 \cdot 8$ & 26 & $9 \cdot 5$ & $64 \cdot 2$ & $65 \cdot 8$ & $-1 \cdot 6$ & $75 \cdot 7$ \\
\hline 98. ․ 28. 11 & ô & $15 \cdot 0$ & 32 & $10 \cdot 7$ & $71 \cdot 3$ & $87 \cdot 0$ & $-15 \cdot 7$ & $113 \cdot 3$ \\
\hline 3. j & t & $19 \cdot 7$ & 34 & $10 \cdot 6$ & $53 \cdot 8$ & $64 \cdot 0$ & $-10 \cdot 2$ & $72 \cdot 6$ \\
\hline o. a & to & $18 \cdot 0$ & 37 & $13 \cdot 4$ & $74 \cdot 4$ & $82 \cdot 8$ & $-8 \cdot 4$ & $105 \cdot 6$ \\
\hline O. $\mathrm{d}$ & o & $15 \cdot 6 !$ & 39 & $11 \cdot 9$ & $76 \cdot 3$ & $106 \cdot 9$ & $-30 \cdot 6$ & $150 \cdot 0$ \\
\hline 3. $\mathrm{q}^{2}$ & o & $12 \cdot 4$ & 25 & $9 \cdot 4$ & $75 \cdot 8$ & $80 \cdot 5$ & $-4 \cdot 7$ & $101 \cdot 6$ \\
\hline 3. $\mathrm{c}^{2}$ & o & $13 \cdot 8$ & $32 ?$ & $10 \cdot 9$ & $79 \cdot 0$ & $97 \cdot 2$ & $-18 \cdot 2$ & $131 \cdot 9$ \\
\hline 92.11 .5 .5 & o & $20 \cdot 8$ & 37 & $11 \cdot 0$ & $52 \cdot 9$ & $67 \cdot 1$ & $-14 \cdot 2$ & 77.9 \\
\hline 68.16.4? & to & $16 \cdot 0$ & $28 \cdot 5 ?$ & $10 \cdot 2$ & $63 \cdot 8$ & $67 \cdot 2$ & $-3 \cdot 4$ & $78 \cdot 1$ \\
\hline 98.11 .5 .8 & to & $20 \cdot 8$ & 32 & $8 \cdot 4$ & $40 \cdot 4$ & $52 \cdot \overline{7}$ & $-12 \cdot 3$ & $53 \cdot 9$ \\
\hline 85. 20. \%. 1 & s & $16 \cdot 0$ & $29 ?$ & $9 \cdot 0$ & $56 \cdot 3$ & $69 \cdot 0$ & $-12 \cdot 7$ & $81 \cdot 3$ \\
\hline 85. 2. a'. & & $10 \cdot 8$ & 25 & $9 \cdot 5$ & $88 \cdot 0$ & $97 \cdot 0$ & $-9 \cdot 0$ & $131 \cdot 5$ \\
\hline 4 & $\hat{\delta}$ & $14 \cdot 7$ & $34 ?$ & $11 \cdot 8$ & $80 \cdot 3$ & $96 \cdot 9$ & $-16 \cdot 6$ & $131 \cdot 3$ \\
\hline 3 & ? & $16 \cdot 0$ & 34 & $12 \cdot 4$ & $77 \cdot 5$ & $86 \cdot 6$ & $-9 \cdot 1$ & $112 \cdot 5$ \\
\hline 2 & $?$ & $13 \cdot 0$ & $325 ?$ & $11 \cdot 4$ & $87 \cdot 7$ & $106 \cdot 9$ & $-19 \cdot 2$ & $150 \cdot 0$ \\
\hline 1 & of & $15 \cdot 7 ?$ & 33 ? & $12 \cdot 2$ & $77 \cdot 7$ & $85 \cdot 3$ & $-7 \cdot 6$ & $110 \cdot 2$ \\
\hline 5 & $? 9$ & $10 \cdot 5 ?$ & $26 ?$ & $9 \cdot 7$ & $92 \cdot 4$ & $105 \cdot 6$ & $-13 \cdot 2$ & $147 \cdot 6$ \\
\hline 1160. A & $\hat{o}$ & $15 \cdot 0 ?$ & $26 ?$ & $7 \cdot 1$ & $47 \cdot 3$ & $64 \cdot 4$ & $-17 \cdot 1$ & $73 \cdot 3$ \\
\hline $1160 . \mathrm{G}$ & of & $13 \cdot 0$ & 32 & $11 \cdot 7$ & $90 \cdot 0$ & $104 \cdot 9$ & $-14 \cdot 9$ & $146 \cdot 2$ \\
\hline 1160. D & o & $12 \cdot 5$ & 33 & $11 \cdot 7$ & $93 \cdot 6$ & $114 \cdot 4$ & $-20 \cdot 8$ & $164 \cdot 0$ \\
\hline 1163. C & o & $12 \cdot 0$ & 26 & $8 \cdot 4$ & $70 \cdot 0$ & $88 \cdot 9$ & $-18 \cdot 9$ & $116 \cdot 7$ \\
\hline 1196 & $? \stackrel{+}{+}$ & $9 \cdot 8$ & 34 & $12 \cdot 0$ & $122 \cdot 4$ & $157 \cdot 9$ & $-35 \cdot 5$ & $246 \cdot 9$ \\
\hline D. 1 & o & $15 \cdot 0$ & 28 & $9 \cdot 3$ & $62 \cdot 0$ & $72 \cdot 1$ & $-10 \cdot 1$ & $86 \cdot 7$ \\
\hline D. $\mathscr{2}$ & to & $15 \cdot 0$ & $32 ?$ & $10 \cdot 0$ & $66 \cdot 7$ & $87 \cdot 0$ & $-20 \cdot 3$ & $113 \cdot 3$ \\
\hline 2 & o & $14 \cdot 7 ?$ & 32 & $10 \cdot 3$ & $70 \cdot 1$ & $89 \cdot 4$ & $-19 \cdot 3$ & $117 \cdot 7$ \\
\hline A & o & $17 \cdot \tilde{5}$ & 43 & $15 \cdot 7$ & $89 \cdot 7$ & $104 \cdot 6$ & $-14 \cdot 9$ & $145 \cdot 7$ \\
\hline $1^{\mathrm{a}}$ & q & $11 \cdot 0$ & 27 & $8 \cdot 4$ & $76 \cdot 4$ & $104 \cdot 5$ & $-28 \cdot 1$ & $145 \cdot 5$ \\
\hline $2043^{2 a}$ & o & $9 \cdot 0$ & $28 ?$ & $10 \cdot 1$ & $112 \cdot 2$ & $139 \cdot 2$ & $-27 \cdot 0$ & $211 \cdot 1$ \\
\hline 2043 & ô & $14 \cdot 7$ & $41 ?$ & $15 \cdot 3$ & $104 \cdot 1$ & $122 \cdot 3$ & $-18 \cdot 2$ & $178 \cdot 9$ \\
\hline 1 & o & $15 \cdot 7$ & $35 \cdot 5$ & $11 \cdot 9$ & $75 \cdot 8$ & $94^{\circ} 0$ & $-18 \cdot 2$ & $126 \cdot 1$ \\
\hline
\end{tabular}


Kathleen V. Ryley anj) Julia Bell

\section{Nasal Bridge in the Orang-utan.}

\begin{tabular}{|c|c|c|c|c|c|c|c|}
\hline \multicolumn{7}{|c|}{ Locus } & \multirow[b]{2}{*}{ t skull with ill-fitting ha } \\
\hline \multicolumn{5}{|c|}{ Royal College of Surgeons } & $\ldots$ & $\ldots$ & \\
\hline , & & $"$ & \multicolumn{2}{|l|}{ " } & $\ldots$ & $\ldots$ & Sutures very vague \\
\hline$"$ & & $"$ & \multicolumn{2}{|l|}{$"$} & $\ldots$ & $\ldots$ & Sutures clear \\
\hline$"$ & & $"$ & \multirow{2}{*}{\multicolumn{2}{|c|}{$"$}} & ... & $\ldots$ & Sutures clear \\
\hline$"$ & & $"$ & & & .. & $\cdots$ & Sutures clear \\
\hline$"$ & & $"$ & \multicolumn{2}{|l|}{$"$} & $\ldots$ & $\ldots$ & Sutures clear \\
\hline$"$ & & 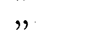 & \multicolumn{2}{|l|}{$"$} & ... & $\cdots$ & Sutures clear \\
\hline " & & $"$ & \multirow{2}{*}{$"$} & & $\ldots$ & $\ldots$ & Sutures vague. Teeth misplaced \\
\hline$"$ & & $"$ & & & $\ldots$ & $\ldots$ & Sutures clear \\
\hline$"$ & & $"$ & $"$ & & $\ldots$ & $\ldots$ & Young. Sutures clear. Third molars erupting \\
\hline$"$ & & $"$ & \multicolumn{2}{|l|}{," } & $\ldots$ & $\ldots$ & Adult, but one third molar never erupted. Sutures clear' \\
\hline \multirow{2}{*}{\multicolumn{4}{|c|}{$", \quad, \quad, \quad}}$, & & .. & $\ldots$ & Sutures clear \\
\hline & & & & \multicolumn{3}{|c|}{ University C̈ollege, Z̈oology Department } & Sutures clear \\
\hline \multicolumn{5}{|c|}{ Natural History Museum ... } & $\begin{array}{l}\text { Depar } \\
\quad \ldots\end{array}$ & ent & $\begin{array}{l}\text { Lacrymo-maxillary suture not very clear } \\
\text { Sutures clear }\end{array}$ \\
\hline 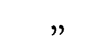 & & , & , & $\ldots$ & $\ldots$ & $\cdots$ & $\begin{array}{l}\text { Sutue } \\
\text { No nasal bones. Maxillary bones meeting with ossicle on right }\end{array}$ \\
\hline " & & $"$ & $"$ & ... & $\ldots$ & $\ldots$ & Sutures fairly clear. Unusually broad nose for an orang \\
\hline$"$ & & $"$ & $"$ & $\cdots$ & $\cdots$ & $\cdots$ & $\begin{array}{l}\text { Very aged. A large skull with broad nose and much deve- } \\
\text { loped crests. Sutures vague }\end{array}$ \\
\hline " & & " & $"$ & $\ldots$ & $\ldots$ & $\ldots$ & Fragment only. Sutures clear \\
\hline ” & & $"$ & $"$ & $\ldots$ & $\ldots$ & $\ldots$ & In the Whale Room \\
\hline ", & & , & $"$ & $\ldots$ & $\ldots$ & $\ldots$ & \\
\hline$"$ & & $"$ & $"$ & $\ldots$ & $\ldots$ & $\ldots$ & In the Whale Room \\
\hline$"$ & & 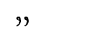 & $"$ & $\ldots$ & $\ldots$ & $\ldots$ & Sutures clear \\
\hline$"$ & & $"$ & ", & $\ldots$ & $\ldots$ & $\ldots$ & Sutures clear \\
\hline$"$ & & $"$ & $"$ & $\ldots$ & $\ldots$ & $\ldots$ & Aged. Sutures rather vague \\
\hline ” & & $"$ & $"$ & $\ldots$ & $\ldots$ & $\ldots$ & Lacrymo-maxillary suture obliterated \\
\hline$"$ & & $"$ & $"$ & ... & $\ldots$ & $\ldots$ & Lacrymo-maxillary suture obliterated \\
\hline$"$ & & $"$ & ," & $\ldots$ & $\ldots$ & $\ldots$ & Sutures clear. No nasal bones \\
\hline$"$ & & $"$ & $"$ & $\ldots$ & $\ldots$ & $\ldots$ & Aged. Sutures clear \\
\hline " & & $"$ & $"$ & ... & $\ldots$ & $\ldots$ & Aged. Sutures clear. Very long "spindle" nasal bone and \\
\hline$"$ & & $"$ & $"$ & $\ldots$ & $\ldots$ & $\ldots$ & A large skull with rather vague sutures \\
\hline$"$ & & $"$ & $"$ & $\ldots$ & $\ldots$ & $\ldots$ & Lacrymo-maxillary suture obliterated \\
\hline$"$ & & $"$ & $"$ & $\ldots$ & $\ldots$ & $\ldots$ & Sutures clear \\
\hline$"$ & & $"$ & $"$ & $\ldots$ & $\ldots$ & $\ldots$ & Sutures clear \\
\hline$"$ & & ", & ", & $\ldots$ & ... & ... & Sutures clear. Nasal bones very narrow \\
\hline " & & $"$ & $"$ & $\ldots$ & $\ldots$ & $\ldots$ & Lacrymo-maxillary suture obliterated \\
\hline$"$ & & $"$ & $"$ & $\ldots$ & $\ldots$ & $\ldots$ & $\begin{array}{l}\text { Sutures clear. Very wide nose [bones extremely narrow } \\
\text { [ }\end{array}$ \\
\hline$"$ & & $"$ & $"$ & ... & $\ldots$ & $\ldots$ & Broken orbits and therefore measurements uncertain. Nasal \\
\hline$"$ & & $"$ & $"$ & $\ldots$ & $\ldots$ & $\ldots$ & Sutures clear. Very large skull \\
\hline$"$ & & $"$ & $"$ & $\cdots$ & $\cdots$ & $\cdots$ & Sutures clear \\
\hline "̈pri & idoe & $"$ & & & $\cdots$ & $\ldots$ & Young adult. Sutures clear \\
\hline Cambri & & Anth & hropole & gical & Labo & $01 \mathrm{y}$ & Young adult. Sutures clear \\
\hline " & & $"$ & & 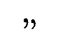 & & & Sutures clear \\
\hline$"$ & & $"$ & & $"$ & & & Young adult. Sutures clear \\
\hline$"$ & & $"$ & & $"$ & & & Lacrymo-maxillary suture absent, other sutures clear \\
\hline$"$ & & $"$ & & $"$ & & & $\begin{array}{l}\text { Young. Third molar and canine erupting. Split skull and } \\
\text { therefore uncertain measurements. Believed to be large } \\
\text { species. Omitted from statistical reductions }\end{array}$ \\
\hline Cambri & idge & Zoolo & gical 1 & abora & atory & $\ldots$ & Right lacrymo-maxillary suture obliterated, left placed high on \\
\hline " & & , & , & , & & $\ldots$ & $\begin{array}{l}\text { Sutures clear } \\
\text { [side of nose }\end{array}$ \\
\hline$"$ & & , & , & 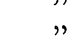 & & $\ldots$ & Young adult. Four upper molars on both sides and four lower \\
\hline$"$ & & , & " & " & & $\ldots$ & Sutures clear $\quad$ [molars on left side \\
\hline$"$ & & & & $"$ & & .. & $\begin{array}{l}\text { Young. Third molar and canines erupting. Believed to be } \\
\text { large species. Omitted from statistical reductions }\end{array}$ \\
\hline Dr Du & ackwo & orth & $\ldots$ & ... & $\ldots$ & $\ldots$ & Sutures clear \\
\hline$"$ & , & & ... & $\ldots$ & $\cdots$ & $\ldots$ & Sutures clear \\
\hline$"$ & $"$ & & ... & ... & ... & $\ldots$ & Sutures clear \\
\hline " & ” & & $\ldots$ & $\ldots$ & $\ldots$ & $\ldots$ & No nasal bones. Maxillary bones much developed \\
\hline & & & $\ldots$ & $\ldots$ & $\ldots$ & $\ldots$ & Sutures clear [incisors and canines \\
\hline Oxford & Mús & seum & $\ldots$ & $\ldots$ & $\ldots$ & $\ldots$ & Young adult. Bicuspids on each side misplaced behind lateral \\
\hline , & , & & $\ldots$ & $\ldots$ & $\ldots$ & $\ldots$ & Young adult. Sutures clear \\
\hline$"$ & $"$ & & ... & $\ldots$ & $\ldots$ & $\ldots$ & Sutures clear. ?Ossicle at dacryon on left side \\
\hline
\end{tabular}


444 A Study of the Nasal Bridge in the Anthropoid Apes

T'ABLE D. Characters of the Nasal Bridge

\begin{tabular}{|c|c|c|c|c|c|c|c|c|c|c|}
\hline \multirow{2}{*}{$\begin{array}{l}\text { Museum } \\
\text { Number }\end{array}$} & \multirow{2}{*}{ Sex } & \multirow{2}{*}{$\begin{array}{l}\text { Meso- } \\
\text { dacryal } \\
\text { Chord }\end{array}$} & \multirow{2}{*}{$\begin{array}{l}\text { Meso- } \\
\text { dacryal } \\
\text { Are }\end{array}$} & \multirow{2}{*}{$\begin{array}{c}\text { Meso- } \\
\text { dacryal } \\
\text { Subtense }\end{array}$} & \multicolumn{4}{|c|}{ Mesodacryal Indices } & \multirow{2}{*}{$\begin{array}{c}\text { Simotic } \\
\text { Choord }\end{array}$} & \multirow{2}{*}{$\begin{array}{l}\text { Simotic } \\
\text { Subtense }\end{array}$} \\
\hline & & & & & $a$ & $a^{\prime}$ & $a-a^{\prime}$ & $\beta$ & & \\
\hline 6.10 .4 .1 & ot & $13 \cdot 2$ & 20 & $4 \cdot 3$ & $32 \cdot 6$ & $51 \cdot 2$ & $-18 \cdot 6$ & 51.5 & -... & - \\
\hline 58. 3.13.7 & 3 & $11 \cdot 0$ & 16 & $3 \cdot 5$ & $31 \cdot 8$ & $47 \cdot 4$ & $-15 \cdot 6$ & $45 \cdot 5$ & $5 \cdot 5$ & $\cdot 9$ \\
\hline 38.3 .13 .5 & $\ddot{o}$ & $9 \cdot 0$ & 10 & $1 \cdot 2$ & $13 \cdot 3$ & $21 \cdot 2$ & $-7 \cdot 9$ & $11 \cdot 1$ & $4 \cdot 3$ & 3 \\
\hline 81. 3. 15.1 & oै & $11 \cdot 8$ & 17 & $3 \cdot 9$ & $33 \cdot 1$ & $46 \cdot 5$ & $-13 \cdot 4$ & $44 \cdot 1$ & $6 \cdot 6$ & $\cdot 8$ \\
\hline & $? \hat{0}$ & $15 \cdot 0$ & 20 & $4 \cdot 3$ & $28 \cdot 7$ & $39 \cdot 2$ & $-10 \cdot 5$ & $33 \cdot 3$ & $5 \cdot 4$ & $\cdot 2$ \\
\hline $6 \% 11.19 .5$ & 3 & $15 \cdot 8$ & 22 & $3 \cdot 9$ & $24 \cdot 7$ & $43 \cdot 3$ & $-18 \cdot 6$ & $39 \cdot 2$ & - & - \\
\hline 8. 7.201 & $\hat{o}$ & $12 \cdot 5$ & $17 \cdot 5$ & $3 \cdot 5$ & $28 \cdot 0$ & $43 \cdot 8$ & $-15 \cdot 8$ & $40 \cdot 0$ & - & - \\
\hline 58 & o & $16 \cdot 0 ?$ & $23 \cdot 8 ?$ & $5 \cdot 9 ?$ & $36 \cdot 9$ & $49 \cdot 5$ & $-12 \cdot 6$ & $48 \cdot 8$ & $8 \cdot 0 ?$ & $\cdot 7 ?$ \\
\hline 59 & to & $14 \cdot 2$ & $20 \cdot 5$ & $4 \cdot 5$ & $31 \cdot 7$ & $46 \cdot 7$ & $-15 \cdot 0$ & $44 \cdot 4$ & $6 \cdot 2$ & $\cdot 8$ \\
\hline 64 & o & $10 \cdot 0$ & 15 & $3 \cdot 3$ & $33 \cdot 0$ & $50 \cdot 3$ & $-17 \cdot 3$ & $50 \cdot 0$ & $5 \cdot 6$ & $\cdot 5$ \\
\hline 65 & 3 & $9 \cdot 8$ & 15 & $4 \cdot 1$ & $41 \cdot 8$ & $52 \cdot 2$ & $-10 \cdot 4$ & $53 \cdot 1$ & $5 \cdot 5$ & $\cdot 3$ \\
\hline 66 & $\ddot{z}$ & $9 \cdot 9$ & 15 & $4 \cdot 3$ & $43 \cdot 4$ & $51 \cdot 2$ & $-7 \cdot 8$ & $51 \cdot 5$ & $4 \cdot 3$ & $\cdot 4$ \\
\hline ro & 3 & $11 \cdot 0$ & $16 \cdot 5 ?$ & $3 \cdot 6$ & $32 \cdot 7$ & $50 \cdot 3$ & $-17 \cdot 6$ & $50 \cdot 0$ & $5 \cdot 8 ?$ & $\cdot 3$ \\
\hline 71 & 0 & $9 \cdot 8$ & $13 \cdot 5$ & $2 \cdot 8$ & $28 \cdot 6$ & $42 \cdot 3$ & $-13 \cdot 7$ & $37 \cdot 8$ & $6 \cdot 0$ & $\cdot 4$ \\
\hline & фq & $9 \cdot 0$ & $14 \cdot 2$ & $3 \cdot 6$ & $40 \cdot 0$ & $55 \cdot 1$ & $-15 \cdot 1$ & $57 \cdot 8$ & $4 \cdot 0$ & 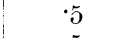 \\
\hline (5. a) $43.1 \%$. 5 & 3 & $11 \cdot 4$ & $16 \cdot 5$ & $4 \cdot 2$ & $36 \cdot 8$ & $46 \cdot 9$ & $-10 \cdot 1$ & $44 \cdot 8$ & $4 \cdot 0 ?$ & $\cdot 5$ \\
\hline 11. 2.24 .4 & o & $9 \cdot 9$ & 20 & $5 \cdot 7$ & $57 \cdot 6$ & $80 \cdot 8$ & $-23 \cdot 2$ & $102 \cdot 0$ & $6 \cdot 0$ & $1 \cdot 0$ \\
\hline 8. 11.1.1 & 3 & $13 \cdot 0 ?$ & $22 ?$ & $5 \cdot 4$ & $41 \cdot \tilde{5}$ & $62 \cdot 0$ & $-20 \cdot 5$ & $69 \cdot 2$ & - & - \\
\hline 90.1 .28 .1 & $\ddot{b}$ & $12 \cdot 0$ & $15 \cdot 5$ & $1 \cdot 7$ & $14 \cdot 2$ & $36 \cdot 3$ & $-22 \cdot 1$ & $29 \cdot 2$ & $6 \cdot 0$ & $-\cdot 1$ \\
\hline $109^{\text {r a }}$ & 3 & $11 \cdot 8$ & $17 \cdot 3$ & $3 \cdot 9$ & $33 \cdot 1$ & $48 \cdot 1$ & $-15 \cdot 0$ & $46 \cdot 6$ & $5 \cdot 3$ & $\cdot 1$ \\
\hline $1097^{n /} \mathrm{c}$ & o & $10 \cdot 4$ & $17 \cdot 4$ ? & $4 \cdot 6 ?$ & $44 \cdot 2$ & $60 \cdot 8$ & $-16 \cdot 6$ & $67 \cdot 3$ & - & -- \\
\hline 9.1 .51 & d & $10 \cdot 3 ?$ & $17 \cdot 3 !$ & $4 \cdot 3$ & $41 \cdot 7$ & $61 \cdot 3$ & $-19 \cdot 6$ & $68 \cdot 0$ & $4 \cdot 3$ ? & $\cdot 2$ \\
\hline 10106 a & $\ddot{~}$ & $9 \cdot 3$ & 17 & $4 \cdot 0$ & $43 \cdot 0$ & $69 \cdot 9$ & $-26 \cdot 9$ & $82 \cdot 8$ & $5 \cdot 7 ?$ & $\cdot 1$ \\
\hline 0.10 .1 .8 & $q$ & $11 \cdot 0$ ? & $18 ?$ & $4 \cdot 4$ & $40 \cdot 0$ & $58 \cdot 6$ & $-18 \cdot 6$ & $63 \cdot 6$ & - & -- \\
\hline 10. 10.1 .6 & to & $10 \cdot 7$ & 18 & $3 \cdot 1$ & $29 \cdot 0$ & $61 \cdot 4$ & $-32 \cdot 4$ & $68 \cdot 2$ & $5 \cdot 0 ?$ & $\cdot 2$ ? \\
\hline 79.8 .30 .1 & 3 & $11 \cdot 3$ & 16 & $3 \cdot 5$ & $31 \cdot 0$ & $44 \cdot 8$ & $-13 \cdot 8$ & $41 \cdot 6$ & $6 \cdot 0$ & $\cdot 8$ \\
\hline 10.10.1.7 & $\stackrel{\circ}{q}$ & $11 \cdot 4$ & $16 \cdot 6$ & $3 \cdot 0$ & $26 \cdot 3$ & $47 \cdot 5$ & $-21 \cdot 2$ & $45 \cdot 6$ & $5 \cdot 2$ & 5 \\
\hline 54.10 .5 .1 & 3 & $12 \cdot 8$ & 20 & $3 \cdot 7$ & $28 \cdot 9$ & $54 \cdot 2$ & $-25 \cdot 3$ & $56 \cdot 3$ & - & - \\
\hline$\left\{\begin{array}{l}1006 \mathrm{~d} \\
48.1 .27 .46\end{array}\right.$ & $\bar{\sigma}$ & $11 \cdot 0 ?$ & 19 & $4 \cdot 5$ & $40 \cdot 9$ & $64 \cdot 0$ & $-23 \cdot 1$ & $72 \cdot 7$ & - & - \\
\hline 60.5 .4 .48 & 3 & $9 \cdot() ?$ & 16 & $3 \cdot 7$ & $41 \cdot 1$ & $67 \cdot 0$ & $-25 \cdot 9$ & $77 \cdot 8$ & - & - \\
\hline 60.5 .4 .49 & 3 & $9 \cdot 8$ & 17 & $4 \cdot 2$ & $42 \cdot 9$ & $64 \cdot 5$ & $-22 \cdot 6$ & $73 \cdot 5$ & -- & - \\
\hline $1095 \mathrm{a}$ & $\overline{3}$ & $9 \cdot 0$ & 12 & $2 \cdot 4$ & $26 \cdot 7$ & $39 \cdot 2$ & $-12 \cdot 5$ & $33 \cdot 3$ & $5 \cdot 9$ & $\cdot 9$ \\
\hline 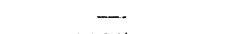 & 3 & $11 \cdot 0$ & $17 \cdot 5$ & $3 \cdot 7$ & $33 \cdot 6$ & $55 \cdot 9$ & $-22 \cdot 3$ & $59 \cdot 1$ & - & -. \\
\hline $1095 \mathrm{c}$ & 3 & $9 \cdot 0$ & $15 \cdot 3$ & $4 \cdot 5$ & $50 \cdot 0$ & $62 \cdot 4$ & $-12 \cdot 4$ & $70 \cdot 0$ & $6 \cdot 6$ & $\cdot 7$ \\
\hline
\end{tabular}

The symbol $\delta$ denotes sex unknown. 
Kathleen V. Ryley and Julia Bell

in the Gibbons, Hylobates and Symphalangus.

\begin{tabular}{|c|c|c|c|c|}
\hline $\begin{array}{l}\text { Simotic } \\
\text { Index }\end{array}$ & \multicolumn{3}{|c|}{ Locus } & Remarks \\
\hline - & Natural & I History & Museum & Hylobates syndactylus. From Pahang. Sutures obliterated \\
\hline $\begin{array}{r}16 \cdot 4 \\
7 \cdot 0\end{array}$ & " & $"$ & $"$ & From Sumatra. Very young \\
\hline $\begin{array}{r}7 \cdot 0 \\
12 \cdot 1\end{array}$ & $"$ & $"$ & $"$ & $\begin{array}{l}\text { Symphalangus. From Sumatra. Young adult } \\
\text { Symphalangus. From Sumatra. Asymmetric lacrymal bones }\end{array}$ \\
\hline $3 \cdot 7$ & $"$ & $"$ & $"$ & $\begin{array}{l}\text { Symphalangus syndactylus. From Sumatra. Old. Sutures } \\
\text { vague }\end{array}$ \\
\hline- & $"$ & $\because$ & " & $\begin{array}{l}\text { Symphalangus syndactylus. Sutures vague. Nasalis absent } \\
\text { at the bridge }\end{array}$ \\
\hline - & $"$ & $"$ & $"$ & $\begin{array}{l}\text { Symphalangus syndactylus. From Pahang. Very old. Sutures } \\
\text { quite obliterated }\end{array}$ \\
\hline $8 \cdot 8$ & Royal C & Jollege of & Surgeons & Symphalangus. Old. Sutures obliterated \\
\hline $12 \cdot 9$ & ” & $"$ & " & Symphalangus. Old. Sutures rather vague \\
\hline $8 \cdot 9$ & $"$ & $"$ & 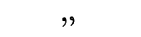 & Hylobates sp. \\
\hline $\begin{array}{l}5 \cdot 5 \\
9 \cdot 3\end{array}$ & $"$ & $"$ & $"$ & $\begin{array}{l}\text { Hylobates sp. Young } \\
\text { Hylobates lar. Adult }\end{array}$ \\
\hline $5 \cdot 2$ & $"$ & $"$ & $"$ & Hylobates sp. Old. Sutures vague, nasal sutures obliterated \\
\hline $6 \cdot 7$ & $"$ & 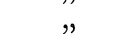 & 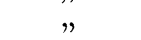 & Hylobates sp. Young \\
\hline $12 \cdot 5$ & & & & Hylobates sp. Very young \\
\hline $12 \cdot 5$ & Natural & 1 History & Museum & Hylobates leuciscus from Malacea. Very old. Sutures oblite- \\
\hline $16 \cdot 7$ & $"$ & $"$ & 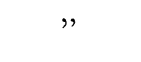 & $\begin{array}{l}\text { Hylobates hainanus from Hainan. Young. Peculiar lacry- } \\
\text { mal bones }\end{array}$ \\
\hline- & $"$ & $"$ & 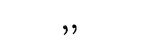 & Hylobates gabriella from Annam. Old. Sutures quite oblite- \\
\hline$-1 \cdot 7$ & , & $"$ & $"$ & Hylobates mulleri from N. Borneo. Nasal sutures vague \\
\hline $1 \cdot 9$ & $"$ & $"$ & $"$ & $\begin{array}{l}\text { Hylobates agilis } \\
\text { Hylobates agilis from Sumatra. Sutures obliterated }\end{array}$ \\
\hline $4 \cdot 7$ & $"$ & $"$ & $"$ & Hylobates leuciscus from Java. Sutures obliterated \\
\hline $1 \cdot 8$ & $"$ & $"$ & $"$ & $\begin{array}{l}\text { Hylobates hoolock. Young. Apparently no nasals, but pro- } \\
\text { cess of frontal }\end{array}$ \\
\hline$\overline{4 \cdot 0}$ & $"$ & $"$ & $"$ & $\begin{array}{lll}\text { Hylobates lar. } & \text { From Malay Peninsula. } & \text { Sutures obliterated } \\
\text { Hylobates lar. } & \text { From Nalay Peninsula. } & \text { Sutures obliterated }\end{array}$ \\
\hline $13 \cdot 3$ & $"$ & $"$ & $"$ & Hylobates leuciscus from Porneo \\
\hline $9 \cdot 6$ & $"$ & $"$ & 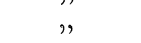 & Hylobates lar. From Malay Peninsula \\
\hline - & $"$ & $"$ & $"$ & Hylobates lar. From Malacca. Sutures obliterated \\
\hline 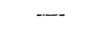 & $"$ & " & $"$ & Hylobates sp. Ridge on maxilla. Nasal sutures obliterated \\
\hline 一 & $"$ & $"$ & $"$ & Hylobates lar. From Malacea. Sutures obliterated \\
\hline $15 \cdot 3$ & $"$ & $"$ & $"$ & Hylobates lar. From Malacca. Nasals broken \\
\hline & $"$ & $"$ & $"$ & Hylobates lar. Sutures obliterated, bisected skull \\
\hline $10 \cdot 6$ & $"$ & $"$ & ", & Hylobates sp. Very young \\
\hline
\end{tabular}

